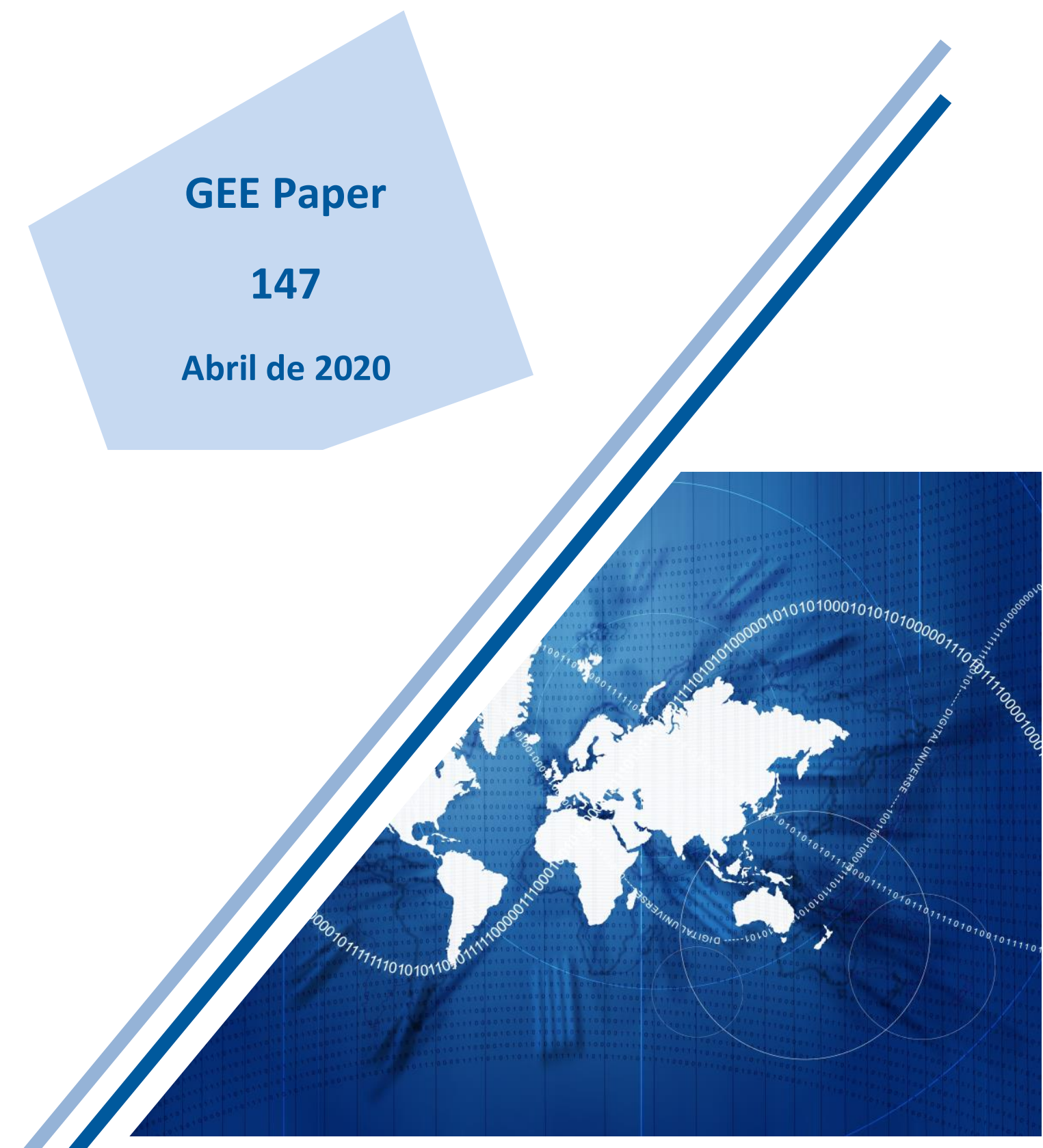

\title{
Collusion in Two-Sided Markets
}

\author{
Yassine Lefouili | Joana Pinho
}


Gabinete de Estratégia e Estudos 


\title{
Collusion in Two-Sided Market: $\square$
}

Yassine Lefouil: ${ }^{2}$ Joana Pinht ${ }^{3}$

\begin{abstract}
:
This paper explores the incentives for, and the effects of, collusion in prices between two-sided platforms. We characterize the most profitable sustainable agreement when platforms collude on both sides of the market and when they collude on a single side of the market. Under two-sided collusion, prices on both sides are higher than the competitive prices, implying that agents on both sides become worse off as compared to the competitive outcome. An increase in cross-group externalities makes two-sided collusion harder to sustain, and reduces the harm from collusion suffered by the agents on a given side as long as the collusive price on that side is lower than the monopoly price. When platforms collude on a single side of the market, the price on the collusive side is lower (higher) than the competitive price if the magnitude of the cross-group externalities exerted on that side is sufficiently large (small). As a result, one-sided collusion may benefit the agents on the collusive side and harm the agents on the competitive side.
\end{abstract}

JEL Classification: L41, D43.

Keywords: Collusion; Two-sided markets; Cross-group externalities.

Note: This article is sole responsibility of the authors and do not necessarily reflect the positions of GEE or the Portuguese Ministry of Economy. This paper was one of the winners of the Call for Papers about Telecommunications and Digitalization in the Economy (GEE and ANACOM).

\footnotetext{
${ }^{1}$ We are grateful to Cédric Argenton, João Correia-da-Silva, Carmen García, Bruno Jullien, Martin Peitz, Joana Resende, Hélder Vasconcelos, Yaron Yehezkel and our audiences at SAET 2017, EARIE 2017, CRESSE 2018, PEJ 2018 and at seminars given at University of Vigo, the University of Porto, the University of Minho and Católica Porto Business School for useful comments and suggestions. The financial support of the NET Institute, www.netinst.org, the European Research Council (ERC) under the European Union's Horizon 2020 research and innovation programme (grant agreement No 670494), and the Fundação para a Ciência e a Tecnologia (FCT) through a post-doctoral scholarship (BPD/79535/2011) and project are gratefully acknowledged. This work was also funded by FEDER (COMPETE) and Portuguese public funds (FCT), through projects PEst-OE/EGE/UI4105/2014, UID/GES/00731/2016 and NORTE-01-0145-FEDER-028540.

${ }^{2}$ Toulouse School of Economics - University of Toulouse Capitole, (yassine.lefouili@tse-fr.eu)

${ }^{3}$ Católica Porto Business School and CEGE - Universidade Católica Portuguesa, (jpinho@porto.ucp.pt)
} 


\section{Introduction}

Several cartels involving newspaper publishers have been uncovered all around the world. In 1969, a U.S. District Court convicted of monopolization the two daily newspapers of general circulation in Tucson, Arizona, for jointly setting subscription and advertising rates 4 In 1996, several Venezuelan newspapers were convicted of forming a cartel to fix advertising rates for movie theaters 5 In 2005 , the Brazilian antitrust authority fined the four largest newspapers in Rio de Janeiro for forming a cartel, after a simultaneous increase in cover prices by $20 \% 6$ In 2010 , the Croatian antitrust authority established that nine publishers of daily newspapers engaged in concerted practices that translated into a uniform increase in newspapers' cover prices 7 In 2014, the Hungarian antitrust authority convicted the four major newspapers publishers in the country of price-fixing conspiracy ${ }^{8}$ Also in 2014, the Montenegrin antitrust authority convicted the three major daily newspapers publishers in the country for price-fixing conspiracy ${ }^{9}$

Newspapers are two-sided platforms that enable the interaction between two distinct types of agents: advertisers and readers. As pointed out by Evans and Schmalensee (2013, p. 2), "a number of results for single-sided firms, which are the focus of much of the applied antitrust economics literature, do not apply directly to multi-sided platforms." However, the theoretical literature on collusion in two-sided markets is remarkably scarce, which is striking given the empirical evidence on collusion in these markets 10 In particular, our understanding of the sustainability and impact of imperfect collusion among two-sided platforms, i.e., collusion that does not yield the monopoly outcome, is very limited.

In this paper, we explore the incentives for, and effects of, collusion between two horizontally differentiated platforms, allowing for any degree of collusion. Our model is an infinitely repeated version of the canonical Armstrong (2006)'s model, with single-homing on both sides ${ }^{11}$ and (positive or negative) cross-group externalities 12

We first consider the scenario in which platforms engage in two-sided collusion, that is, collusion on the prices set on both sides of the market. We show that the most profitable collusive agreement involves supra-competitive prices on both sides, and a price structure that minimizes the platforms' incentives to deviate from the agreement. We also find that an increase in cross-group externalities makes two-sided collusion (at a given profit level) harder to sustain, and affects the harm from collusion suffered by the agents using the platforms in a different way depending on whether perfect collusion is sustainable or not. More specifically, an increase in cross-group externalities reduces the harm from collusion suffered by the

${ }^{4}$ Citizen Publishing Co.v. United States 394 U.S. 131 (1969).

${ }^{5}$ See page 9 of the 2005 report by the Venezuelan antitrust authority available at: http://www.oecd.org/daf/competition/ prosecutionandlawenf orcement/38835563.pdf

${ }^{6}$ CADE - Processo Administrativo no. 08012.002097/99-81.

${ }^{7} \mathrm{CCA}$ vs. daily newspaper publishers: UP/I 030-02/2008-01/072.

${ }^{8}$ Gazdas $\tilde{A}_{i g i}$ Versenyhivatal $(\mathrm{GVH})$ - Case Number: Vj/23/2011.

${ }^{9}$ Agency for Protection of Competition - Case Number: 02-UPI-68/1-14. In this case, there was even a written agreement signed by three of the convicted publishers, where they combined to simultaneously increase the retail price of newspapers.

${ }^{10}$ For other examples of collusion in two-sided markets, see Ruhmer (2011) and Dewenter et al. (2011).

${ }^{11}$ Our model is, in particular, suitable for our leading example (the newspaper market). According to Argentesi and Filistrucchi (2007), the assumption of single-homing on both market sides is reasonable in the newspaper market. Concretely, the authors found that "On each day of the week, more than $84 \%$ of advertisers put an advertising message in only one of the four newspapers, and only $10 \%$ in two of them. This evidence seems to give support to the assumption that multi-homing is not a widespread practice". Kaiser and Wright (2006) also found that in the German magazine market, from 1972 to 2003 , only $8 \%$ of the readers and $17 \%$ of the advertisers multihome. Taking this evidence into account, the authors estimated a modified version of the Armstrongs's (2006) model.

${ }^{12}$ There is some controversy in the literature about the readers' tastes for advertising, which we account for since we do not restrict the sign of the cross-group externalities. 
agents on a given side as long as the collusive price on that side is lower than the monopoly price, but increases it otherwise.

Next, we consider the scenario in which platforms engage in one-sided collusion, i.e., they set their prices cooperatively on one side of the market and non-cooperatively on the other side. Such a collusive behavior can be explained by the existence of coordination or antitrust costs that make it optimal for platforms to collude on a single side of the market, and has been documented empirically in the case of newspapers. For instance, using data from the Italian daily newspaper market from 1976 to 2003, Argentesi and Filistrucchi (2007) found empirical evidence that the four biggest newspapers colluded on cover prices, but found no evidence for collusion on advertising rates.

One-sided collusive agreements affect the prices on the non-cooperative side of the market because of the existence of cross-group externalities. If increasing the price on the collusive side softens competition on the non-cooperative side, the most profitable one-sided collusive agreement leads to supra-competitive prices on both sides of the market. This happens when the cross-group externalities exerted on the collusive side are negative. By contrast, if increasing the price on the collusive side strengthens competition on the non-cooperative side, the price on one of the two sides will be above its static Nash level, while the price on the other side will be below its static Nash level. This scenario occurs when the cross-group externalities exerted on the collusive side are positive. Interestingly, if these externalities are sufficiently high (compared to the degree of differentiation between platforms), the price on the collusive side is below its static Nash level, while the price on the non-cooperative side is above its static Nash level. As a result, one-sided collusion may benefit the agents on the collusive side and harm the agents on the non-cooperative side. Note, however, that in all scenarios, one-sided collusion decreases the overall surplus of the platforms' users.

Related literature. The work by Ruhmer (2011) is the closest to our paper. She also considers a repeated version of Armstrong's model but her setting is less general than ours. First, in the context of two-sided collusion, she focuses on perfect collusion (i.e., collusion at the monopoly prices) while we allow for imperfect collusion as well. This is natural when platforms are differentiated: in this case, perfect collusion may not be sustainable while (profitable) collusion at other prices could be. The distinction between perfect and imperfect two-sided collusion turns out to be crucial, for instance, for the effects of cross-group externalities on the harm suffered by the agents using the platforms. Second, in the context of one-sided collusion, Ruhmer (2011) focuses on the profitability and sustainability of a very specific collusive agreement in which platforms set the price on the collusive side at the maximum level that allows them to fully cover that side of the market (which is above the static Nash level). In contrast, we do not restrict the type of one-sided collusive agreements that platforms can achieve and show that they may find it optimal to decrease the price on the collusive side below its static Nash level. This explains, in particular, why one-sided collusion may be unprofitable in Ruhmer's setting, while this is never the case in our setting.

Our paper is also related to the contribution of Dewenter et al. (2011) who build a model to investigate the welfare impacts of collusion between newspaper publishers. They consider a static setting where newspapers compete in prices in the reader market and in quantities in the advertising market, and compare the platforms' profits when there is two-sided perfect collusion, one-sided perfect collusion (on the advertising side) and two-sided competition. In contrast, we investigate, in a dynamic setting, the 
most profitable sustainable agreement, allowing for intermediate degrees of collusion and analyzing the incentives for platforms to comply with the collusive agreement. Dewenter et al. (2011) find that, when newspapers only collude on the advertisers' side, the price is lower on the non-cooperative side while it is higher on the collusive side (as compared to the static Nash prices). By contrast, we show that one-sided collusion may also lead to a price lower than the competitive price on the collusive side ${ }^{13}$

Another paper our work is related to is Boffa and Filistrucchi (2014). These authors build a model of collusion between two TV channels and use it to show that prices above the two-sided monopoly price may prevail on one side of the market as a means to enhance cartel sustainability. However, they consider collusion in quantities while we study collusion in prices, which makes our papers complementary. Moreover, they focus on the case of two-sided collusion while we also deal with one-sided collusion.

Finally, our paper is also linked to the work of Choi and Gerlach (2013) on competing firms' incentives to collude when they interact in multiple markets and demands in these markets are interrelated. The main goal of Choi and Gerlach (2013) is, however, fundamentally different from ours. They focus their analysis on antitrust enforcement issues and, in particular, on whether the discovery of a cartel in one market favors the emergence or collapse of a cartel in another market. Moreover, they restrict their attention to homogeneous goods, which implies in particular that collusion at the monopoly price is sustainable whenever some collusion is sustainable. In contrast, we consider a setting with differentiated platforms and possibly imperfect collusion, and abstract away from antitrust enforcement issues.

The remainder of the paper is organized as follows. In Section 2, we lay out the model. In Section 3 , we characterize the most profitable sustainable agreement under two-sided collusion. In Section 4, we make a similar analysis for the case in which platforms collude on a single side of the market. We discuss some limitations of our model in Section 5 and conclude in Section 6. Most of the proofs are relegated to the Appendix.

\section{Setup}

We consider an infinitely repeated version of Armstrong's (2006) model. There are two platforms in the market, $A$ and $B$, that enable the interaction between two groups of agents, 1 and 2. Agents on each side are uniformly distributed along the interval $[0,1]$ and platforms are located at the extremes: $x^{A}=0$ and $x^{B}=1$. Platform $i \in\{A, B\}$ sets a subscription fee $p_{j}^{i}$ to the agents on each side of the market $j \in\{1,2\}$. There is single-homing on both sides of the market and the utility of an agent on side $j$ located at $x \in[0,1]$ that joins platform $i$ is:

$$
u_{j}^{i}\left(x, p_{1}^{i}, p_{2}^{i}, p_{1}^{-i}, p_{2}^{-i}\right)=k_{j}+\alpha_{j} n_{-j}^{i}\left(p_{1}^{i}, p_{2}^{i}, p_{1}^{-i}, p_{2}^{-i}\right)-t\left|x^{i}-x\right|-p_{j}^{i},
$$

where: $k_{j}$ is the intrinsic benefit that an agent on side $j$ gets from joining a platform; $\alpha_{j}$ captures the benefit (which can be positive or negative) that an agent on side $j$ enjoys from the existence of an agent on the other side of the market that joined the same platform; and $t>0$ measures the degree of differentiation between platforms.

\footnotetext{
${ }^{13}$ In both papers, the agents on the collusive side may benefit from a one-sided collusive agreement, but the mechanisms driving this result in the two papers are different. In Dewenter et al. (2011), this result may hold despite the price increase on the collusive side because of an indirect feedback effect: the price decrease on the non-cooperative side leads to more participation on that side, which benefits the agents on the collusive side. In contrast, in our paper, the result that one-sided collusion may benefit the agents on the collusive side is driven by the direct impact on the price paid by these agents.
} 
The demand addressed to platform $i$ on side $j$ is 14

$$
n_{j}^{i}\left(p_{1}^{i}, p_{2}^{i}, p_{1}^{-i}, p_{2}^{-i}\right)=\frac{1}{2}+\frac{\alpha_{j}\left(p_{-j}^{-i}-p_{-j}^{i}\right)+t\left(p_{j}^{-i}-p_{j}^{i}\right)}{2\left(t^{2}-\alpha_{1} \alpha_{2}\right)} .
$$

Platforms interact for an infinite number of periods and have a common discount factor $\delta \in(0,1)$. In each period $t \in\{0,1,2 \ldots\}$, they simultaneously set membership fees, $p_{j}^{i}$. Platforms have constant marginal production costs, which, for simplicity, are set to zero. Thus, the per-period profit function of platform $i \in\{A, B\}$ is:

$$
\pi^{i}\left(p_{1}^{i}, p_{2}^{i}, p_{1}^{-i}, p_{2}^{-i}\right)=p_{1}^{i} n_{1}^{i}\left(p_{1}^{i}, p_{2}^{i}, p_{1}^{-i}, p_{2}^{-i}\right)+p_{2}^{i} n_{2}^{i}\left(p_{1}^{i}, p_{2}^{i}, p_{1}^{-i}, p_{2}^{-i}\right)
$$

We make the following assumptions which ensure, in particular, that the stage game has a unique (symmetric) Nash equilibrium, in which both sides of the market are fully covered.

Assumption $12 t>\left.\left|\alpha_{1}+\alpha_{2}\right|\right|^{15}$

Assumption $2 k_{1}-\frac{\alpha_{1}}{2} \leq k_{2}-\frac{\alpha_{2}}{2}$.

Assumption $3 k_{1}>\frac{3 t-\alpha_{1}-2 \alpha_{2}}{2}$

We now recall the equilibrium prices and profits when platforms compete against each other.

Lemma 1 (Armstrong, 2006) Under Assumptions 1 -3, if platforms behave non-cooperatively, they set equal prices given by $p_{j}^{N}=t-\alpha_{-j}, j \in\{1,2\}$, fully cover both market sides, and get equal market shares on each side. Their individual profit is given by $\pi^{N}=\frac{2 t-\alpha_{1}-\alpha_{2}}{2}$.

Proof. See Armstrong (2006) for the determination of the Nash prices and profits. Market $j \in\{1,2\}$ is fully covered if and only if:

$$
u_{j}^{i}\left(\frac{1}{2}, p_{1}^{N}, p_{2}^{N}, p_{1}^{N}, p_{2}^{N}\right) \geq 0 \Leftrightarrow k_{j}-\frac{\alpha_{j}}{2} \geq \frac{3 t-2 \alpha_{1}-2 \alpha_{2}}{2} .
$$

which holds by Assumptions 2 and 3 .

\section{Two-sided collusion}

Suppose that, at the beginning of period $t=0$, platforms may agree to collude using grim trigger strategies that involve a permanent reversion to the static Nash prices in case of a deviation from the

\footnotetext{
${ }^{14}$ For details, see Armstrong (2006). Under full market coverage, the demands addressed to the two platforms on side $j \in\{1,2\}$ are related in the following way: $n_{j}^{i}=1-n_{j}^{-i}$, for $i \in\{A, B\}$.

${ }^{15}$ The assumption $2 t>\alpha_{1}+\alpha_{2}$ ensures that the second-order condition corresponding to the individual profit-maximization problem is satisfied, as it implies that $t^{2}>\alpha_{1} \alpha_{2}$. In addition, we assume that $2 t>-\alpha_{1}-\alpha_{2}$ for the second-order conditions of the maximization problem under two-sided collusion to be satisfied (see footnote 36 .
} 
collusive agreement. In this section, we consider the scenario in which platforms seek to collude on both sides of the market.

Let us first determine, for each set of parameters, the most profitable collusive agreement among those that are sustainable. We restrict our attention to symmetric agreements, i.e., such that the two platforms set equal prices on each market side $\left(p_{j}^{A}=p_{j}^{B}\right.$, for $\left.j \in\{1,2\}\right)$. Denote by

$$
\pi\left(p_{1}, p_{2}\right)=\pi^{i}\left(p_{1}, p_{2}, p_{1}, p_{2}\right)
$$

the profit of platform $i \in\{A, B\}$ if the two platforms set equal prices $p_{j}^{A}=p_{j}^{B}=p_{j}$ on each side $j \in\{1,2\}$. The most profitable sustainable symmetric agreement involves prices that solve the following maximization program:

$$
\max _{\left(p_{1}, p_{2}\right) \in \mathbb{R}^{2}} \pi\left(p_{1}, p_{2}\right)
$$

subject to the sustainability constraint (hereafter, ICC):

$$
\frac{\pi\left(p_{1}, p_{2}\right)}{1-\delta} \geq \pi^{d}\left(p_{1}, p_{2}\right)+\frac{\delta}{1-\delta} \pi^{N}
$$

where $\pi^{d}\left(p_{1}, p_{2}\right)=\max _{\left(p_{1}^{i}, p_{2}^{i}\right)} \pi^{i}\left(p_{1}^{i}, p_{2}^{i}, p_{1}, p_{2}\right)$ is the optimal deviation profit if the collusive prices are $\left(p_{1}, p_{2}\right)$.

\subsection{Preliminaries}

For any given $\delta \in(0,1)$, denote by

$$
I(\delta)=\left\{\left(p_{1}, p_{2}\right) \in \mathbb{R}^{2} \mid \frac{\pi\left(p_{1}, p_{2}\right)}{1-\delta} \geq \pi^{d}\left(p_{1}, p_{2}\right)+\frac{\delta}{1-\delta} \pi^{N}\right\}
$$

the set of price pairs such that the ICC is satisfied, and by

$$
\bar{I}(\delta)=\left\{\left(p_{1}, p_{2}\right) \in \mathbb{R}^{2} \mid \frac{\pi\left(p_{1}, p_{2}\right)}{1-\delta}=\pi^{d}\left(p_{1}, p_{2}\right)+\frac{\delta}{1-\delta} \pi^{N}\right\}
$$

the set of price pairs such that the ICC is binding. Moreover, define

$$
\pi^{c}(\delta)=\max _{\left(p_{1}, p_{2}\right) \in I(\delta)} \pi\left(p_{1}, p_{2}\right)
$$

and

$$
\delta^{m}=\frac{\pi^{d}\left(p_{1}^{m}, p_{2}^{m}\right)-\pi^{m}}{\pi^{d}\left(p_{1}^{m}, p_{2}^{m}\right)-\pi^{N}}
$$

where $\left(p_{1}^{m}, p_{2}^{m}\right)$ is the unique solution to the unconstrained maximization program

$$
\max _{\left(p_{1}, p_{2}\right) \in \mathbb{R}^{2}} \pi\left(p_{1}, p_{2}\right)
$$

and $\pi^{m} \equiv \pi\left(p_{1}^{m}, p_{2}^{m}\right)$ is the profit each firm derives from perfect collusion.

The following preliminary results are useful for the subsequent analysis. Lemma 2 shows that the collusive profit is (weakly) increasing in the platform's discount factor and that the ICC is binding for 
sufficiently small values of the discount factor.

Lemma 2 The prices and profits under the most profitable sustainable agreement satisfy the following properties:

(i) $\pi^{c}(\delta) \leq \pi^{c}\left(\delta^{\prime}\right)<\pi^{m}, \forall \delta, \delta^{\prime} \in\left(0, \delta^{m}\right)$ such that $\delta<\delta^{\prime}$; and $\pi^{c}(\delta)=\pi^{m}, \forall \delta \in\left[\delta^{m}, 1\right)$.

(ii) If $\delta \in\left(0, \delta^{m}\right)$ and $\left(p_{1}^{c}(\delta), p_{2}^{c}(\delta)\right)$ is a pair of prices in $I(\delta)$ such that $\pi^{c}(\delta)=\pi\left(p_{1}^{c}(\delta), p_{2}^{c}(\delta)\right)$, then $\left(p_{1}^{c}(\delta), p_{2}^{c}(\delta)\right) \in \bar{I}(\delta)$.

Proof. See Appendix.

The next lemma shows that the price structure under the most profitable sustainable agreement minimizes the platforms' incentives to deviate (among all possible price structures for a given collusive profit).

Lemma 3 Consider $\delta \in\left(0, \delta^{m}\right)$ and let $\left(p_{1}^{c}(\delta), p_{2}^{c}(\delta)\right)$ be a pair of prices in $I(\delta)$ such that $\pi^{c}(\delta)=$ $\pi\left(p_{1}^{c}(\delta), p_{2}^{c}(\delta)\right)$. Then, $\left(p_{1}^{c}(\delta), p_{2}^{c}(\delta)\right)$ is necessarily a solution to the following constrained minimization program:

$$
\min _{\left(p_{1}, p_{2}\right) \in \mathbb{R}^{2}} \pi^{d}\left(p_{1}, p_{2}\right)
$$

subject to

$$
\pi\left(p_{1}, p_{2}\right)=\pi^{c}(\delta)
$$

Proof. See Appendix.

\subsection{The most profitable sustainable agreement}

We now make use of the results above to characterize the most profitable sustainable agreement when platforms collude on both sides of the market.

For tractability reasons, we impose lower bounds on the agents' stand-alone values to ensure that the market is fully covered under two-sided collusion (Assumption 44). This simplifies the analysis by reducing the number of possible demand configurations under collusion.

\section{Assumption 4}

$$
\begin{aligned}
& -k_{1} \geq \frac{2 t-\alpha_{1}}{2} \text { and } k_{2} \geq \frac{2 t-\alpha_{2}}{2} ; \\
& -2 t \min \left\{k_{1}, k_{2}\right\}+\left(\alpha_{1}+\alpha_{2}\right) \max \left\{k_{1}, k_{2}\right\} \geq \frac{\left(2 t-\alpha_{1}-\alpha_{2}\right)\left(2 t+\alpha_{1}+\alpha_{2}\right)}{2} .
\end{aligned}
$$


Lemma 4 Under Assumptions 1 and 4 , both sides of the market are fully covered under the most profitable sustainable two-sided collusive agreement.

Proof. See Appendix.

If platforms set equal prices, there is full coverage of side $j \in\{1,2\}$ if and only if the utility of the indifferent consumer, located at $x=\frac{1}{2}$, is non-negative. Thus, the maximum price that platforms can charge on side $j$ for this side to be fully covered is ${ }^{16}$

$$
p_{j}^{m}=p_{j}^{N}+u_{j}^{i}\left(\frac{1}{2}, p_{1}^{N}, p_{2}^{N}, p_{1}^{N}, p_{2}^{N}\right)=\frac{2 k_{j}-t+\alpha_{j}}{2} .
$$

The following lemma shows how prices under the most profitable sustainable agreement relate to the profit generated by this agreement.

Lemma 5 Under Assumptions 1 -4 for any $\delta \in(0,1)$, there exists a unique pair of prices $\left(p_{1}^{c}(\delta), p_{2}^{c}(\delta)\right) \in$ $I(\delta)$ satisfying $\pi^{c}(\delta)=\pi\left(p_{1}^{c}(\delta), p_{2}^{c}(\delta)\right)$. These prices are such that:

$$
\left(p_{1}^{c}(\delta), p_{2}^{c}(\delta)\right)=\left\{\begin{array}{llc}
\left(\pi^{c}(\delta)+\frac{\alpha_{1}-\alpha_{2}}{2}, \pi^{c}(\delta)-\frac{\alpha_{1}-\alpha_{2}}{2}\right) & \text { if } & 0<\delta \leq \tilde{\delta} \\
\left(p_{1}^{m}, 2 \pi^{c}(\delta)-p_{1}^{m}\right) & \text { if } & \tilde{\delta}<\delta<\delta^{m} \\
\left(p_{1}^{m}, p_{2}^{m}\right) & \text { if } & \delta^{m} \leq \delta<1,
\end{array}\right.
$$

where $p_{j}^{m}=\frac{2 k_{j}-t+\alpha_{j}}{2}$, and $\tilde{\delta}$ is the solution of $\pi^{c}(\tilde{\delta})=\frac{2 k_{1}-t+\alpha_{2}}{2}$.

Proof. See Appendix.

This lemma implies that, for any $\delta \in(0, \tilde{\delta})$ :

$$
p_{1}^{c}(\delta)-p_{2}^{c}(\delta)=p_{1}^{N}-p_{2}^{N} .
$$

Therefore, as long as the collusive price is below the monopoly level on both sides, the price structure (defined as the difference between the prices on the two sides) under two-sided collusion and under competition is the same. In other words, for sufficiently small discount factors, collusion distorts the total price, $p_{1}+p_{2}$, but not the price structure, $p_{1}-p_{2}$. This implies that competition authorities should not rely on changes in the price structure to detect a switch from a competitive regime to a collusive regime, and stands in sharp contrast with the case of perfect collusion (Ruhmer, 2011).

Moreover, since the collusive profit $\pi^{c}(\delta)$ is (weakly) increasing in $\delta$ (by Lemma 2), Lemma 5 implies that collusive prices are (weakly) increasing in the discount factor. This leads in particular to the following result.

\footnotetext{
${ }^{16}$ Expressions for Nash prices are provided in Lemma 1
} 
Proposition 1 Under Assumptions 1-4, the collusive prices generating the most profitable two-sided sustainable agreement are (weakly) greater than the static Nash prices, i.e., for any $\delta>0$,

$$
p_{j}^{c}(\delta) \geq p_{j}^{N}
$$

Proposition 1 implies that two-sided collusion harms the agents on both sides of the market. To show that collusive prices are strictly greater than the competitive prices, and derive the effects of crossgroup externalities on the sustainability and profitability of two-sided collusion, we make an additional assumption. Under Assumption 5, a platform disrupting the collusive agreement would monopolize both sides of the market or none 17 Therefore, this assumption reduces the number of possible demand configurations in the deviating period 18

\section{Assumption 5}

- $k_{1}>\bar{k}_{1}$, with $\bar{k}_{1}=\frac{7 t-3 \alpha_{1}-4 \alpha_{2}}{2}$;

$-2 t^{2}>\alpha_{1} \alpha_{2}+\alpha_{2}^{2}$.

Proposition 2 Under Assumptions 1 - 5, the highest sustainable profit if platforms cooperatively set the prices on both sides of the market is 19

$$
\pi^{c}(\delta)=\left\{\begin{array}{lll}
\frac{1+3 \delta}{1-\delta} \pi^{N} & \text { if } & 0<\delta<\frac{1}{3} \\
\frac{2-3 \delta}{1-2 \delta} \pi^{N} & \text { if } \quad \frac{1}{3} \leq \delta<\delta^{m} \\
\pi^{m} & \text { if } & \delta^{m} \leq \delta<1
\end{array}\right.
$$

with $\pi^{m}=\frac{2\left(k_{1}+k_{2}\right)-\left(2 t-\alpha_{1}-\alpha_{2}\right)}{4}$ and $\delta^{m}=\frac{2\left(k_{1}+k_{2}\right)-5\left(2 t-\alpha_{1}-\alpha_{2}\right)}{4\left[k_{1}+k_{2}-2\left(2 t-\alpha_{1}-\alpha_{2}\right)\right]}<\frac{1}{2}$. The collusive prices are:

$$
\left(p_{1}^{c}(\delta), p_{2}^{c}(\delta)\right)= \begin{cases}\left(p_{1}^{N}+\frac{2 \delta}{1-\delta}\left(2 t-\alpha_{1}-\alpha_{2}\right), p_{2}^{N}+\frac{2 \delta}{1-\delta}\left(2 t-\alpha_{1}-\alpha_{2}\right)\right) & \text { if } \quad 0<\delta<\frac{1}{3} \\ \left(p_{1}^{N}+\frac{1-\delta}{2(1-2 \delta)}\left(2 t-\alpha_{1}-\alpha_{2}\right), p_{2}^{N}+\frac{1-\delta}{2(1-2 \delta)}\left(2 t-\alpha_{1}-\alpha_{2}\right)\right) & \text { if } \quad \frac{1}{3}<\delta<\tilde{\delta} \\ \left(p_{1}^{m}, p_{2}^{N}+\frac{t(7-10 \delta)-2 \alpha_{2}(2-3 \delta)-\alpha_{1}(3-4 \delta)-2 k_{1}(1-2 \delta)}{2(1-2 \delta)}\right) & \text { if } \quad \tilde{\delta}<\delta<\delta^{m} \\ \left(p_{1}^{m}, p_{2}^{m}\right) & \text { if } \quad \delta^{m} \leq \delta<1 .\end{cases}
$$

with $p_{j}^{m}=\frac{2 k_{j}-t+\alpha_{j}}{2}$, for $j \in\{1,2\}$, and $\tilde{\delta}=\frac{2 k_{1}-5 t+2 \alpha_{1}+3 \alpha_{2}}{4 k_{1}-8 t+3 \alpha_{1}+5 \alpha_{2}}$.

Proof. See Appendix.

\footnotetext{
${ }^{17}$ Otherwise, the deviating platform could monopolize side 2 but not side 1 (see the proof of Proposition 2, in which case, we would not be able to get a closed-form solution for the most sustainable profit.

${ }^{18}$ Assumption 5 implies that the stand-alone value on side 2 is also sufficiently large: $k_{2}>\frac{7 t-4 \alpha_{1}-3 \alpha_{2}}{2}$. Notice further that Assumption 3 is implied by the condition $k_{1}>\bar{k}_{1}$.

${ }^{19}$ For $\delta<\frac{1}{3}$, a deviating platform would not monopolize any side of the market; while, for $\delta \geq \frac{1}{3}$, a deviating platform would monopolize both market sides.
} 


\subsection{Impact of cross-group externalities}

When the externality that side $-j$ agents exert on side $j$ agents increases (i.e., $\alpha_{j}$ increases), agents on side $j$ become more valuable for platforms because their willingness to pay for the service provided by the platforms increases. This is why, under competition, an increase in $\alpha_{j}$ leads platforms to set prices more aggressively on side $-j$ : by decreasing $p_{-j}$, platforms attract more side $-j$ agents and, therefore, extract more surplus from side $j$ agents. In sum, when $\alpha_{j}$ increases, the Nash equilibrium price on side $-j$ decreases (Armstrong, 2006).

Let us now derive the impact of cross-group externalities on the most profitable collusive prices and profit. Ceteris paribus, an increase in $\alpha_{j}$ would translate into a higher surplus to agents on side $j$. Platforms could extract this additional surplus by increasing the price charged to side $j$ agents (and, therefore, increase collusive profits). However, if $\delta<\delta^{m}$, an increase in the collusive price changes the platforms' incentives to comply with the agreement. Indeed, an increase in $\alpha_{j}$ has two countervailing effects on the sustainability of collusion: $(i)$ it increases the one-shot gain from a deviation, $\pi^{d}-\pi^{c}$, which harms collusion ${ }^{20}$ but $(i i)$ it also increases the severity of the punishment after a deviation, $\frac{\delta}{1-\delta}\left(\pi^{c}-\pi^{N}\right)$, which benefits collusion. Writing down the ICC for the collusive profit $\pi^{c} \in\left[\pi^{N}, \pi^{m}\right)$ to be sustainable ${ }^{21}$

$$
(I C C): \begin{cases}(3 \delta+1)\left(2 t-\alpha_{1}-\alpha_{2}\right)-2(1-\delta) \pi^{c} \geq 0 & \text { if } \quad \pi^{N} \leq \pi^{c}<\frac{3}{2}\left(2 t-\alpha_{1}-\alpha_{2}\right) \\ 2(2 \delta-1) \pi^{c}+(2-3 \delta)\left(2 t-\alpha_{1}-\alpha_{2}\right) \geq 0 & \text { if } \quad \frac{3}{2}\left(2 t-\alpha_{1}-\alpha_{2}\right)<\pi^{c} \leq \pi^{m}\end{cases}
$$

we conclude that an increase in $\alpha_{j}$ makes the ICC more difficult to satisfy. Thus, an increase in the cross-group externalities increases more the gain from a deviation than the severity of the punishment following a deviation. As a result, if $\delta<\delta^{m}$, the highest sustainable profit decreases with the cross-group externalities. For $\delta>\delta^{m}$, the ICC is not binding and, as a result, platforms are able to sustain the highest prices ensuring full market coverage: $\pi^{c}(\delta)=\pi^{m}{ }^{22}$ In this case, an increase in cross-group externalities increases the collusive profit, because platforms are able to increase the price on side $j$ resulting from the higher willingness to pay of side $j$ agents.

In order to study the impact of cross-group externalities on the sustainability of collusion in our model, we define $\underline{\delta}\left(\pi, \alpha_{1}, \alpha_{2}\right) \in\left(0, \delta^{m}\right]$ as the minimum discount factor allowing to sustain a collusive agreement generating a profit $\pi \in\left(\pi^{N}, \pi^{m}\right]$, and study how it is affected by $\alpha_{1}$ and $\alpha_{2}$. Since $\pi^{c}(\delta)$ is increasing in $\alpha_{1}$ and $\alpha_{2}$ for any $\delta \in\left(0, \delta^{m}\right]$, the threshold $\underline{\delta}\left(\pi, \alpha_{1}, \alpha_{2}\right)$ is increasing in $\alpha_{1}$ and $\alpha_{2}$ for any $\pi \in\left(\pi^{N}, \pi^{m}\right]$. This means that an increase in the magnitude of network externalities makes collusion (at a given profit level) harder to sustain.

The following corollary sums up the impact of an increase in cross-group externalities on the highest sustainable profit as well as the sustainability of collusion.

${ }^{20}$ For a given $\pi^{c} \in\left[\pi^{N}, \pi^{m}\right)$, the deviation profit is increasing in $\alpha_{j}$ :

$$
\pi^{d}=\left\{\begin{array}{lll}
\frac{\left[2 \pi^{c}+2 t-\alpha_{1}-\alpha_{2}\right]^{2}}{8\left(2 t-\alpha_{1}-\alpha_{2}\right)} & \text { if } & \pi^{N} \leq \pi^{c}<\frac{3}{2}\left(2 t-\alpha_{1}-\alpha_{2}\right) \\
2 \pi^{c}-2 t+\alpha_{1}+\alpha_{2} & \text { if } \quad \frac{3}{2}\left(2 t-\alpha_{1}-\alpha_{2}\right)<\pi^{c} \leq \pi^{m} .
\end{array}\right.
$$

${ }^{21}$ These ICCs are derived in the proof of Proposition 2

${ }^{22}$ Recall that platforms profit more if they establish a collusive agreement that ensures full market coverage than if they only cover partially one of the sides of the market (Lemma 4 . 


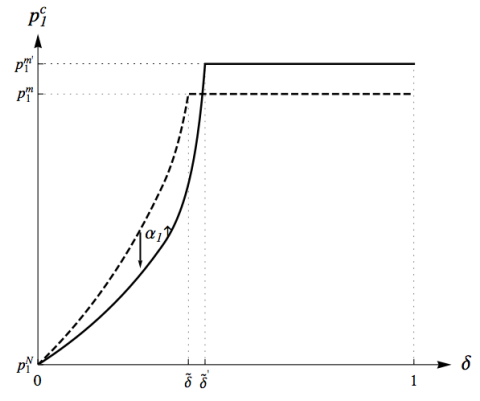

(a) Impact on $p_{1}^{c}$.

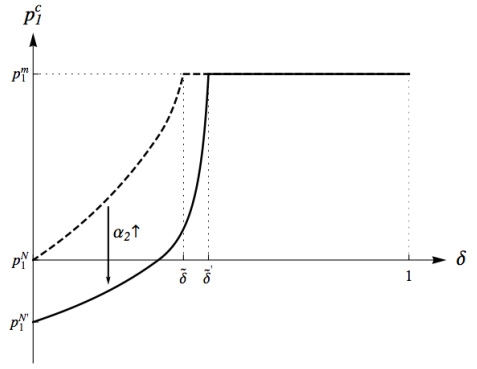

(d) Impact on $p_{1}^{c}$.

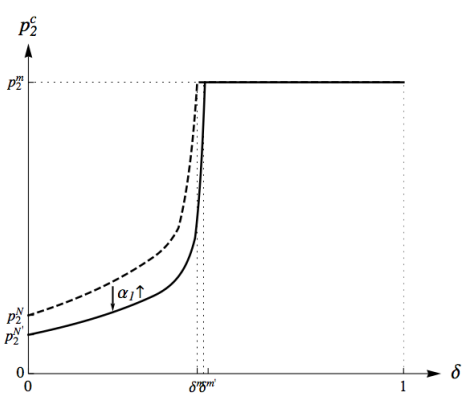

(b) Impact on $p_{2}^{c}$.

[Increase in $\alpha_{1}$ ]

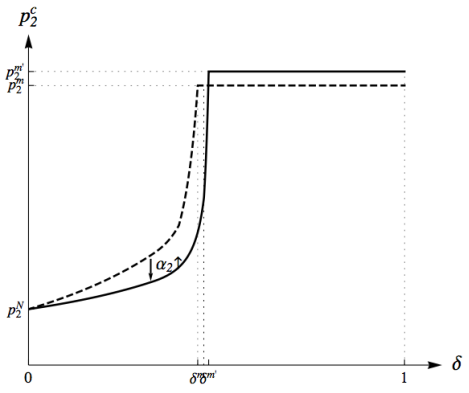

(e) Impact on $p_{2}^{c}$.

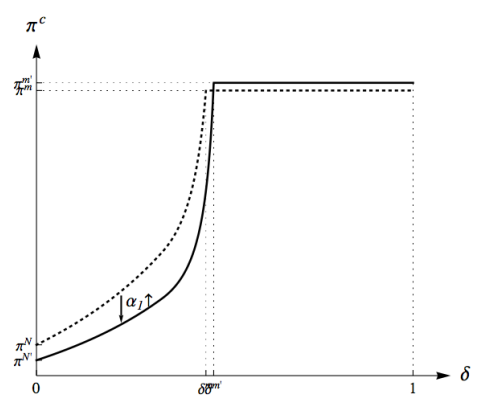

(c) Impact on $\pi^{c}$.

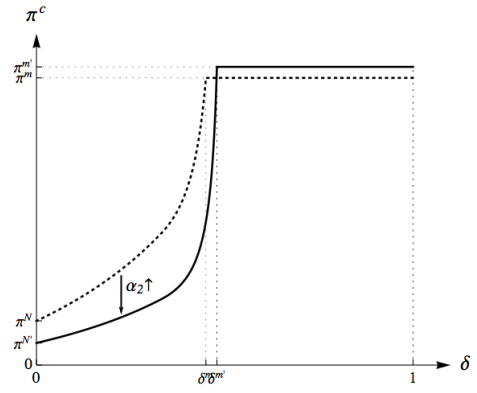

(f) Impact on $\pi^{c}$.

[Increase in $\alpha_{2}$ ]

Figure 1: Impact of an increase in cross-group externalities on prices and individual profits under two-sided collusion ${ }^{23}$

Corollary 1 Under Assumptions 1-15:

(i) If perfect collusion is not sustainable $\left(\delta<\delta^{m}\right)$, a marginal increase in the cross-group externalities on any market side decreases the highest sustainable profit.

(ii) If perfect collusion is sustainable $\left(\delta \geq \delta^{m}\right)$, a marginal increase in the cross-group externalities on any market side increases the highest sustainable profit.

(iii) An increase in the magnitude of cross-group externalities makes collusion (at a given profit level) harder to sustain, i.e., $\underline{\delta}\left(\pi, \alpha_{1}, \alpha_{2}\right)$ is increasing in $\alpha_{1}$ and $\alpha_{2}$.

Proof. Follows in a straightforward way from Proposition 2 combined with Lemma 1.

The last part of Corollary 1 implies that the finding by Ruhmer (2011) that an increase in cross-group externalities makes perfect collusion harder to sustain extends to the case of imperfect collusion. The

${ }^{23}$ To build these figures, we considered: $t=1, \alpha_{1}=-2, \alpha_{1}^{\prime}=-1, \alpha_{2}=1, \alpha_{2}^{\prime}=\frac{5}{2}, k_{1}=6, k_{2}=15$. 
next proposition shows, however, that the effect of cross-group externalities on the loss in users' surplus is fundamentally different under perfect and imperfect collusion. Before stating this result, note that the damage caused by collusion to the agents on side $j$ is given by $p_{j}^{c}(\delta)-p_{j}^{N}$ because the market is fully covered both under competition and collusion.

Corollary 2 Under Assumptions 1-5, a marginal increase in cross-group externalities may either increase or decrease the damage caused by collusion to side $j$ agents. Precisely, a marginal increase in the crossgroup externalities on any market side:

- decreases the harm from collusion for agents on both sides if $\delta<\tilde{\delta}$.

- increases the harm from collusion for side-1 agents but reduces the harm for side-2 agents if $\tilde{\delta}<\delta<$ $\delta^{m}$.

- increases the harm from collusion for agents on both sides if $\delta>\delta^{m}$.

Proof. See Appendix.

The harm from collusion suffered by platforms' users is affected by cross-group externalities through two channels as both the collusive price and the static Nash price depend on these externalities. When $\delta \leq \tilde{\delta}$, the collusive price on each side decreases with $\alpha_{1}$ and $\alpha_{2}$, while the competitive price on side $j$ decreases with $\alpha_{-j}$ but does not depend on $\alpha_{j}$. Therefore, the way the collusive harm on side $j$ depends on $\alpha_{-j}$ is a priori ambiguous. Corollary 2 shows that the overall effect is a decrease (with $\alpha_{1}$ and $\alpha_{2}$ ) in the harm from collusion for agents on both sides.

Moreover, Corollary 2 shows that the effect of cross-group externalities on the two sides need not be qualitatively the same. This results (partly) from the following two observations. First, the collusive price on side $j$ is decreasing in $\alpha_{1}$ and $\alpha_{2}$ as long as it does not reach the monopoly price on side $j$; but it decreases in $\alpha_{j}$ (and does not depend on $\alpha_{-j}$ ) when the monopoly price is reached. Second, because of the heterogeneity in the agents' stand-alone value across sides, the collusive price on side 1 reaches the monopoly level for lower values of the discount factor than the collusive price on side 2 (this follows from Assumption 22. Therefore, there may exist a range of discount factor values $\left(\tilde{\delta}<\delta<\delta^{m}\right)$ for which the impact of cross-group externalities on the collusive price on one side is fundamentally different from their effect on the collusive price on the other side 24

\section{One-sided collusion}

\subsection{The most profitable sustainable agreement}

Let us now characterize the most profitable sustainable agreement when platforms collude on a single side of the market. Without loss of generality, we assume that platforms collude on side 1 and set prices non-cooperatively and simultaneously on side 2 . We focus our analysis on symmetric collusive agreements, i.e., such that the two platforms set the same price on the collusive side $\left(p_{1}^{A}=p_{1}^{B}=p_{1}\right)$. Thus, given

\footnotetext{
${ }^{24}$ Note that this range of discount factor values is empty if the two sides of the market are perfectly symmetric (i.e., $\left.k_{1}=k_{2}\right)$,
} since in this case $\tilde{\delta}=\delta^{m}$. 
$\delta \in(0,1)$, the most profitable sustainable one-sided symmetric agreement features a price on side 1 that solves the following constrained maximization program:

$$
\max _{p_{1}}\left\{\pi^{A}\left(p_{1}, p_{2}^{A}, p_{1}, p_{2}^{B}\right)+\pi^{B}\left(p_{1}, p_{2}^{A}, p_{1}, p_{2}^{B}\right)\right\}
$$

subject to the following three constraints:

$$
\left\{\begin{array}{l}
p_{2}^{A}=\operatorname{argmax}_{\tilde{p}_{2}} \pi^{A}\left(p_{1}, \tilde{p}_{2}, p_{1}, p_{2}^{B}\right) \\
p_{2}^{B}=\operatorname{argmax}_{\tilde{p}_{2}} \pi^{B}\left(p_{1}, p_{2}^{A}, p_{1}, \tilde{p}_{2}\right) \\
p_{1} \in I^{o c}\left(\delta, p_{2}^{A}, p_{2}^{B}\right) \equiv\left\{p_{1} \in \mathbb{R} \mid \frac{\pi^{A}\left(p_{1}, p_{2}^{A}, p_{1}, p_{2}^{B}\right)}{1-\delta} \geq \max _{\left(\tilde{p}_{1}, \tilde{p}_{2}\right)} \pi^{A}\left(\tilde{p}_{1}, \tilde{p}_{2}, p_{1}, p_{2}^{B}\right)+\frac{\delta}{1-\delta} \pi^{N}\right\} .
\end{array}\right.
$$

Since the first two constraints are equivalent to

$$
p_{2}^{A}=p_{2}^{B}=p_{2}=\frac{t^{2}-\alpha_{1} \alpha_{2}}{t}-\frac{\alpha_{1}}{t} p_{1} \equiv g\left(p_{1}, \alpha_{1}, \alpha_{2}\right)
$$

we can rewrite the maximization program above as:

$$
\max _{p_{1}}\left\{\pi^{A}\left(p_{1}, p_{2}, p_{1}, p_{2}\right)+\pi^{B}\left(p_{1}, p_{2}, p_{1}, p_{2}\right)\right\}
$$

subject to:

$$
\left\{\begin{array}{l}
p_{2}=g\left(p_{1}, \alpha_{1}, \alpha_{2}\right) \\
p_{1} \in I^{o c}\left(\delta, p_{2}, p_{2}\right) \equiv\left\{p_{1} \in \mathbb{R} \mid \frac{\pi^{A}\left(p_{1}, p_{2}, p_{1}, p_{2}\right)}{1-\delta} \geq \max _{\left(\tilde{p}_{1}, \tilde{p}_{2}\right)} \pi^{A}\left(\tilde{p}_{1}, \tilde{p}_{2}, p_{1}, p_{2}\right)+\frac{\delta}{1-\delta} \pi^{N}\right\}
\end{array}\right.
$$

For a given $\delta \in(0,1)$, let $p_{1}^{o c}(\delta)$ denote the solution to the above maximization program, and $p_{2}^{o c}(\delta)$ the corresponding non-cooperative price on side $2{ }^{25}$ Moreover, define

$$
\Delta p_{j} \equiv p_{j}^{o c}(\delta)-p_{j}^{N}
$$

as the effect of one-sided collusion on the price on side $j \in\{1,2\}$. Let us first notice that $\Delta p_{1}$ and $\Delta p_{2}$ have the same sign if $\frac{\partial g}{\partial p_{1}}>0$ and have opposite signs if $\frac{\partial g}{\partial p_{1}}<0$. To see why, note that:

$$
\Delta p_{2}=p_{2}^{o c}(\delta)-p_{2}^{N}=g\left(p_{1}^{o c}(\delta), \alpha_{1}, \alpha_{2}\right)-g\left(p_{1}^{N}, \alpha_{1}, \alpha_{2}\right)=\int_{p_{1}^{N}}^{p_{1}^{o c}(\delta)} \frac{\partial g}{\partial p_{1}} d p_{1}
$$

Therefore, if increasing the price on the collusive side strengthens competition on the non-cooperative side, i.e., $\frac{\partial g}{\partial p_{1}}<0$, the price on one market side under one-sided collusion is higher than the static Nash price, while the other price is lower than the static Nash price. In contrast, if increasing the price on the collusive side softens competition on the non-cooperative side, i.e., $\frac{\partial g}{\partial p_{1}}>0$, prices on the two sides of the market are both below or both above Nash prices. In Armstrong (2006)'s setting, platforms never find

\footnotetext{
${ }^{25}$ The existence and uniqueness of the solution are established later.
} 
it optimal to agree on decreasing their prices below their static Nash levels on both sides of the market because the market is already fully covered under competition (by Assumptions 2 and $3 \longdiv { 2 6 }$

The following lemma relates the magnitude of the price variations on each side of the market induced by one-sided collusion.

Lemma 6 Under Assumptions 1-13, the most profitable one-sided sustainable agreement leads to price variations on both sides that are related as follows:

$$
\Delta p_{2}=-\frac{\alpha_{1}}{t} \Delta p_{1}
$$

Proof. We have: $\Delta p_{2}=\int_{p_{1}^{N}}^{p_{1}^{o c}(\delta)} \frac{\partial g}{\partial p_{1}} d p_{1}=-\frac{\alpha_{1}}{t}\left[p_{1}^{o c}(\delta)-p_{1}^{N}\right]=-\frac{\alpha_{1}}{t} \Delta p_{1}$.

Even though platforms collude only on one side of the market, the price on the non-cooperative side is also affected by collusion due to the existence of cross-group externalities. Suppose that $p_{1}^{o c}>p_{1}^{N}$. Collusion makes side- 1 agents more valuable to platforms. As a result, platforms would like to increase their market share on side 1 (as compared to the competitive scenario). As $p_{1}$ is fixed by the collusive agreement, the only way for a platform to conquer more side-1 agents without triggering a punishment from the rival platform is to increase the attractiveness of its platform to these agents by changing the number of agents on side 2. If $\alpha_{1}>0$, side- 1 agents enjoy the presence of more side- 2 agents, and platforms have, therefore, incentives to decrease $p_{2}$. By contrast, if $\alpha_{1}<0$, platforms have incentives to increase $p_{2}$ to attract less side- 2 agents, and increase their attractiveness to side- 1 agents. If $p_{1}^{o c}<p_{1}^{N}$, the reasoning is exactly the opposite: as collusion makes side-1 agents less valuable to platforms (as compared to the competitive scenario), they use $p_{2}$ to decrease the value that side- 1 agents get from joining a platform.

To gain further insights we need to distinguish between the scenario in which the ICC

$$
\frac{\pi^{A}\left(p_{1}, g\left(p_{1}, \alpha_{1}, \alpha_{2}\right), p_{1}, g\left(p_{1}, \alpha_{1}, \alpha_{2}\right)\right)}{1-\delta} \geq \max _{\left(\tilde{p}_{1}, \tilde{p}_{2}\right)} \pi^{A}\left(\tilde{p}_{1}, \tilde{p}_{2}, p_{1}, g\left(p_{1}, \alpha_{1}, \alpha_{2}\right)\right)+\frac{\delta}{1-\delta} \pi^{N}
$$

is binding (imperfect one-sided collusion) and the scenario in which it is not (perfect one-sided collusion). Given $\delta \in(0,1)$, defining $\pi^{o c}(\delta)$ as the highest sustainable profit under one-sided collusion and $\pi^{o m}$ as a firm's profit in the absence of the ICC, it is straightforward to show that $\pi^{o c}(\delta)$ is (weakly) increasing in $\delta{ }^{27}$ and that there exists a unique threshold $\delta^{o m} \in(0,1)$ such that $\pi^{o c}(\delta)<\pi^{o m}$ if and only if $\delta<\delta^{o m}$.

Let us first consider that perfect one-sided collusion is sustainable, i.e., $\delta \geq \delta^{o m}$. In this scenario, firms can increase or decrease $p_{1}$ (with respect to its Nash level) without any constraint. Let $p_{1}^{\text {om }}$ denote the firms' optimal price on side 1 in this case, i.e., $p_{1}^{o m}=p_{1}^{o c}(\delta), \forall \delta \geq \delta^{o m}$. If $\alpha_{1}<0$, a decrease in $p_{1}$ leads to a decrease in $p_{2}$ and, therefore, decreasing $p_{1}$ below its Nash level is surely unprofitable. This implies that $p_{1}^{o m}>p_{1}^{N}$. In contrast, if $\alpha_{1}>0$, an increase in $p_{1}$ is followed by a decrease in $p_{2}$. In this case, increasing

${ }^{26}$ In Section 5 , we discuss the implications of relaxing the assumption of inelastic demand.

${ }^{27}$ This follows from the fact that an increase in $\delta$ does not affect the firms' objective function but relaxes the constraints (or, equivalently, widen the subspace of prices over which firms maximize their joint profits). 
$p_{1}$ is profitable if and only if the gain on side $1, p_{1}^{o m}-p_{1}^{N}$, outweighs the loss on side 2 , i.e, $\frac{\alpha_{1}}{t}\left(p_{1}^{o m}-p_{1}^{N}\right)$, which is the case if and only if $t>\alpha_{1}$. If, instead, $t<\alpha_{1}$, side- 1 agents are so valuable that platforms decrease $p_{2}$ so much (to increase their attractiveness on side 1 ) that the profit loss on side 2 offsets the profit gain on side 1 . This leads to the following proposition.

Proposition 3 Suppose that Assumptions $1-3$ hold and consider $\delta \geq \delta^{o m}$.

(i) If $\alpha_{1}<0$, the prices under the most profitable one-sided agreement are above their static Nash levels on both sides of the market.

(ii) In contrast, if $\alpha_{1}>0$, the prices under the most profitable one-sided agreement are such that the price on one side is above its static Nash level while the price on the other side is below its static Nash level.

More precisely, the following holds:

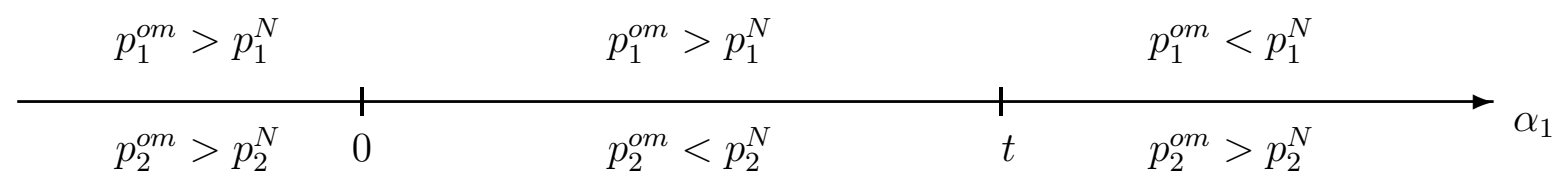

When the cross-group externalities exerted on the collusive side are positive, the relative price variation on the two sides due to collusion depends on the ratio between the strength of these externalities and the degree of differentiation on the collusive side, $\frac{\alpha_{1}}{t}$. If $\left|\alpha_{1}\right|>t$, the price variation due to collusion is higher in the non-cooperative side, $\left|\Delta p_{2}\right|>\left|\Delta p_{1}\right|$. In contrast, if $\left|\alpha_{1}\right|<t$, the price variation is higher in the collusive side: $\left|\Delta p_{1}\right|>\left|\Delta p_{2}\right|$. This is due to the fact that an additional side-2 agent attracts $\frac{\alpha_{1}}{t}$ additional side- 1 agents to a platform (Armstrong, 2006). If $t=\alpha_{1}$, any price change in the collusive side is followed by a change of the same magnitude but on the opposite direction on side 2 . Therefore, if $t=\alpha_{1}$, the (oneperiod) collusive profit coincides with the static Nash profit, corresponding to the conjecture of Evans and Schmalensee (2008) that if platforms "agree to fix prices on one side only, the cartel members will tend to compete the supracompetitive profits away on the other side." (p.689) We prove, however, that this only happens in a very particular case 28

To show that the comparison between the prices under one-sided collusion and competition provided by Proposition 3 extends to the case of imperfect one sided-collusion (i.e., for $\delta<\delta^{o m}$ ), we make Assumption 6. which ensures full market coverage under one-sided collusion.

\footnotetext{
${ }^{28}$ Dewenter et al. (2011) also find that the claim by Evans and Schmalensee (2008) is true only in a very special case in their model.
} 


\section{Assumption 6}

- If $t \geq \alpha_{1}$, let $k_{1}>t-\alpha_{1}$.

- If $t \leq \alpha_{1}$, let $k_{2}>\frac{2 \alpha_{1} t-\alpha_{1} \alpha_{2}-t^{2}}{2 \alpha_{1}}$.

Lemma 7 Under Assumptions 1 -3 and 6, the most profitable sustainable one-sided agreement is such that both market sides are fully covered.

Proof. See Appendix.

Lemma 8 Let $\tilde{u}_{j}^{N} \equiv u_{j}^{i}\left(\frac{1}{2}, p_{1}^{N}, p_{2}^{N}, p_{1}^{N}, p_{2}^{N}\right)$ denote the utility of the side- $j$ agent located at $x=\frac{1}{2}$ if platforms set the static Nash prices. Under Assumptions 1 - 3 and 6 , the prices under the most profitable sustainable one-sided agreement are such that:

1. If $-\frac{\tilde{u}_{2}^{N}}{\tilde{u}_{1}^{N}} t \leq \alpha_{1}<t$ :

$$
\left(p_{1}^{o c}(\delta), p_{2}^{o c}(\delta)\right)=\left\{\begin{array}{lll}
\left(\frac{2 t \pi^{o c}(\delta)-t^{2}+\alpha_{1} \alpha_{2}}{t-\alpha_{1}}, \frac{t^{2}-\alpha_{1} \alpha_{2}-2 \alpha_{1} \pi^{o c}(\delta)}{t-\alpha_{1}}\right) & \text { if } & 0<\delta \leq \tilde{\delta}^{o m} \\
\left(p_{1}^{m}, t-\frac{\alpha_{1}\left(2 k_{1}-t+\alpha_{1}+2 \alpha_{2}\right)}{2 t}\right) & \text { if } & \tilde{\delta}^{o m} \leq \delta<1,
\end{array}\right.
$$

where $p_{1}^{m}$ is given by (5), and $\tilde{\delta}^{\text {om }}$ is the value of $\delta^{o m}$ in this scenario and is given by $\pi^{o c}\left(\tilde{\delta}^{o m}\right)=$ $\frac{2 k_{1}\left(t-\alpha_{1}\right)+t\left(t+2 \alpha_{1}\right)-\alpha_{1}\left(\alpha_{1}+2 \alpha_{2}\right)}{4 t}$.

2. If $0<t<\alpha_{1}$ or $\alpha_{1}<-\frac{\tilde{u}_{2}^{N}}{\tilde{u}_{1}^{N}} t<t$ :

$$
\left(p_{1}^{o c}(\delta), p_{2}^{o c}(\delta)\right)=\left\{\begin{array}{lll}
\left(\frac{2 t \pi^{o c}(\delta)-t^{2}+\alpha_{1} \alpha_{2}}{t-\alpha_{1}}, \frac{t^{2}-\alpha_{1} \alpha_{2}-2 \alpha_{1} \pi^{o c}(\delta)}{t-\alpha_{1}}\right) & \text { if } & 0<\delta \leq \hat{\delta}^{o m} \\
\left(\frac{3 t^{2}-t \alpha_{2}-2 \alpha_{1} \alpha_{2}-2 t k_{2}}{2 \alpha_{1}}, p_{2}^{m}\right) & \text { if } & \hat{\delta}^{o m} \leq \delta<1,
\end{array}\right.
$$

where $p_{2}^{m}$ is given by (5), and $\hat{\delta}^{o m}$ is the value of $\delta^{o m}$ in this scenario and is given by $\pi^{o c}\left(\hat{\delta}^{o m}\right)=$ $\frac{2 k_{2}\left(\alpha_{1}-t\right)+t\left(3 t-\alpha_{1}-\alpha_{2}\right)-\alpha_{1} \alpha_{2}}{4 \alpha_{1}}$.

Proof. See Appendix.

Using the fact that the highest sustainable profit under one-sided collusion, $\pi^{o c}(\delta)$, is increasing in $\delta$ over $\left(0, \delta^{o m}\right)$ (where $\delta^{o m}$ is equal to either $\tilde{\delta}^{o m}$ or $\hat{\delta}^{o m}$ depending on the considered scenario), it is straightforward to derive from the lemma above the monotonicity of the prices under one-sided collusion with respect to $\delta$. This allows, in particular, to compare these prices to the static Nash prices (recall that $p_{1}^{N}=p_{1}^{o c}(0)$ and $\left.p_{2}^{N}=p_{2}^{o c}(0)\right)$. 
Proposition 4 Under Assumptions $1-3$ and 6 and for $\delta<\delta^{o m}$, the prices under the most profitable one-sided collusive agreement are as follows:

(i) If $\alpha_{1}<0$, platforms charge prices that are increasing in $\delta$ on both sides. Therefore, the prices are above their static Nash level on both sides.

(ii) If $0<\alpha_{1}<t$, the price on side 1 is increasing in $\delta$ while the price on side 2 is decreasing in $\delta$. Therefore, the price on side 1 is above its static Nash level while the price on side 2 is below its static Nash level.

(iii) If $\alpha_{1}>t$, the price on side 1 is decreasing in $\delta$ while the price on side 2 is increasing in $\delta$. Therefore, the price on side 1 is below its static Nash level while the price on side 2 is above its static Nash level.

We can now state the effect of one-sided collusion on the surplus of the agents on each side of the market.

Corollary 3 Under Assumptions 1 - 3 and 6, the impact of one-sided collusion on the surplus of side $j \in\{1,2\}$ agents is equal to the price change on this side, $\Delta p_{j}$. Thus:

(i) If $\alpha_{1}<0$, agents on both market sides are damaged. Side-1 agents are the most damaged iff $\left|\alpha_{1}\right|>t$.

(ii) If $0<\alpha_{1}<t$, collusion damages side-1 agents and benefits side-2 agents.

(iii) If $0<t<\alpha_{1}$, collusion benefits side-1 agents and damages side-2 agents.

(iv) Collusion always decreases the joint surplus of side-1 and side-2 agents.

Proof. The first three statements follow in a straightforward way from Proposition 44. The fourth statement follows from the fact that $\Delta p_{1}+\Delta p_{2}$ is positive (since this also represents the increase in the platforms' joint profits due to collusion).

To derive the effect of cross-group externalities on the sustainability of one-sided collusion, we provide a closed-form expression for collusive profits under an additional assumption on the parameters of the model. More precisely, we impose lower bounds on the stand-alone values, $k_{1}$ and $k_{2}$, to get the richest possible setting 29

\footnotetext{
${ }^{29}$ As shown in the proof of Proposition 5 if $k_{1}$ is large enough, $\exists \bar{\pi}^{o c} \in\left[\pi^{N}, \tilde{\pi}^{o m}\right)$ such that: a deviating platform would not monopolize any side of the market if $\pi^{o c}(\delta)<\bar{\pi}^{o c}$; it would monopolize the collusive side 1 (but not the non-cooperative side 2) if $\pi^{o c}(\delta) \geq \bar{\pi}^{o c}$. For lower values of $k_{1}$, the deviating platform would never monopolize any side of the market. In that case, the second branch of 16 would disappear. Similarly, if $k_{2}$ is not sufficiently large, a deviating platform would never monopolize the non-cooperative side 2, and the expression for the one-sided collusive profit would be given by (17) without the second branch. Note that assumption 7 is more demanding than Assumption 6
} 


\section{Assumption 7}

- If $-\frac{\tilde{u}_{2}^{N}}{\tilde{u}_{1}^{N}} t \leq \alpha_{1}<t$, let $k_{1}>\frac{14 t^{3}-\left(2 t^{2}-\alpha_{1}^{2}-\alpha_{1} \alpha_{2}\right)\left(\alpha_{1}+2 \alpha_{2}\right)-t\left(\alpha_{1}+\alpha_{2}\right)\left(5 \alpha_{1}+2 \alpha_{2}\right)}{2\left(2 t^{2}-\alpha_{1}^{2}-\alpha_{1} \alpha_{2}\right)}$
- If $0<t<\alpha_{1}$ or $\alpha_{1}<-\frac{\tilde{u}_{2}^{N}}{\tilde{u}_{1}^{N}} t<t$, let $k_{2}>\frac{t^{2}\left(11 \alpha_{1}-3 \alpha_{2}\right)-\left(\alpha_{1}-\alpha_{2}\right)\left(2 \alpha_{1}+\alpha_{2}\right) t-2 \alpha_{1}\left(\alpha_{1}+\alpha_{2}\right)^{2}}{2 t\left(\alpha_{1}-\alpha_{2}\right)}$.

We present in the next proposition the expressions for the highest sustainable profit under one-sided collusion.

Proposition 5 Under Assumptions 1 - 3 and 7 , given $\delta \in(0,1)$, the most sustainable profit if platforms collude on side 1 and set prices non-cooperatively on side 2 is:

1. If $-\frac{\tilde{u}_{2}^{N}}{\tilde{u}_{1}^{N}} t \leq \alpha_{1}<t$ :

$$
\pi^{o c}(\delta)= \begin{cases}\frac{\left(2 t-\alpha_{1}-\alpha_{2}\right)\left[t\left(t^{2}-\alpha_{1} \alpha_{2}\right)+\left[\left(t^{3}-t^{2}\left(3 \alpha_{1}-\alpha_{2}\right)-t \alpha_{1} \alpha_{2}+\alpha_{1}^{2}\left(\alpha_{1}+\alpha_{2}\right)\right] \delta\right]\right.}{2 t\left(t^{2}-\alpha_{1} \alpha_{2}\right)(1-\delta)} & \text { if } 0<\delta<\tilde{\delta}^{o c} \\ \tilde{\pi}^{o c}(\delta) & \text { if } \tilde{\delta}^{o c} \leq \delta<\tilde{\delta}^{o m} \\ \tilde{\pi}^{o m} & \text { if } \tilde{\delta}^{o m} \leq \delta<1\end{cases}
$$

with $\tilde{\delta}^{o c}=\frac{t\left(t^{2}-\alpha_{1} \alpha_{2}\right)}{t\left(t^{2}-\alpha_{1} \alpha_{2}\right)+\left(t-\alpha_{1}\right)\left(2 t^{2}-\alpha_{1}^{2}-\alpha_{1} \alpha_{2}\right)}$ and $\tilde{\pi}^{o m}=\frac{2 k_{1}\left(t-\alpha_{1}\right)+t\left(t+2 \alpha_{1}\right)-\alpha_{1}\left(\alpha_{1}+2 \alpha_{2}\right)}{4 t} 30$

2. If $0<t<\alpha_{1}$ or $\alpha_{1}<-\frac{\tilde{u}_{2}^{N}}{\tilde{u}_{1}^{N}} t<t$ :

$$
\pi^{o c}(\delta)= \begin{cases}\frac{\left(2 t-\alpha_{1}-\alpha_{2}\right)\left[t\left(t^{2}-\alpha_{1} \alpha_{2}\right)+\left[\left(t^{3}-t^{2}\left(3 \alpha_{1}-\alpha_{2}\right)-t \alpha_{1} \alpha_{2}+\alpha_{1}^{2}\left(\alpha_{1}+\alpha_{2}\right)\right] \delta\right]\right.}{2 t\left(t^{2}-\alpha_{1} \alpha_{2}\right)(1-\delta)} & \text { if } 0<\delta<\hat{\delta}^{o c} \\ \hat{\pi}^{o c}(\delta) & \text { if } \quad \hat{\delta}^{o c} \leq \delta<\hat{\delta}^{o m} \\ \hat{\pi}^{o m} & \text { if } \quad \hat{\delta}^{o m} \leq \delta<1,\end{cases}
$$

with $\hat{\delta}^{o c}=\frac{t^{2}-\alpha_{1} \alpha_{2}}{t^{2}-\alpha_{1} \alpha_{2}+\left(\alpha_{1}-\alpha_{2}\right)\left(\alpha_{1}-t\right)}$ and $\hat{\pi}^{o m}=\frac{2 k_{2}\left(\alpha_{1}-t\right)+t\left(3 t-\alpha_{1}-\alpha_{2}\right)-\alpha_{1} \alpha_{2}}{4 \alpha_{1}} 31$

Proof. See Appendix.

\subsection{Effects of cross-group externalities}

The mathematical expression for the highest sustainable one-sided collusive profit makes it difficult to derive the effect of a unilateral increase in the externalities exerted by one side of the market on the other side on profits. Nevertheless, we are able to sign the effect of a joint increase in cross-group externalities when they are symmetric.

${ }^{30}$ The expressions for $\tilde{\pi}^{o c}(\delta)$ and $\tilde{\delta}^{o m}$ are, respectively, given by $\sqrt[48]{51}$ and $\sqrt{49}$ in the Appendix.
${ }^{31}$ The expressions for $\hat{\pi}^{o c}(\delta)$ and $\hat{\delta}^{o m}$ are, respectively, given by $\sqrt{58}$ and $\sqrt{61}$ in the Appendix. 
Proposition 6 Under Assumptions 1 - 3 and 7 , if cross-group externalities are symmetric across sides $\left(\alpha_{1}=\alpha_{2}=\alpha\right)$, an increase in $\alpha$ leads to a decrease of the highest sustainable one-sided collusive profit:

$$
\frac{\partial \pi^{o c}}{\partial \alpha}<0
$$

As a result, an increase in cross-group externalities makes one-sided collusion at a given profit level harder to sustain.

Proof. See Appendix.

Proposition 6 shows that the effect of an increase in cross-group externalities on one-sided collusive profits (with symmetric externalities) is qualitatively the same as under imperfect two-sided collusion.

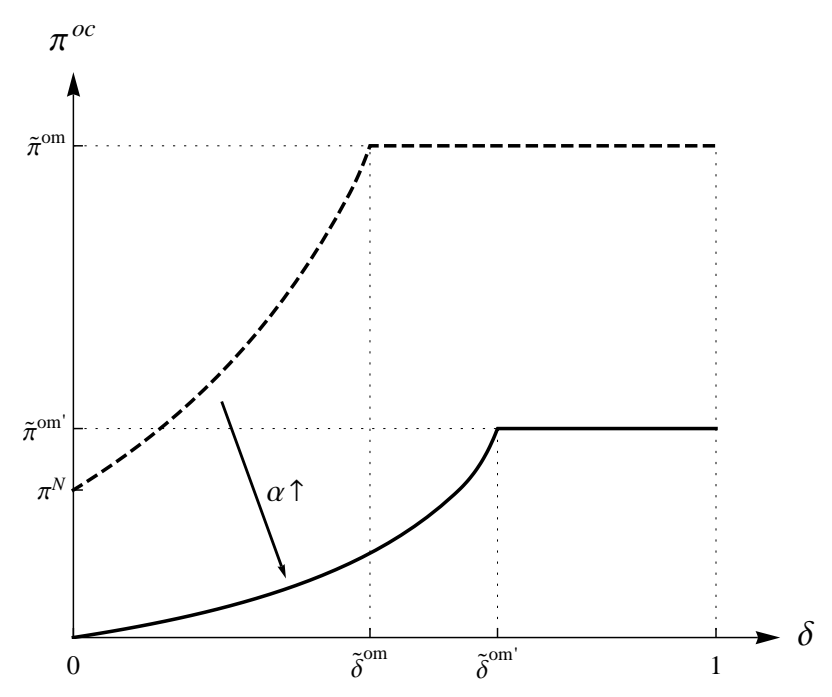

Figure 2: Impact of a joint increase in cross-group externalities when they are symmetric ${ }^{32}$

\section{Discussion}

\section{Demand expansion}

In our model, both sides of the market are fully covered and split equally between the two platforms under competition and collusion. Thus, collusion does not affect total demand (and individual demand in a symmetric equilibrium). While this feature allows to have a tractable model and derive neat results, it also imposes limitations. In particular, in a setting where collusion would affect the size of demand, the result that two-sided collusion always leads to higher prices on both sides of the market may not hold. The reason is that a decrease in price on one side would expand demand on that side and would, therefore, increase the willingness to pay of the agents on the other side if cross-group externalities are positive. If the magnitude of this effect (which does not exist in our setting) is relatively large, it might be the case that collusion leads to a lower price on one side of the market than competition. Note, however, that the striking result that, under one-sided collusion, the price on the collusive side may be lower than the static

$\overline{32}$ To build these figures, we considered: $t=3, \alpha=1, \alpha^{\prime}=2, k_{1}=10, k_{2}=4$. 
Nash price on that side would be strengthened if we allowed for demand expansion. To see why, note that, in our setting, firms' incentives to set a price below the Nash level are solely driven by the incentive to soften competition on the other side. In an environment where, following a decrease in the price on side $j$, there is a demand expansion on that side and potentially also on side $-j$ (if $\alpha_{-j}>0$ ), our result is even more likely to hold.

\section{Endogenous choice of the collusive side(s)}

In our setting, platforms can always sustain some degree of collusion in equilibrium both when they collude on the two market sides, and when they just collude on one side of the market. Our model also suggests that platforms should always prefer to collude on both sides (since this is the most profitable scenario). However, as mentioned before, there is evidence of platforms being convicted of just coordinating the price on one market side. Coordination costs and the possibility of they being (prohibitively) higher when platforms coordinate two prices instead of one may underlie actual platforms' choice ${ }^{33}$ Relatedly, platforms may engage in one-sided collusion to attempt to reduce the risk of being caught and punished by antitrust authorities.

In the context of one-sided collusion, a natural question that arises concerns the choice of the collusive side. While a general treatment of this issue is outside the scope of this paper, we provide two special cases where we are able to determine the platforms' choice. Collusion on side 1 yields the same outcome as competition if $\alpha_{1}=t$, and the same outcome as two-sided collusion if $\alpha_{1}=-t$ and $\delta<\delta^{m} 34$ Therefore, platforms (weakly) prefer to collude on side 2 in the former case while they (weakly) prefer to collude on side 1 in the latter case. There are other reasons outside our model that may also affect the choice of the side to collude on. For instance, it may be harder for platforms to coordinate prices on one side of the market than on the other one. For example, in the case of newspapers, coordinating cover prices may probably be easier than coordinating ad prices (as the latter are likely to be more heterogeneous). Moreover, monitoring might be easier on one side of the market than on the other one. Considering again the newspapers example, cover prices are typically more transparent and, therefore, easier to monitor, than ad prices.

\section{Multi-homing}

In the standard competitive bottleneck model (Armstrong, 2006), there is no strategic interaction on the multi-homing side. A first implication is that there is no incentive to engage in collusion on the multihoming side 35 Thus, in that context, platforms may collude on the single-homing side. An agreement on supra-competitive (infra-competitive) prices on the single-homing side generates three potential effects: (i) higher (lower) margins on the single-homing side; (ii) potentially lower (higher) demand on the singlehoming side; and (iii) potentially lower (higher) prices on the multi-homing side. Therefore, whether platforms increase or decrease the price on the (collusive) single-homing side, relative to its static Nash level, depends on whether the price effect on the single-homing side outweighs or is outweighed by the

\footnotetext{
${ }^{33}$ One (perhaps simplistic) way of incorporating these ingredients in our model would be to introduce a fixed coordination cost. It follows straightforwardly that: if this cost is not much higher when platforms coordinate prices on both sides of the market than when they just coordinate one price, platforms will settle a two-sided collusive agreement; while, if the coordination cost is larger enough under two-sided collusion, platforms will settle a one-sided collusive agreement. For intermediate values of this coordination cost, platforms' choice may depend on the discount factor.

${ }^{34}$ Both results follow from Lemma 6

${ }^{35}$ In particular, two-sided collusion and one-sided collusion on the single-homing side of the market yield the same outcome.
} 
combination of the demand effect on the single-homing side and the price effect on the multi-homing side. In a setting where the single-homing side takes the form of a Hotelling line, fully covered under both competition and collusion, the latter two effects do not exist (as collusion on the single-homing side does not affect the demand on that side and, therefore, does not affect the price on the multi-homing side). Thus, in that special case, collusion on the single-homing side would lead to an increase in price on that side and leave the price on the multi-homing side unaffected.

\section{Conclusion}

We investigate collusion between two-sided platforms in a repeated version of Armstrong (2006)'s canonical model. Considering first the scenario in which collusion occurs on both sides of the market, we show that platforms use the structure of prices as an instrument to minimize the incentives to deviate. Moreover, we establish that collusion (at a given profit level) is harder to sustain if cross-group externalities increase. Turning to the case where firms collude only on one side of the market, we show that the price on the collusive (non-cooperative) side may be lower (higher) than the competitive price, thus leading to an increase (decrease) in the surplus of this side's agents.

Our results also provide interesting insights into the effects of collusion on prices in a multi-product setting with demand linkages. When the parameters capturing cross-group externalities in our model are positive, the latter can be reinterpreted as a model in which two firms selling two complementary products compete against each other. Our results show in particular that single-product collusion in such an environment can lead to a decrease in the price of the product for which there is collusion and an increase in the price of the product for which there is competition. 


\section{Appendix}

\section{Proof of Lemma 2 ,}

Note first that ICC (4) can be rewritten as:

$$
\frac{1}{\delta}\left[\pi^{d}\left(p_{1}, p_{2}\right)-\pi\left(p_{1}, p_{2}\right)\right] \leq \pi^{d}\left(p_{1}, p_{2}\right)-\pi^{N} .
$$

(i) From the fact that $\pi^{d}\left(p_{1}, p_{2}\right)-\pi\left(p_{1}, p_{2}\right) \geq 0$, it follows that $\delta<\delta^{\prime} \Rightarrow I(\delta) \subseteq I\left(\delta^{\prime}\right) \Rightarrow \pi^{c}(\delta) \leq \pi^{c}\left(\delta^{\prime}\right)$. For $\delta \in\left(0, \delta^{m}\right),\left(p_{1}^{m}, p_{2}^{m}\right) \notin I(\delta)$. This, combined with the fact that $\left(p_{1}^{m}, p_{2}^{m}\right)$ is the unique solution to the unconstrained maximization program $\max _{\left(p_{1}, p_{2}\right) \in \mathbb{R}^{2}} \pi\left(p_{1}, p_{2}\right)$ implies then that $\pi^{c}(\delta)<\pi^{m}$. For $\delta \in\left[\delta^{m}, 1\right)$, $\left(p_{1}^{m}, p_{2}^{m}\right) \in I(\delta)$ and, therefore, $\pi^{c}(\delta)=\pi^{m}$.

(ii) Let $\delta \in\left(0, \delta^{m}\right)$ and assume by way of contradiction that

$$
\frac{1}{\delta}\left[\pi^{d}\left(p_{1}^{c}(\delta), p_{2}^{c}(\delta)\right)-\pi\left(p_{1}^{c}(\delta), p_{2}^{c}(\delta)\right)\right]<\pi^{d}\left(p_{1}^{c}(\delta), p_{2}^{c}(\delta)\right)-\pi^{N},
$$

i.e., the constraint is not binding at the optimum. Then, by a (standard) continuity argument, there exists $\epsilon>0$ such that

$$
\frac{1}{\delta}\left[\pi^{d}\left(p_{1}, p_{2}\right)-\pi\left(p_{1}, p_{2}\right)\right]<\pi^{d}\left(p_{1}, p_{2}\right)-\pi^{N}
$$

for any $\left(p_{1}, p_{2}\right) \in\left[p_{1}^{c}(\delta)-\epsilon, p_{1}^{c}(\delta)+\epsilon\right] \times\left[p_{2}^{c}(\delta)-\epsilon, p_{2}^{c}(\delta)+\epsilon\right]$. This implies that the pair of prices $\left(p_{1}^{c}(\delta), p_{2}^{c}(\delta)\right)$ is a local maximum of $\pi\left(p_{1}, p_{2}\right)$. However, straightforward computations show that $\pi\left(p_{1}, p_{2}\right)$ does not have a local maximum but its global maximum, which is uniquely reached at $\left(p_{1}^{m}, p_{2}^{m}\right)$. This implies that $\left(p_{1}^{c}(\delta), p_{2}^{c}(\delta)\right)=\left(p_{1}^{m}, p_{2}^{m}\right)$, and contradicts (i).

\section{Proof of Lemma 3 ,}

Assume, by way of contradiction, that $\left(p_{1}^{c}(\delta), p_{2}^{c}(\delta)\right)$ is not a solution to the constrained minimization program. Denoting $\left(\hat{p}_{1}(\delta), \hat{p}_{2}(\delta)\right)$ a solution to that program, we then have

$$
\pi^{d}\left(\hat{p}_{1}(\delta), \hat{p}_{2}(\delta)\right)<\pi^{d}\left(p_{1}^{c}(\delta), p_{2}^{c}(\delta)\right) .
$$

Therefore

$$
\begin{aligned}
\frac{\pi\left(\hat{p}_{1}(\delta), \hat{p}_{2}(\delta)\right)}{1-\delta} & =\frac{\pi\left(p_{1}^{c}(\delta), p_{2}^{c}(\delta)\right)}{1-\delta}= \\
& =\pi^{d}\left(p_{1}^{c}(\delta), p_{2}^{c}(\delta)\right)+\frac{\delta}{1-\delta} \pi^{N}>\pi^{d}\left(\hat{p}_{1}(\delta), \hat{p}_{2}(\delta)\right)+\frac{\delta}{1-\delta} \pi^{N}
\end{aligned}
$$


which implies that

$$
\frac{1}{\delta}\left[\pi^{d}\left(\hat{p}_{1}(\delta), \hat{p}_{2}(\delta)\right)-\pi\left(\hat{p}_{1}(\delta), \hat{p}_{2}(\delta)\right)\right]<\pi^{d}\left(\hat{p}_{1}(\delta), \hat{p}_{2}(\delta)\right)-\pi^{N}
$$

Again, by a continuity argument, there exists $\mu>0$ such that

$$
\frac{1}{\delta}\left[\pi^{d}\left(p_{1}, p_{2}\right)-\pi\left(p_{1}, p_{2}\right)\right]<\pi^{d}\left(p_{1}, p_{2}\right)-\pi^{N}
$$

for any $\left(p_{1}, p_{2}\right) \in\left[\hat{p}_{1}(\delta)-\mu, \hat{p}_{1}(\delta)+\mu\right] \times\left[\hat{p}_{2}(\delta)-\mu, \hat{p}_{2}(\delta)+\mu\right]$. There are only two possible scenarios, which both lead to a contradiction:

- If $\pi\left(p_{1}, p_{2}\right)$ reaches a local maximum at $\left(\hat{p}_{1}(\delta), \hat{p}_{2}(\delta)\right)$ then it is necessarily the case that $\left(\hat{p}_{1}(\delta), \hat{p}_{2}(\delta)\right)=\left(p_{1}^{m}, p_{2}^{m}\right)$, and, therefore, $\pi\left(\hat{p}_{1}(\delta), \hat{p}_{2}(\delta)\right)=\pi^{m}>\pi^{c}(\delta)$ because $\delta \in\left(0, \delta^{m}\right)$, a contradiction.

- If $\pi\left(p_{1}, p_{2}\right)$ does not reach a local maximum at $\left(\hat{p}_{1}(\delta), \hat{p}_{2}(\delta)\right)$ then there exists $\left(\breve{p}_{1}, \breve{p}_{2}\right) \in$ $\left[\hat{p}_{1}(\delta)-\mu, \hat{p}_{1}(\delta)+\mu\right] \times\left[\hat{p}_{2}(\delta)-\mu, \hat{p}_{2}(\delta)+\mu\right]$ such that

$$
\pi\left(\breve{p}_{1}, \breve{p}_{2}\right)>\pi\left(\hat{p}_{1}(\delta), \hat{p}_{2}(\delta)\right)=\pi^{c}(\delta)
$$

Since $\left(\breve{p}_{1}, \breve{p}_{2}\right) \in I(\delta)$, this contradicts the fact that $\pi^{c}(\delta)=\max _{\left(p_{1}, p_{2}\right) \in I(\delta)} \pi\left(p_{1}, p_{2}\right)$.

\section{Proof of Lemma 4}

We are focusing on symmetric collusive agreements, i.e., such that platforms set the same cooperative price on each side of the market, i.e., $p_{j}^{A}=p_{j}^{B}=p_{j}, j \in\{1,2\}$. Let $\tilde{x}_{j}$ denote the consumer on side $j$ that is indifferent between joining platform $A$ and not joining any platform.

1. We start by deriving the conditions that ensure that, if platforms fully serve side 2 , they will also prefer to fully serve side 1 .

Given $\tilde{x}_{2}=\frac{1}{2}$ :

$$
u_{1}^{A}\left(\tilde{x}_{1}, p_{1}, p_{2}, p_{1}, p_{2}\right)=0 \Leftrightarrow \tilde{x}_{1}=\frac{2 k_{1}-2 p_{1}+\alpha_{1}}{2 t} .
$$

If $\tilde{x}_{1} \leq \frac{1}{2}$, the individual collusive profit is:

$$
\pi^{c}\left(p_{1}, p_{2}\right)=p_{1} \tilde{x}_{1}+\frac{p_{2}}{2}=\frac{p_{1}\left(2 k_{1}-2 p_{1}+\alpha_{1}\right)}{2 t}+\frac{p_{2}}{2} .
$$

As $\pi^{c}$ is strictly increasing in $p_{2}$, platforms will choose the highest price that leaves the consumer $\tilde{x}_{2}$ with zero utility:

$$
u_{2}^{A}\left(\frac{1}{2}, p_{1}, p_{2}, p_{1}, p_{2}\right)=0 \Leftrightarrow p_{2}=k_{2}+\alpha_{2} \tilde{x}_{1}-\frac{t}{2} \Leftrightarrow p_{2}=k_{2}+\frac{\alpha_{2}\left(2 k_{1}-2 p_{1}+\alpha_{1}\right)}{2 t}-\frac{t}{2} .
$$

Combining this expression with the FOC corresponding to the maximization of $\pi^{c}$ with respect to $p_{1}$, 
$\frac{\partial \pi^{c}}{\partial p_{1}}=0$, we obtain:

$$
p_{1}=\frac{2 k_{1}+\alpha_{1}}{4} \quad \text { and } \quad p_{2}=\frac{4 k_{2} t-2 t^{2}+2 k_{1} \alpha_{2}+\alpha_{1} \alpha_{2}}{4 t} .
$$

Given these prices:

$$
\tilde{x}_{1}=\frac{2 k_{1}+\alpha_{1}}{4 t} .
$$

As a result, there is a local maximum of $\pi^{c}$ with partial coverage of side 1 if:

$$
\tilde{x}_{1}<\frac{1}{2} \Leftrightarrow k_{1}<t-\frac{\alpha_{1}}{2} .
$$

Similarly, there is a local maximum of $\pi^{c}$ with partial coverage of side 2 if:

$$
k_{2}<t-\frac{\alpha_{2}}{2} \text {. }
$$

2. Let us now see under which conditions platforms prefer to partially serve both sides instead of fully serving them.

For $j \in\{1,2\}$, we have:

$$
k_{j}+\alpha_{j} \tilde{x}_{-j}-t \tilde{x}_{j}-p_{j}=0 .
$$

Solving this system of two equations, we obtain:

$$
\tilde{x}_{1}=\frac{\alpha_{1}\left(k_{2}-p_{2}\right)+t\left(k_{1}-p_{1}\right)}{t^{2}-\alpha_{1} \alpha_{2}} \quad \text { and } \quad \tilde{x}_{2}=\frac{\alpha_{2}\left(k_{1}-p_{1}\right)+t\left(k_{2}-p_{2}\right)}{t^{2}-\alpha_{1} \alpha_{2}} .
$$

If $\tilde{x}_{j} \leq \frac{1}{2}$, the individual collusive profit is given by:

$$
\pi^{c}=p_{1} \tilde{x}_{1}+p_{2} \tilde{x}_{2}
$$

Solving the FOCs corresponding to the maximization of $\pi^{c}$, we obtain:

$$
p_{1}=\frac{k_{2} t\left(\alpha_{1}-\alpha_{2}\right)+k_{1}\left(2 t^{2}-\alpha_{2} \alpha_{1}-\alpha_{2}^{2}\right)}{\left(2 t-\alpha_{1}-\alpha_{2}\right)\left(2 t+\alpha_{1}+\alpha_{2}\right)} \wedge p_{2}=\frac{k_{1} t\left(\alpha_{2}-\alpha_{1}\right)+k_{2}\left(2 t^{2}-\alpha_{2} \alpha_{1}-\alpha_{1}^{2}\right)}{\left(2 t-\alpha_{1}-\alpha_{2}\right)\left(2 t+\alpha_{1}+\alpha_{2}\right)} .
$$

Given these prices:

$$
\tilde{x}_{j}=\frac{2 k_{j} t+k_{-j}\left(\alpha_{j}+\alpha_{-j}\right)}{\left(2 t-\alpha_{1}-\alpha_{2}\right)\left(2 t+\alpha_{1}+\alpha_{2}\right)} .
$$

There is an interior local maximum (with partial coverage of both market sides) iff $\tilde{x}_{1}<\frac{1}{2} \wedge \tilde{x}_{2}<\frac{1}{2}$, i.e.:

$$
\tilde{x}_{j}<\frac{1}{2} \Leftrightarrow 2 t k_{j}+\left(\alpha_{1}+\alpha_{2}\right) k_{-j}<\frac{\left(2 t-\alpha_{1}-\alpha_{2}\right)\left(2 t+\alpha_{1}+\alpha_{2}\right)}{2} .
$$

Thus, the two platforms prefer to fully cover the two market sides iff:

$$
\begin{aligned}
k_{1} \geq \frac{2 t-\alpha_{1}}{2} & \wedge k_{2} \geq \frac{2 t-\alpha_{2}}{2} \wedge \\
& \wedge 2 t \min \left\{k_{1}, k_{2}\right\}+\left(\alpha_{1}+\alpha_{2}\right) \max \left\{k_{1}, k_{2}\right\} \geq \frac{\left(2 t-\alpha_{1}-\alpha_{2}\right)\left(2 t+\alpha_{1}+\alpha_{2}\right)}{2} .
\end{aligned}
$$


Under Assumption 1, a sufficient condition for the last inequality to hold is:

$$
k_{1}+k_{2} \geq \frac{\left(2 t-\alpha_{1}-\alpha_{2}\right)\left(2 t+\alpha_{1}+\alpha_{2}\right)}{2\left(\alpha_{1}+\alpha_{2}\right)} .
$$

\section{Proof of Lemma 5 .}

A deviating platform (say $A$ ) sets prices $\left(p_{1}^{d}, p_{2}^{d}\right)$ that maximize its individual profit given that platform $B$ charges the collusive prices $\left(p_{1}^{c}, p_{2}^{c}\right)$ :

$$
\pi^{d}\left(p_{1}^{d}, p_{2}^{d}\right)=\frac{-t\left(p_{1}^{d}\right)^{2}-t\left(p_{2}^{d}\right)^{2}-\left(\alpha_{1}+\alpha_{2}\right) p_{1}^{d} p_{2}^{d}+p_{1}^{d}\left(t p_{1}^{c}+\alpha_{1} p_{2}^{c}+t^{2}-\alpha_{1} \alpha_{2}\right)+p_{2}^{d}\left(t p_{2}^{c}+\alpha_{2} p_{1}^{c}+t^{2}-\alpha_{1} \alpha_{2}\right)}{2\left(t^{2}-\alpha_{1} \alpha_{2}\right)} .
$$

The FOCs corresponding to the maximization of $\pi^{d}$ are $(j \in\{1,2\})$ :

$$
\frac{\partial \pi^{d}}{\partial p_{j}^{d}}=0 \Leftrightarrow \frac{1}{2}-\frac{2 t p_{j}^{d}+\left(\alpha_{1}+\alpha_{2}\right) p_{-j}^{d}-t p_{j}^{c}-\alpha_{j} p_{-j}^{c}}{2\left(t^{2}-\alpha_{1} \alpha_{2}\right)}=0 .
$$

Combining the two FOCs, we obtain ${ }^{36}$

$$
p_{j}^{d}\left(p_{1}^{c}, p_{2}^{c}\right)=\frac{\left(2 t^{2}-\alpha_{1} \alpha_{2}-\alpha_{-j}^{2}\right) p_{j}^{c}+t\left(\alpha_{j}-\alpha_{-j}\right) p_{-j}^{c}+\left(2 t-\alpha_{1}-\alpha_{2}\right)\left(t^{2}-\alpha_{1} \alpha_{2}\right)}{\left(2 t-\alpha_{1}-\alpha_{2}\right)\left(2 t+\alpha_{1}+\alpha_{2}\right)} .
$$

Replacing these prices in $(19)$, we obtain the deviation profit (for given $p_{1}^{c}$ and $p_{2}^{c}$ ):

$$
\pi^{d}\left(p_{1}^{c}, p_{2}^{c}\right)=\frac{1}{2\left(2 t+\alpha_{1}+\alpha_{2}\right)}\left[\frac{t}{2 t-\alpha_{1}-\alpha_{2}}\left(p_{1}^{c}+p_{2}^{c}\right)^{2}+t\left(p_{1}^{c}+p_{2}^{c}\right)+\alpha_{1} p_{2}^{c}+\alpha_{2} p_{1}^{c}-p_{1}^{c} p_{2}^{c}+t^{2}-\alpha_{1} \alpha_{2}\right] .
$$

From Lemma 4 if platforms charge prices $\left(p_{1}, p_{2}\right)$, their individual per-period collusive profit is:

$$
\pi^{c}\left(p_{1}, p_{2}\right)=\frac{p_{1}+p_{2}}{2}
$$

From Lemma 3 collusive prices $\left(p_{1}^{c}, p_{2}^{c}\right)$ solve the following constrained minimization program:

$$
\min _{\left(p_{1}, p_{2}\right) \in R^{2}} \pi^{d}\left(p_{1}, p_{2}\right) \quad \text { s.t. } \quad \pi^{c}=\frac{p_{1}+p_{2}}{2} .
$$

Solving this program, we obtain 37

$$
\left(p_{1}^{c}(\delta), p_{2}^{c}(\delta)\right)=\left(\frac{2 \pi^{c}(\delta)+\alpha_{1}-\alpha_{2}}{2}, \frac{2 \pi^{c}(\delta)-\alpha_{1}+\alpha_{2}}{2}\right) .
$$

${ }^{36}$ Under Assumption 1 the second-order conditions are satisfied since: $\frac{\partial^{2} \pi^{d}}{\partial\left(p_{j}^{d}\right)^{2}}=-\frac{t}{t^{2}-\alpha_{1} \alpha_{2}}<0$ and $\frac{\partial^{2} \pi^{d}}{\partial\left(p_{1}^{d}\right)^{2}} \frac{\partial^{2} \pi^{d}}{\partial\left(p_{2}^{d}\right)^{2}}-$ $\left(\frac{\partial^{2} \pi^{d}}{\partial p_{1}^{d} \partial p_{2}^{d}}\right)^{2}=\frac{\left(2 t-\alpha_{1}-\alpha_{2}\right)\left(2 t+\alpha_{1}+\alpha_{2}\right)}{4\left(t^{2}-\alpha_{1} \alpha_{2}\right)^{2}}>0$.

${ }^{37}$ The second-order is satisfied, $\frac{d^{2} \pi^{d}}{d p_{1}^{c 2}}\left(p_{1}^{c}, 2 \pi^{c}-p_{1}^{c}\right)>0$, meaning that our candidate is, indeed, a minimum. 
Given these prices, the utility of the consumer on side $j \in\{1,2\}$ located at $x=\frac{1}{2}$ that is indifferent between joining platform $A$ or platform $B$ is:

$$
u_{j}^{i}\left(\frac{1}{2}, p_{1}^{c}, p_{2}^{c}, p_{1}^{c}, p_{2}^{c}\right)=\frac{2 k_{j}-2 \pi^{c}(\delta)-t+\alpha_{-j}}{2},
$$

for $i \in\{A, B\}$ and $j \in\{1,2\}$. Under Assumption 2, the utility of the marginal consumer on side 1 is lower than that of the marginal consumer on side 2 . Thus, prices $(23)$ are valid iff:

$$
u_{1}^{i}\left(\frac{1}{2}, p_{1}^{c}, p_{2}^{c}, p_{1}^{c}, p_{2}^{c}\right) \geq 0 \Leftrightarrow \pi^{c}(\delta) \leq \frac{2 k_{1}-t+\alpha_{2}}{2} \equiv \tilde{\pi} .
$$

Combining Lemma 2 with $\pi^{c}(0)=\pi^{N}$ and the continuity of $\pi^{c}(\delta)$, we conclude that, as long as $\tilde{\pi} \in$ $\left(\pi^{N}, \pi^{m}\right), \exists \tilde{\delta} \in(0,1)$ such that $\pi^{c}(\delta) \leq \tilde{\pi}, \forall \delta \leq \tilde{\delta}$. For $\pi^{c}(\delta)>\tilde{\pi}$, the price on side 1 is no longer given by 23. Replacing $p_{1}^{m}=\frac{2 k_{1}-t+\alpha_{1}}{2}$ in 22 , we obtain: $p_{2}^{c}(\delta)=2 \pi^{c}(\delta)-p_{1}^{m}=\frac{4 \pi^{c}(\delta)-2 k_{1}+t-\alpha_{1}}{2}$. For values of $\pi^{c}(\delta)$ above a given threshold, the indifferent consumer on side 2 would get negative utility. Thus, to ensure full coverage of side 2 , the maximum price that platforms can charge on this side is $p_{2}^{m}=\frac{2 k_{2}-t+\alpha_{2}}{2}$. Thus, the maximum profit with full coverage of both market sides is:

$$
\pi^{m}=\frac{2\left(k_{1}+k_{2}\right)-\left(2 t-\alpha_{1}-\alpha_{2}\right)}{4} .
$$

Combining Assumptions 1 and 4 , we obtain $k_{1}+k_{2} \geq \frac{3}{2}\left(2 t-\alpha_{1}-\alpha_{2}\right)$, which implies that $\left(\pi^{N}, \pi^{m}\right] \neq \emptyset$.

\section{Proof of Proposition 2,}

In this proof we assume, w.l.o.g., that the deviating platform is platform $A$.

1. We start by analyzing the case of $\pi^{c}(\delta) \in\left(\pi^{N}, \tilde{\pi}\right)$ with $\tilde{\pi}=\frac{2 k_{1}-t+\alpha_{2}}{2}$.

Replacing $(6)$ in $(20)$, we obtain the prices charged by the deviating platform:

$$
p_{j}^{d}(\delta)=\frac{2 \pi^{c}(\delta)+2 t-\alpha_{1}-\alpha_{2}}{2\left(2 t-\alpha_{1}-\alpha_{2}\right)}\left(t-\alpha_{-j}\right) .
$$

Let us check whether, for these prices, the deviating platform monopolizes any side of the market. Replacing $p_{j}^{i}=p_{j}^{d}(\delta)$ and $p_{j}^{-i}=p_{j}^{c}(\delta), j \in\{1,2\}$, in the demand functions 2 , we obtain:

$$
n_{j}^{d}(\delta)=\frac{2 \pi^{c}(\delta)+2 t-\alpha_{1}-\alpha_{2}}{4\left(2 t-\alpha_{1}-\alpha_{2}\right)}, \quad j \in\{1,2\} .
$$

Notice that despite the deviating platform charging different prices on the two market sides, it gets the same market share on both. Thus, the deviating platform does not monopolize any side of the market iff:

$$
n_{j}^{d}(\delta)<1 \Leftrightarrow \pi^{c}(\delta)<\frac{3}{2}\left(2 t-\alpha_{1}-\alpha_{2}\right) \equiv \hat{\pi} .
$$


As $k_{1} \geq \bar{k}_{1}$ (Assumption 5), we have $\hat{\pi} \leq \tilde{\pi}$. Thus, for $\pi^{c}(\delta) \in\left(\pi^{N}, \tilde{\pi}\right)$, the deviating platform may or may not monopolize both sides of the market.

1.1. If $\pi^{c}(\delta)<\hat{\pi}$, the deviating platform does not monopolize any side of the market. Replacing (6) in (21), we obtain the deviation profit:

$$
\pi^{d}(\delta)=\frac{\left[2 \pi^{c}(\delta)+2 t-\alpha_{1}-\alpha_{2}\right]^{2}}{8\left(2 t-\alpha_{1}-\alpha_{2}\right)} .
$$

Replacing the expressions for profits in the ICC (4), and after simple algebraic manipulation, we obtain that the collusive profit $\pi^{c}$ is sustainable iff:

$$
\frac{2 \pi^{c}-2 t+\alpha_{1}+\alpha_{2}}{8\left(2 t-\alpha_{1}-\alpha_{2}\right)}\left\{(3 \delta+1)\left(2 t-\alpha_{1}-\alpha_{2}\right)-2(1-\delta) \pi^{c}\right\} \geq 0
$$

For collusion to be profitable, we must have $\pi^{c} \geq \pi^{N}$. Thus: $2 \pi^{c}-2 t+\alpha_{1}+\alpha_{2} \geq 0$, and the ICC is satisfied iff:

$$
\pi^{c} \leq \frac{1+3 \delta}{2(1-\delta)}\left(2 t-\alpha_{1}-\alpha_{2}\right)
$$

Recall that this analysis is only valid for $\pi^{c}(\delta)<\hat{\pi}$ and:

$$
\frac{1+3 \delta}{2(1-\delta)}\left(2 t-\alpha_{1}-\alpha_{2}\right)<\hat{\pi} \Leftrightarrow \delta<\frac{1}{3}
$$

Thus, for $\delta \in\left(0, \frac{1}{3}\right)$, the highest sustainable collusive profit is:

$$
\pi^{c}(\delta)=\frac{1+3 \delta}{2(1-\delta)}\left(2 t-\alpha_{1}-\alpha_{2}\right)
$$

1.2. If $\hat{\pi} \leq \pi^{c}(\delta) \leq \tilde{\pi}$, the deviating platform monopolizes both sides of the market. In this case, the deviating platform charges the highest prices that guarantee that the furthest consumer on each market side does not prefer to join the rival platform. Let $p_{j}^{d}$ denote the deviating price on side $j \in\{1,2\}$. The utility of the consumer on side $j$ located at $x=1$ that joins platform $A$ is:

$$
u_{j}^{A d}(1)=k_{j}+\alpha_{j}-t-p_{j}^{d}
$$

If, instead, this consumer joined platform B (charging the collusive prices), her utility would be:

$$
u_{j}^{B c}(1)=k_{j}-p_{j}^{c}
$$

Thus, the deviating platform $A$ monopolizes both sides of the market iff:

$$
u_{j}^{A d}(1) \geq u_{j}^{B c}(1) \Leftrightarrow p_{j}^{d} \leq p_{j}^{c}-t+\alpha_{j}
$$

As the deviating profit, $\pi^{d}\left(p_{1}, p_{2}\right)=p_{1}+p_{2}$, is strictly increasing in $p_{1}$ and $p_{2}$, the platform will charge 
the highest possible prices $p_{j}^{d}(\delta)=p_{j}^{c}(\delta)-t+\alpha_{j}$, and the deviation profit is ${ }^{38}$

$$
\pi^{d}(\delta)=2 \pi^{c}(\delta)-2 t+\alpha_{1}+\alpha_{2}
$$

In this case, the ICC for collusion sustainability is satisfied iff:

$$
2(2 \delta-1) \pi^{c}+(2-3 \delta)\left(2 t-\alpha_{1}-\alpha_{2}\right) \geq 0
$$

1.2.1. If $\delta<\frac{1}{2}$, the above ICC can be written as:

$$
\pi^{c} \leq \frac{2-3 \delta}{2(1-2 \delta)}\left(2 t-\alpha_{1}-\alpha_{2}\right)
$$

Recall that this analysis is only valid if $\pi^{c} \in(\hat{\pi}, \tilde{\pi})$ and:

$$
\frac{2-3 \delta}{2(1-2 \delta)}\left(2 t-\alpha_{1}-\alpha_{2}\right)<\tilde{\pi} \Leftrightarrow \delta<\frac{2 k_{1}-5 t+2 \alpha_{1}+3 \alpha_{2}}{4 k_{1}-8 t+3 \alpha_{1}+5 \alpha_{2}} \equiv \tilde{\delta}
$$

with $\tilde{\delta}<\frac{1}{2}$ (under Assumption 22. Thus, for $\delta \in\left(\frac{1}{3}, \tilde{\delta}\right)$, the highest sustainable collusive profit is:

$$
\pi^{c}(\delta)=\frac{2-3 \delta}{2(1-2 \delta)}\left(2 t-\alpha_{1}-\alpha_{2}\right)
$$

1.2.2. If $\frac{1}{2} \leq \delta<\frac{2}{3}$, ICC 28$]$ is trivially satisfied $\forall \pi^{c}>0$. As this analysis is only valid for $\pi^{c} \in(\hat{\pi}, \tilde{\pi})$, we conclude that, $\forall \delta \in\left(\frac{1}{2}, \frac{2}{3}\right)$, the highest sustainable collusive profit is $\pi^{c}(\delta)=\tilde{\pi}$.

1.2.3. If $\delta \geq \frac{2}{3}$, the ICC 281 can be written as: $\pi^{c} \geq \frac{3 \delta-2}{2(2 \delta-1)}\left(2 t-\alpha_{1}-\alpha_{2}\right)$. Notice that, for $\delta \in\left(\frac{2}{3}, 1\right)$, we have $\frac{3 \delta-2}{2(2 \delta-1)}<\frac{1}{2}$. As a result, given any $\delta \in\left(\frac{2}{3}, 1\right)$, a collusive profit $\pi^{c}>\frac{1}{2}\left(2 t-\alpha_{1}-\alpha_{2}\right)=\pi^{N}$ is sustainable. Again, as this analysis is only valid for $\pi^{c} \in(\hat{\pi}, \tilde{\pi})$, we conclude that $\pi^{c}(\delta)=\tilde{\pi}$ is the highest sustainable collusive profit $\forall \delta \in\left(\frac{2}{3}, 1\right)$.

2. Consider now that $\pi^{c}(\delta) \in\left(\tilde{\pi}, \pi^{m}\right)$.

Replacing $p_{1}^{c}=p_{1}^{m}$ and $p_{2}^{c}=\frac{4 \pi^{c}-2 k_{1}+t-\alpha_{1}}{2}$ in 20 , we obtain the expressions for the deviating prices:

$$
\begin{aligned}
& p_{1}^{d}=\frac{\left(2 t-\alpha_{1}-\alpha_{2}\right)\left[\left(t+\alpha_{1}\right)\left(t-\alpha_{2}\right)+2 k_{1}\left(t+\alpha_{2}\right)\right]+4 t\left(\alpha_{1}-\alpha_{2}\right) \pi^{c}}{2\left(2 t-\alpha_{1}-\alpha_{2}\right)\left(2 t+\alpha_{1}+\alpha_{2}\right)} \\
& p_{2}^{d}=\frac{\left(2 t-\alpha_{1}-\alpha_{2}\right)\left[3 t^{2}-2 k_{1}\left(t+\alpha_{1}\right)-\alpha_{1}\left(\alpha_{1}+2 \alpha_{2}\right)\right]+4\left[2 t^{2}-\alpha_{1}\left(\alpha_{1}+\alpha_{2}\right)\right] \pi^{c}}{2\left(2 t-\alpha_{1}-\alpha_{2}\right)\left(2 t+\alpha_{1}+\alpha_{2}\right)} .
\end{aligned}
$$

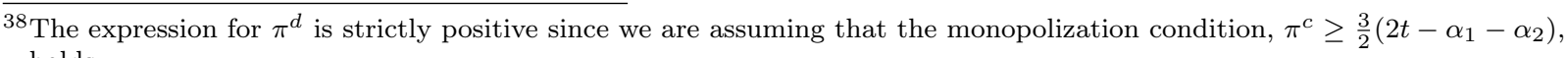
holds. 
Given these prices, the demand of the deviating platform is:

$$
\begin{aligned}
& n_{1}^{d}=\frac{4\left(\alpha_{1}+\alpha_{2}\right) \pi^{c}+\left(2 t-\alpha_{1}-\alpha_{2}\right)\left(2 k_{1}+t+\alpha_{1}+2 \alpha_{2}\right)}{4\left(2 t-\alpha_{1}-\alpha_{2}\right)\left(2 t+\alpha_{1}+\alpha_{2}\right)} \\
& n_{2}^{d}=\frac{8 t \pi^{c}-\left(2 k_{1}-3 t-\alpha_{1}\right)\left(2 t-\alpha_{1}-\alpha_{2}\right)}{4\left(2 t-\alpha_{1}-\alpha_{2}\right)\left(2 t+\alpha_{1}+\alpha_{2}\right)} .
\end{aligned}
$$

The deviating platform monopolizes side 2 iff:

$$
n_{2}^{d} \geq 1 \Leftrightarrow \pi^{c} \geq \frac{\left(2 t-\alpha_{1}-\alpha_{2}\right)\left(2 k_{1}+5 t+3 \alpha_{1}+4 \alpha_{2}\right)}{8 t} \equiv \tilde{\pi}^{n} .
$$

Under Assumption 5

$$
\tilde{\pi}^{n}<\tilde{\pi} \Leftrightarrow-\frac{\left(2 k_{1}-7 t+3 \alpha_{1}+4 \alpha_{2}\right)\left(2 t+\alpha_{1}+\alpha_{2}\right)}{8 t}<0
$$

which implies that the deviating platform always monopolizes side 2 . As we are assuming $\tilde{\pi} \leq \pi^{c}$, we conclude that $n_{1}^{d}-n_{2}^{d}=\frac{\tilde{\pi}-\pi^{c}}{2 t+\alpha_{1}+\alpha_{2}} \leq 0$. As a result, the deviating platform will choose prices that solve:

$$
\begin{gathered}
\left\{\begin{array}{l}
\frac{\partial \pi^{d}\left(p_{1}^{d}, p_{2}^{d}, p_{1}^{m}, \frac{4 \pi^{c}-2 k_{1}+t-\alpha_{1}}{2}\right)}{\partial p_{1}^{d}}=0 \\
n_{2}^{A}\left(p_{1}^{d}, p_{2}^{d}, p_{1}^{m}, \frac{4 \pi^{c}-2 k_{1}+t-\alpha_{1}}{2}\right)=1
\end{array} \Leftrightarrow\right. \\
\Leftrightarrow\left\{\begin{array}{l}
p_{1}^{d}\left(\pi^{c}\right)=\frac{t^{3}+t^{2}\left(2 k_{1}+3 \alpha_{1}+\alpha_{2}\right)+t \alpha_{2}\left(2 k_{1}+\alpha_{2}\right)-\left(2 k_{1}+3 \alpha_{1}\right) \alpha_{2}\left(\alpha_{1}+\alpha_{2}\right)-4 t \alpha_{2} \pi^{c}}{2\left(2 t^{2}-\alpha_{1} \alpha_{2}-\alpha_{2}^{2}\right)} \\
p_{2}^{d}\left(\pi^{c}\right)=\frac{4\left(2 t^{2}-\alpha_{1} \alpha_{2}\right) \pi^{c}-2 t^{3}-t^{2}\left(4 k_{1}+2 \alpha_{1}+3 \alpha_{2}\right)+2 \alpha_{2} t\left(k_{1}+2 \alpha_{1}\right)+\alpha_{1} \alpha_{2}\left(2 k_{1}+\alpha_{1}+2 \alpha_{2}\right)}{2\left(2 t^{2}-\alpha_{1} \alpha_{2}-\alpha_{2}^{2}\right)} .
\end{array}\right.
\end{gathered}
$$

Given these prices, the deviating platform also monopolizes side 1 iff:

$$
n_{1}^{d}\left(p_{1}^{d}, p_{2}^{d}, p_{1}^{m}, \frac{4 \pi^{c}-2 k_{1}+t-\alpha_{1}}{2}\right) \geq 1 \Leftrightarrow \pi^{c} \geq \frac{7 t^{2}-2 k_{1}\left(t-\alpha_{2}\right)-t\left(3 \alpha_{1}-\alpha_{2}\right)-3 \alpha_{1} \alpha_{2}-2 \alpha_{2}^{2}}{4 \alpha_{2}} \equiv \tilde{\pi}^{t} .
$$

Under Assumption 5

$$
\tilde{\pi}^{t}-\tilde{\pi}^{n}=-\frac{\left(2 t^{2}-\alpha_{1} \alpha_{2}-\alpha_{2}^{2}\right)\left(2 k_{1}-7 t+3 \alpha_{1}+4 \alpha_{2}\right)}{8 t \alpha_{2}}<0
$$

From (30), we have $\tilde{\pi}^{n}<\tilde{\pi}$ and, therefore: $\tilde{\pi}^{t}<\tilde{\pi}$. As a result, $\forall \pi^{c} \in\left(\tilde{\pi}, \pi^{m}\right)$, the deviating platform monopolizes both sides of the market. Consequently, the deviating platform prefers to choose prices $\left(p_{1}^{d}, p_{2}^{d}\right)$ such that:

$$
\left\{\begin{array} { l } 
{ n _ { 1 } ^ { d } ( p _ { 1 } ^ { d } , p _ { 2 } ^ { d } , p _ { 1 } ^ { m } , \frac { 4 \pi ^ { c } - 2 k _ { 1 } + t - \alpha _ { 1 } } { 2 } ) = 1 } \\
{ n _ { 2 } ^ { d } ( p _ { 1 } ^ { d } , p _ { 2 } ^ { d } , p _ { 1 } ^ { m } , \frac { 4 \pi ^ { c } - 2 k _ { 1 } + t - \alpha _ { 1 } } { 2 } ) = 1 }
\end{array} \Leftrightarrow \left\{\begin{array}{l}
p_{1}^{d}=\frac{2 k_{1}-3 t+3 \alpha_{1}}{2} \\
p_{2}^{d}=\frac{4 \pi^{c}-2 k_{1}-t-\alpha_{1}+2 \alpha_{2}}{2}
\end{array}\right.\right.
$$

and the deviating platform is:

$$
\pi^{d}(\delta)=2 \pi^{c}(\delta)-2 t+\alpha_{1}+\alpha_{2}
$$


Replacing the expressions for profits in the ICC (4), we conclude that, given $\delta \in\left(\tilde{\delta}, \delta^{m}\right)$, the collusive profit $\pi^{c} \in\left(\tilde{\pi}, \pi^{m}\right)$ is sustainable iff:

$$
2(2 \delta-1) \pi^{c} \geq(3 \delta-2)\left(2 t-\alpha_{1}-\alpha_{2}\right)
$$

2.1. For $\delta<\frac{1}{2}$, the ICC can be rewritten as follows:

$$
\pi^{c} \leq \frac{2-3 \delta}{2(1-2 \delta)}\left(2 t-\alpha_{1}-\alpha_{2}\right)
$$

From Lemma 4 platforms fully cover both sides of the market under collusion. As the maximum (collusive) profit that ensures full market coverage is $\pi^{m}$, it is the upper bound for $\pi^{c}$. Notice further that 39

$$
\frac{2-3 \delta}{2(1-2 \delta)}\left(2 t-\alpha_{1}-\alpha_{2}\right) \leq \pi^{m} \Leftrightarrow \delta \leq \frac{2\left(k_{1}+k_{2}\right)-5\left(2 t-\alpha_{1}-\alpha_{2}\right)}{4\left[k_{1}+k_{2}-2\left(2 t-\alpha_{1}-\alpha_{2}\right)\right]} \equiv \delta^{m} .
$$

It is easy to check that, under Assumption 2, we have $\delta^{m}<\frac{1}{2}$. Thus: if $\delta \in\left(\tilde{\delta}, \delta^{m}\right)$, the highest sustainable collusive profit is given by:

$$
\pi^{c}(\delta)=\frac{2-3 \delta}{1-2 \delta}\left(2 t-\alpha_{1}-\alpha_{2}\right)
$$

while, for $\delta \in\left(\delta^{m}, \frac{1}{2}\right)$, it is $\pi^{c}(\delta)=\pi^{m}$.

2.2. Consider now $\delta \geq \frac{1}{2}$. If $\delta \leq \frac{2}{3}$, the ICC (31) is trivially satisfied $\forall \pi^{c} \geq 0$. As a result, the highest sustainable collusive profit (that ensures full market coverage) is $\pi^{c}(\delta)=\pi^{m}$. Finally, if $\delta>\frac{2}{3}$, the ICC 31 can be rewritten as: $\pi^{c} \geq \frac{3 \delta-2}{2(2 \delta-1)}\left(2 t-\alpha_{1}-\alpha_{2}\right)$. Notice, however, that:

$$
\frac{3 \delta-2}{2(2 \delta-1)}\left(2 t-\alpha_{1}-\alpha_{2}\right) \leq \frac{2 t-\alpha_{1}-\alpha_{2}}{2}=\pi^{N} \leq \pi^{m}
$$

which implies that $\pi^{c}(\delta)=\pi^{m}$ is sustainable $\forall \delta \geq \frac{2}{3}$.

Summing up:

$$
\pi^{c}(\delta)=\left\{\begin{array}{lll}
\frac{1+3 \delta}{2(1-\delta)}\left(2 t-\alpha_{1}-\alpha_{2}\right) & \text { if } \quad 0<\delta<\frac{1}{3} \\
\frac{2-3 \delta}{2(1-2 \delta)}\left(2 t-\alpha_{1}-\alpha_{2}\right) & \text { if } \quad \frac{1}{3} \leq \delta<\delta^{m} \\
\pi^{m} & \text { if } \quad \delta^{m} \leq \delta<1 .
\end{array}\right.
$$

To obtain the expressions for prices, simply replace these expressions in (6).

\footnotetext{
$\left.\overline{{ }^{39} \text { Assumption } 5 \text { implies that } k_{1}+k_{2}>\frac{7}{2}\left(2 t-\alpha_{1}\right.}-\alpha_{2}\right)$.
} 
Proof of Corollary 2,

Using $(9)$, we obtain:

$$
\left(\Delta p_{1}(\delta), \Delta p_{2}(\delta)\right)=\left\{\begin{array}{lll}
\left(\frac{2 \delta}{1-\delta}\left(2 t-\alpha_{1}-\alpha_{2}\right), \frac{2 \delta}{1-\delta}\left(2 t-\alpha_{1}-\alpha_{2}\right)\right) & \text { if } \quad 0<\delta<\frac{1}{3} \\
\left(\frac{1-\delta}{2(1-2 \delta)}\left(2 t-\alpha_{1}-\alpha_{2}\right), \frac{1-\delta}{2(1-2 \delta)}\left(2 t-\alpha_{1}-\alpha_{2}\right)\right) & \text { if } \quad \frac{1}{3}<\delta<\tilde{\delta} \\
\left(\frac{2 k_{1}-3 t+\alpha_{1}+2 \alpha_{2}}{2}, \frac{2\left(2 k_{1}-5 t+2 \alpha_{1}+3 \alpha_{2}\right) \delta-2 k_{1}+7 t-3 \alpha_{1}-4 \alpha_{2}}{2(1-2 \delta)}\right) & \text { if } & \tilde{\delta}<\delta<\delta^{m} \\
\left(\frac{2 k_{1}-3 t+\alpha_{1}+2 \alpha_{2}}{2}, \frac{2 k_{2}-3 t+2 \alpha_{1}+\alpha_{2}}{2}\right) & \text { if } \quad \delta^{m} \leq \delta<1 .
\end{array}\right.
$$

The sign of $\frac{\partial \Delta p_{j}}{\partial \alpha_{k}}$ follows straightforwardly when $0<\delta<\tilde{\delta}$ and when $\delta \geq \delta^{m}$. When $\tilde{\delta}<\delta<\delta^{m}$, the sign of $\frac{\partial\left(\Delta p_{1}\right)}{\partial \alpha_{k}}$ is also straightforward and:

$$
\frac{\partial \Delta p_{2}}{\partial \alpha_{1}}=-\frac{3-4 \delta}{2(1-2 \delta)}<0 \quad \text { and } \quad \frac{\partial \Delta p_{2}}{\partial \alpha_{2}}=-\frac{2-3 \delta}{1-2 \delta}<0
$$

\section{Proof of Lemma 7.}

Let us analyze under which conditions platforms prefer to fully cover the market when they collude only on side 1 . We focus on symmetric collusive agreements such that platforms set the same price on the collusive side, i.e., $p_{1}^{A}=p_{1}^{B}=p_{1}, j \in\{1,2\}$. Let $\tilde{x}_{j}$ denote the consumer on side $j$ that is indifferent between joining platform $A$ and not joining any platform.

1. If $t \geq \alpha_{1}, \pi^{o c}$ is increasing in $p_{1}$. If $n_{2}^{i}=\frac{1}{2}$, the maximum price that platforms can set on side 1 for this side be fully covered is $p_{1}^{m}$, given in (5). As $p_{1}^{o c}>p_{1}^{N}$, it follows that $p_{2}^{o c}<p_{2}^{N}$ (Lemma 6). Thus, if $p_{1}^{o c} \leq p_{1}^{m}$, there will be full coverage of both market sides (under the condition for full coverage under Nash competition).

Let us analyze the incentives for platforms to set $p_{1}^{o c}>p_{1}^{m}$ and not fully cover side 1 . We start by studying the incentives for small deviations, i.e., to set $p_{1}^{o c}=p_{1}^{m}+\epsilon$, for sufficiently small $\epsilon>0$. If platforms set $p_{1}^{o c}=p_{1}^{m}$, the price on side 2 is such that $p_{2}\left(p_{1}^{m}\right)<p_{2}^{N}$, and the utility of side-2 agents is higher than their utility when platforms engage in Nash competition. Therefore, the utility of side-2 agents under collusion is strictly positive. Thus, a slightly increase in $p_{1}^{o c}$ will decrease the network size on side 1 , but not up to a point that side- 2 agents get negative utility if joining a platform (notice further that $p_{2}^{o c}\left(p_{1}\right)<p_{2}^{o c}\left(p_{1}^{m}\right)$ if $\left.p_{1}>p_{1}^{m}\right)$. As a result, when platforms slightly increase $p_{1}$ above $p_{1}^{m}$, side 2 remains fully covered, i.e., $n_{2}^{i}=\frac{1}{2}$. Thus, the demand of platform $A$ on side 1 is equal to $\tilde{x}_{1}$ that solves:

$$
u_{1}^{A}\left(\tilde{x}_{1}, p_{1}^{o c}, p_{2}^{o c}, p_{1}^{o c}, p_{2}^{o c}\right)=0 \Leftrightarrow k_{1}+\frac{\alpha_{1}}{2}-t \tilde{x}_{1}-p_{1}^{o c}=0 \Leftrightarrow \tilde{x}_{1}=\frac{2 k_{1}+\alpha_{1}-2 p_{1}^{o c}}{2 t} .
$$

Combining the first-order conditions corresponding to the maximization problems in the constraints of the maximization program (10), we obtain that, for a given $p_{1}$, platforms charge the same price on side 2 , 
given by 40

$$
p_{2}\left(p_{1}, \alpha_{1}, \alpha_{2}\right)=\frac{t^{2}-\alpha_{1} \alpha_{2}}{t}-\frac{\alpha_{1}}{t} p_{1} .
$$

Using (34), the profit of platform $A$ can be written as follows:

$$
\pi^{A}\left(p_{1}^{o c}\right)=p_{1}^{o c} \tilde{x}_{1}+\frac{p_{2}^{o c}\left(p_{1}^{o c}\right)}{2}=\left(\frac{2 k_{1}+\alpha_{1}-2 p_{1}^{o c}}{2 t}\right) p_{1}^{o c}+\frac{t^{2}-\alpha_{1} \alpha_{2}-\alpha_{1} p_{1}^{o c}}{2 t} .
$$

Using (5):

$$
\left.\frac{\partial \pi^{A}}{\partial p_{1}^{o c}}\right|_{p_{1}^{o c}=p_{1}^{m}} \leq 0 \Leftrightarrow \frac{k_{1}-2 p_{1}^{m}}{t} \leq 0 \Leftrightarrow k_{1} \geq t-\alpha_{1}
$$

As $\pi^{A}$ is concave, if $k_{1} \geq t-\alpha_{1}$, we have $\pi^{A}\left(p_{1}^{o c}\right)<\pi^{A}\left(p_{1}^{m}\right)$ for any price $p_{1}^{o c}>p_{1}^{m}$ (that ensures full coverage of side 2). As a result, a greater increase in $p_{1}$ that compromises full coverage of side 2 is even less profitable, since demand on side 2 decreases, and, consequently, revenues on this side also decreases ${ }^{41}$

2. If $t \leq \alpha_{1}, \pi^{o c}$ is decreasing in $p_{1}$ and, therefore, platforms want to set the lowest possible price on side 1. In particular, platforms will set $p_{1}^{o c}<p_{1}^{N}$. Thus, if side 2 is fully covered, full coverage of side 1 is implied by the condition for full market coverage under Nash competition $(3)$. However, as $p_{2}\left(p_{1}^{o c}\right)>p_{2}^{N}$ (Lemma 6), the condition for full coverage with Nash competition is not sufficient to ensure full coverage of side 2 under one-sided collusion.

Following the same steps as above, we have that, if $p_{2}^{o c}>p_{2}^{m}$, the demand of each platform on side 2 is:

$$
\tilde{x}_{2}=\frac{2 k_{2}+\alpha_{1}-2 p_{2}^{o c}}{2 t} \text {. }
$$

Replacing $\Delta p_{j}=p_{j}^{o c}-\left(t-\alpha_{-j}\right)$ in 13 and solving the equation with respect to $p_{1}^{o c}$, we obtain: $p_{1}^{o c}\left(p_{2}^{o c}\right)=$ $\frac{t^{2}-\alpha_{1} \alpha_{2}}{\alpha_{1}}-\frac{t}{\alpha_{1}} p_{2}^{o c}$. Thus, the profit of platform $A$ can be written:

$$
\pi^{A}\left(p_{2}^{o c}\right)=\frac{p_{1}^{o c}\left(p_{2}^{o c}\right)}{2}+p_{2}^{o c} \tilde{x}_{2}=\frac{t^{2}-\alpha_{1} \alpha_{2}-t p_{2}^{o c}}{2 \alpha_{1}}+p_{2}^{o c}\left(\frac{2 k_{2}+\alpha_{1}-2 p_{2}^{o c}}{2 t}\right)
$$

As we are assuming $t \leq \alpha_{1}$, we necessarily have $\alpha_{1}>0$ and, therefore, using (5):

$$
\left.\frac{\partial \pi^{A}}{\partial p_{2}^{o c}}\right|_{p_{2}^{o c}=p_{2}^{m}}<0 \Leftrightarrow \frac{\alpha_{1}\left(2 k_{2}-4 p_{2}^{m}+\alpha_{2}\right)-t^{2}}{2 t \alpha_{1}}<0 \Leftrightarrow k_{2}>\frac{2 \alpha_{1} t-\alpha_{1} \alpha_{2}-t^{2}}{2 \alpha_{1}} .
$$

Again, as $\pi^{A}$ is concave, if $k_{2}>\frac{2 \alpha_{1} t-\alpha_{1} \alpha_{2}-t^{2}}{2 \alpha_{1}}$, we have $\pi^{A}\left(p_{2}^{o c}\right)<\pi^{A}\left(p_{2}^{m}\right)$ for any $p_{2}^{o c}>p_{2}^{m}$ (that ensures full coverage of side 1). Additionally, any greater increase in $p_{2}$ that compromises full coverage of side 1 is even less profitable.

${ }^{40}$ The second-order condition is satisfied since: $\frac{\partial^{2} \pi^{i}}{\partial\left(p_{2}^{i}\right)^{2}}=-\frac{t}{t^{2}-\alpha_{1} \alpha_{2}}<0$.
${ }^{41}$ From Lemma 5: $p_{2}\left(p_{1}^{o c}\right)<p_{2}\left(p_{1}^{m}\right)$, for $p_{1}^{o c}>p_{1}^{m}$. 


\section{Proof of Lemma 8 .}

Let $\left(p_{1}^{o c}, p_{2}^{o c}\right)$ denote the (unique) solution of the maximization program 10 .

1. If $t>\alpha_{1} \geq 0$, platforms are willing to collude iff $p_{1}^{o c} \geq p_{1}^{N}$. As $\alpha_{1}>0$, we conclude that $p_{2}^{o c}<p_{2}^{N}$. As platforms charge equal prices on each side of the market, they equally share both sides of the market. Thus, both sides of the market are fully covered iff the (indifferent) consumers located at $x=\frac{1}{2}$ have non-negative utilities:

$$
\begin{aligned}
& u_{1}^{i}\left(\frac{1}{2}, p_{1}^{o c}, t-\frac{\alpha_{1}\left(p_{1}^{o c}+\alpha_{2}\right)}{t}, p_{1}^{o c}, t-\frac{\alpha_{1}\left(p_{1}^{o c}+\alpha_{2}\right)}{t}\right) \geq 0 \Leftrightarrow k_{1} \geq p_{1}^{o c}+\frac{t-\alpha_{1}}{2}, \\
& u_{2}^{i}\left(\frac{1}{2}, p_{1}^{o c}, t-\frac{\alpha_{1}\left(p_{1}^{o c}+\alpha_{2}\right)}{t}, p_{1}^{o c}, t-\frac{\alpha_{1}\left(p_{1}^{o c}+\alpha_{2}\right)}{t}\right) \geq 0 \Leftrightarrow k_{2} \geq \frac{3 t-\alpha_{2}}{2}-\frac{\alpha_{1}\left(p_{1}^{o c}+\alpha_{2}\right)}{t} .
\end{aligned}
$$

Recall that the condition for the market side 2 to be fully covered when platforms charge the Nash price on each side is $k_{2}-\frac{\alpha_{2}}{2}>\frac{3 t-2 \alpha_{1}-2 \alpha_{2}}{2}$. Thus, if $\alpha_{1}>0$, the condition for full coverage of side 2 is implied by the condition for full coverage of side 2 when platforms set the Nash prices on both sides of the market iff $p_{1}^{o c}>t-\alpha_{2}=p_{1}^{N}$.

Using (35), we conclude that there is full coverage of the (two sides of the) market iff $p_{1}^{o c} \leq p_{1}^{m}$ with $p_{1}^{m}=\frac{2 k_{1}-t+\alpha_{1}}{2}$. If platforms set price $p_{1}^{o c}$ on side 1 and price $p_{2}^{o c}$ given in 34 , their individual profit is:

$$
\pi^{o c}\left(p_{1}^{o c}\right)=\frac{t^{2}-\alpha_{1} \alpha_{2}}{2 t}+\frac{t-\alpha_{1}}{2 t} p_{1}^{o c} .
$$

Equivalently:

$$
p_{1}^{o c}\left(\pi^{o c}\right)=\frac{2 t \pi^{o c}-t^{2}+\alpha_{1} \alpha_{2}}{t-\alpha_{1}} .
$$

Replacing this expression in (34), we conclude that, for a given $\delta$, the price on side 2 is:

$$
p_{2}^{o c}(\delta)=\frac{t^{2}-\alpha_{1} \alpha_{2}-2 \alpha_{1} \pi^{o c}(\delta)}{t-\alpha_{1}}
$$

However, for side 1 to be fully covered, the condition $p_{1}^{o c}\left(\pi^{o c}\right) \leq p_{1}^{m}$ must be satisfied:

$$
p_{1}^{o c}\left(\pi^{o c}\right) \leq p_{1}^{m} \Leftrightarrow \frac{-2 k_{1}\left(t-\alpha_{1}\right)-t^{2}-2 t \alpha_{1}+\alpha_{1}^{2}+2 \alpha_{1} \alpha_{2}+4 t \pi^{o c}}{2\left(t-\alpha_{1}\right)} \leq 0 .
$$

Thus, for $t>\alpha_{1}$, the highest collusive profit with full market coverage is:

$$
\pi^{o m}=\frac{2 k_{1}\left(t-\alpha_{1}\right)+t\left(t+2 \alpha_{1}\right)-\alpha_{1}\left(\alpha_{1}+2 \alpha_{2}\right)}{4 t} .
$$

To obtain the expressions for $p_{2}^{o c}$, simply replace $p_{1}^{o c}=p_{1}^{m}$ in 34 .

2. Consider now $0<t<\alpha_{1}$. As in the previous case, both market sides are fully covered iff conditions (35) and (36) are satisfied. Recall that side 1 is fully covered when platforms charge Nash prices iff $k_{1}>p_{1}^{N}+\frac{t-\alpha_{1}}{2}$. As $t<\alpha_{1}$, collusion on side 1 is profitable iff $p_{1}^{o c}<p_{1}^{N}$. As a result: $k_{1}>p_{1}^{N}+\frac{t-\alpha_{1}}{2}>$ 
$p_{1}^{o c}+\frac{t-\alpha_{1}}{2}$, which implies that the condition for full coverage of side 1 under Nash competition is sufficient for full coverage with collusion on side 1 . Thus, there is full coverage of both market sides iff:

$$
u_{2}^{i}\left(\frac{1}{2}, p_{1}^{o c}, t-\frac{\alpha_{1}\left(p_{1}^{o c}+\alpha_{2}\right)}{t}, p_{1}^{o c}, t-\frac{\alpha_{1}\left(p_{1}^{o c}+\alpha_{2}\right)}{t}\right) \geq 0 \Leftrightarrow p_{1}^{o c} \geq \frac{3 t^{2}-t \alpha_{2}-2 \alpha_{1} \alpha_{2}-2 t k_{2}}{2 \alpha_{1}} .
$$

For any $\delta<\delta^{o m}$, the collusive prices on side 1 and 2 are given by (37) and (38), respectively. For $\delta \geq \delta^{o m}$, platforms set the highest price on side 2 that allows full coverage of this side, i.e., $p_{2}^{o c}=p_{2}^{m}$. The price on side 1 is obtained by replacing $p_{2}^{o c}=p_{2}^{m}$ in (34).

3. Finally, consider the case of $\alpha_{1}<0<t$. Expressions 37 and 38 for prices are valid as long as consumers located at $x=\frac{1}{2}$ on each market side get positive utility. If $t>\alpha_{1}$, the collusive profit is strictly increasing in $p_{1}$. As a result, platforms would like to increase $p_{1}^{o c}$ as much as possible. However, for $p_{j}^{o c}>p_{j}^{m}$, with $p_{j}^{m}$ given in $\left[5\right.$, side $j \in\{1,2\}$ would not be fully covered. If $\alpha_{1}<0$, an increase in $p_{1}^{o c}$ is followed by an increase in $p_{2}^{o c}$ (Lemma 6). Thus, using (34), market 2 is not fully covered iff:

$$
p_{2}^{o c}\left(p_{1}^{o c}\right)>p_{2}^{m} \Leftrightarrow p_{1}^{o c}>\frac{t^{2}-\alpha_{1} \alpha_{2}}{\alpha_{1}}-\frac{t}{\alpha_{1}} p_{2}^{m} \equiv \bar{p}_{1}
$$

Using (5), we can write: $\bar{p}_{1}=p_{1}^{N}-\frac{t}{\alpha_{1}} \tilde{u}_{2}^{N}$. In sum, expression $37 p$ for $p_{1}^{o c}$ is valid iff $p_{1}^{o c}<\min \left\{p_{1}^{m}, \bar{p}_{1}\right\}$, with:

$$
p_{1}^{m}<\bar{p}_{1} \Leftrightarrow \alpha_{1}>-\frac{\tilde{u}_{2}^{N}}{\tilde{u}_{1}^{N}} t .
$$

Hence:

- If $\alpha_{1} \geq-\frac{\tilde{u}_{2}^{N}}{\tilde{u}_{1}^{N}} t$, platforms cannot set $p_{1}^{o c}>p_{1}^{m}$ (otherwise, side 1 would not be fully covered). As a result, given $\delta$, the most collusive prices are given by (14).

- If $\alpha_{1}<-\frac{\tilde{u}_{2}^{N}}{\tilde{u}_{1}^{N}} t$, platforms cannot set $p_{1}^{o c}>\bar{p}_{1}$ (otherwise, side 2 would not be fully covered). As a result, given $\delta$, the most collusive prices are given by 15 .

\section{Proof of Proposition 5 .}

Let us assume, without loss of generality, that the deviating platform is platform $A$.

1. Let us first assume that $-\frac{\tilde{u}_{2}^{N}}{\tilde{u}_{1}^{N}} t \leq \alpha_{1}<t$.

If platform $A$ deviated from the collusive agreement, it would set prices that solved $\max _{\left(p_{1}, p_{2}\right)} \pi^{A}\left(p_{1}, p_{2}, p_{1}^{o c}, p_{2}^{o c}\right)$. Replacing (14) in (3):

$$
\begin{aligned}
\pi^{A}\left(p_{1}, p_{2}, p_{1}^{o c}, p_{2}^{o c}\right)= & \frac{1}{2\left(t-\alpha_{1}\right)\left(t^{2}-\alpha_{1} \alpha_{2}\right)}\left\{-p_{1}^{2} t\left(t-\alpha_{1}\right)+p_{1}\left(t-\alpha_{1}\right)\left[2\left(t+\alpha_{1}\right) \pi^{o c}-p_{2}\left(\alpha_{1}+\alpha_{2}\right)\right]-\right. \\
& \left.-p_{2}\left[t\left(t-\alpha_{1}\right) p_{2}+2 t\left[\alpha_{1} \alpha_{2}+\left(\alpha_{1}-\alpha_{2}\right) \pi^{o c}\right]-2 t^{3}+\left(\alpha_{1}+\alpha_{2}\right)\left(t^{2}-\alpha_{1} \alpha_{2}\right)\right]\right\} .
\end{aligned}
$$


Solving the corresponding FOCs, we obtain 42

$$
\begin{aligned}
& p_{1}^{o d}\left(\pi^{o c}\right)=\frac{2 t\left(2 t^{2}-\alpha_{1}^{2}-\alpha_{2}^{2}\right) \pi^{o c}-\left(2 t-\alpha_{1}-\alpha_{2}\right)\left(\alpha_{1}+\alpha_{2}\right)\left(t^{2}-\alpha_{1} \alpha_{2}\right)}{\left(t-\alpha_{1}\right)\left(2 t-\alpha_{1}-\alpha_{2}\right)\left(2 t+\alpha_{1}+\alpha_{2}\right)} \\
& p_{2}^{o d}\left(\pi^{o c}\right)=\frac{2\left[t^{2}\left(\alpha_{2}-3 \alpha_{1}\right)+\alpha_{1}^{2}\left(\alpha_{1}+\alpha_{2}\right)\right] \pi^{o c}+2 t\left(2 t-\alpha_{1}-\alpha_{2}\right)\left(t^{2}-\alpha_{1} \alpha_{2}\right)}{\left(t-\alpha_{1}\right)\left(2 t-\alpha_{1}-\alpha_{2}\right)\left(2 t+\alpha_{1}+\alpha_{2}\right)} .
\end{aligned}
$$

However, these are the actual deviation prices iff $n_{j}^{A}\left(p_{1}^{o d}, p_{2}^{o d}, p_{1}^{o c}, p_{2}^{o c}\right) \leq 1$, for $j \in\{1,2\}$. Notice that ${ }^{43}$

$$
n_{1}^{A}\left(p_{1}^{o d}, p_{2}^{o d}, p_{1}^{o c}, p_{2}^{o c}\right)-n_{2}^{A}\left(p_{1}^{o d}, p_{2}^{o d}, p_{1}^{o c}, p_{2}^{o c}\right)=\frac{\left(t+\alpha_{1}\right)\left(2 \pi^{o c}-2 t+\alpha_{1}+\alpha_{2}\right)}{2\left(t-\alpha_{1}\right)\left(2 t+\alpha_{1}+\alpha_{2}\right)}>0
$$

Thus: if $t>\alpha_{1}$ and the deviating platform does not monopolize side 1, it also does not monopolize side 2 . Replacing expressions 40 in (2), we obtain:

$$
n_{1}^{A}\left(p_{1}^{o d}, p_{2}^{o d}, p_{1}^{o c}, p_{2}^{o c}\right) \leq 1 \Leftrightarrow \pi^{o c} \leq \frac{\left(2 t-\alpha_{1}-\alpha_{2}\right)\left[4 t^{2}-t\left(\alpha_{1}-\alpha_{2}\right)-2 \alpha_{1}\left(\alpha_{1}+\alpha_{2}\right)\right]}{2\left(2 t^{2}-\alpha_{1}^{2}-\alpha_{1} \alpha_{2}\right)} \equiv \bar{\pi}^{o c} .
$$

Under Assumption 1 we have $2 t^{2}-\alpha_{1}^{2}-\alpha_{1} \alpha_{2}=\left(t-\alpha_{1}\right)\left(t+\alpha_{1}\right)+t^{2}-\alpha_{1} \alpha_{2}>0$. Thus:

$$
\bar{\pi}^{o c}>\pi^{N} \Leftrightarrow \frac{\left(t-\alpha_{1}\right)\left(2 t-\alpha_{1}-\alpha_{2}\right)\left(2 t+\alpha_{1}+\alpha_{2}\right)}{2\left(2 t^{2}-\alpha_{1}^{2}-\alpha_{1} \alpha_{2}\right)}>0
$$

is always satisfied and ${ }^{44}$

$$
\bar{\pi}^{o c}>\tilde{\pi}^{o m} \Leftrightarrow k_{1}<\frac{14 t^{3}-\left(2 t^{2}-\alpha_{1}^{2}-\alpha_{1} \alpha_{2}\right)\left(\alpha_{1}+2 \alpha_{2}\right)-t\left(\alpha_{1}+\alpha_{2}\right)\left(5 \alpha_{1}+2 \alpha_{2}\right)}{2\left(2 t^{2}-\alpha_{1}^{2}-\alpha_{1} \alpha_{2}\right)} \equiv \hat{k}_{1} .
$$

In order to get a richer setting, we assume that $k_{1}>\hat{k}_{1} 45$ As a result, the deviating platform does not monopolize any side of the market if $\pi^{o c} \in\left[\pi^{N}, \hat{\pi}^{o c}\right)$, and monopolizes side 1 if $\pi^{o c} \in\left[\hat{\pi}^{o c}, \tilde{\pi}^{o m}\right]$. If $\pi^{o c} \geq \hat{\pi}^{o c}$, the deviating platform chooses $\left(p_{1}, p_{2}\right)$ such that:

$$
\begin{gathered}
\left\{\begin{array}{l}
n_{1}^{A}\left(p_{1}, p_{2}, p_{1}^{o c}, p_{2}^{o c}\right)=1 \\
\frac{\partial \pi^{o d}\left(p_{1}, p_{2}, p_{1}^{o c}, p_{2}^{o c}\right)}{\partial p_{2}}=0
\end{array} \Leftrightarrow\right. \\
\Leftrightarrow\left\{\begin{array}{l}
p_{1}^{o d}\left(\pi^{o c}\right)=\frac{2 t\left(2 t^{2}-\alpha_{1}^{2}-\alpha_{1} \alpha_{2}\right) \pi^{o c}-\left(t^{2}-\alpha_{1} \alpha_{2}\right)\left[2 t\left(2 t-\alpha_{1}\right)-\alpha_{1}\left(\alpha_{1}+\alpha_{2}\right)\right]}{\left(t-\alpha_{1}\right)\left(2 t^{2}-\alpha_{1}^{2}-\alpha_{1} \alpha_{2}\right)} \\
p_{2}^{o d}\left(\pi^{o c}\right)=\frac{\left(2 t^{2}+t \alpha_{1}-2 \alpha_{1}^{2}+t \alpha_{2}-2 \alpha_{1} \alpha_{2}\right)\left(t^{2}-\alpha_{1} \alpha_{2}\right)-2 \alpha_{1}\left(2 t^{2}-\alpha_{1}^{2}-\alpha_{1} \alpha_{2}\right) \pi^{o c}}{\left(t-\alpha_{1}\right)\left(2 t^{2}-\alpha_{1}^{2}-\alpha_{1} \alpha_{2}\right)} .
\end{array}\right.
\end{gathered}
$$

${ }^{42}$ The second-order conditions are satisfied, since: $\frac{\partial^{2} \pi^{A}}{\partial p_{j}^{2}}=-\frac{t}{t^{2}-\alpha_{1} \alpha_{2}}<0$ and $\frac{\partial^{2} \pi^{A}}{\partial p_{1}^{2}} \frac{\partial^{2} \pi^{A}}{\partial p_{2}^{2}}-\left(\frac{\partial^{2} \pi^{A}}{\partial p_{1} \partial p_{2}}\right)^{2}=$ $\frac{\left(2 t-\alpha_{1}-\alpha_{2}\right)\left(2 t+\alpha_{1}+\alpha_{2}\right)}{4\left(t^{2}-\alpha_{1} \alpha_{2}\right)^{2}}>0$.

${ }^{43}$ For collusion to be profitable, we must have $\pi^{o c}>\pi^{N} \Leftrightarrow 2 \pi^{o c}-2 t+\alpha_{1}+\alpha_{2}>0$.

${ }^{44}$ See Lemma 8 for the expression for $\tilde{\pi}^{o m}$.

${ }^{45}$ If $k_{1}<\hat{k}_{1}$, the deviating platform does not monopolize any side of the market $\forall \pi^{o c} \in\left[\pi^{N}, \tilde{\pi}^{o m}\right]$. 
Replacing these expressions in the demand function 22, we obtain:

$$
n_{2}^{A}\left(p_{1}^{o d}, p_{2}^{o d}, p_{1}^{o c}, p_{2}^{o c}\right)=\frac{\left(t-\alpha_{1}\right)\left(2 t+\alpha_{1}+\alpha_{2}\right)}{2\left(2 t^{2}-\alpha_{1}^{2}-\alpha_{1} \alpha_{2}\right)}<1
$$

which means that there is never monopolization of side 2 in the deviating period.

1.1. Start by assuming that $\pi^{o c}<\hat{\pi}^{o c}$. Replacing expressions 40 for prices in $(39)$, we obtain the deviation profit:

$$
\pi^{o d}\left(\pi^{o c}\right)=\frac{t\left(2 t-\alpha_{1}-\alpha_{2}\right)^{2}\left(t^{2}-\alpha_{1} \alpha_{2}\right)-2\left(2 t-\alpha_{1}-\alpha_{2}\right)\left(3 t^{2} \alpha_{1}-\alpha_{1}^{3}-t^{2} \alpha_{2}-\alpha_{1}^{2} \alpha_{2}\right) \pi^{o c}+4 t\left(t^{2}-\alpha_{1} \alpha_{2}\right)\left(\pi^{o c}\right)^{2}}{2\left(t-\alpha_{1}\right)^{2}\left(2 t-\alpha_{1}-\alpha_{2}\right)\left(2 t+\alpha_{1}+\alpha_{2}\right)} .
$$

Replacing this expression and $\pi^{N}=\frac{2 t-\alpha_{1}-\alpha_{2}}{2}$ in the ICC $\sqrt{11}$, we find that one-sided collusion is sustainable iff 46

$$
\begin{aligned}
\frac{2 \pi^{o c}-\left(2 t-\alpha_{1}-\alpha_{2}\right)}{2\left(t-\alpha_{1}\right)^{2}\left(2 t-\alpha_{1}-\alpha_{2}\right)\left(2 t+\alpha_{1}+\alpha_{2}\right)}\{ & \left(2 t-\alpha_{1}-\alpha_{2}\right)\left[t\left(t^{2}-\alpha_{1} \alpha_{2}\right)+\left[\left(t^{3}-t^{2}\left(3 \alpha_{1}-\alpha_{2}\right)-\right.\right.\right. \\
& \left.\left.\left.-t \alpha_{1} \alpha_{2}+\alpha_{1}^{2}\left(\alpha_{1}+\alpha_{2}\right)\right] \delta\right]-2 t\left(t^{2}-\alpha_{1} \alpha_{2}\right)(1-\delta) \pi^{o c}\right\} \geq 0 .
\end{aligned}
$$

Under Assumption 1 the above ICC is equivalent to:

$$
\pi^{o c} \leq \frac{\left(2 t-\alpha_{1}-\alpha_{2}\right)\left[t\left(t^{2}-\alpha_{1} \alpha_{2}\right)+\left[\left(t^{3}-t^{2}\left(3 \alpha_{1}-\alpha_{2}\right)-t \alpha_{1} \alpha_{2}+\alpha_{1}^{2}\left(\alpha_{1}+\alpha_{2}\right)\right] \delta\right]\right.}{2 t\left(t^{2}-\alpha_{1} \alpha_{2}\right)(1-\delta)} \equiv \breve{\pi}^{o c} .
$$

Recall, however, that this analysis is only valid if $\pi^{o c}<\hat{\pi}^{o c}$ and:

$$
\begin{gathered}
\breve{\pi}^{o c}<\bar{\pi}^{o c} \Leftrightarrow \frac{\left(t-\alpha_{1}\right)\left(2 t-\alpha_{1}-\alpha_{2}\right)\left(2 t+\alpha_{1}+\alpha_{2}\right)}{2 t\left(t^{2}-\alpha_{1} \alpha_{2}\right)\left(2 t^{2}-\alpha_{1}^{2}-\alpha_{1} \alpha_{2}\right)(1-\delta)}\left\{-t\left(t^{2}-\alpha_{1} \alpha_{2}\right)+\right. \\
\left.\quad+\left[\left(t-\alpha_{1}\right)\left(2 t^{2}-\alpha_{1}^{2}-\alpha_{1} \alpha_{2}\right)+t\left(t^{2}-\alpha_{1} \alpha_{2}\right)\right] \delta\right\}<0 \\
\Leftrightarrow \delta<\frac{t\left(t^{2}-\alpha_{1} \alpha_{2}\right)}{t\left(t^{2}-\alpha_{1} \alpha_{2}\right)+\left(t-\alpha_{1}\right)\left(2 t^{2}-\alpha_{1}^{2}-\alpha_{1} \alpha_{2}\right)} \equiv \tilde{\delta}^{o c} .
\end{gathered}
$$

1.2. Suppose now that $\pi^{o c} \geq \bar{\pi}^{o c}$, or, equivalently, that $\delta \geq \tilde{\delta}^{o c}$. Replacing expressions 42 in 39 , we obtain:

$$
\begin{aligned}
\pi^{o d}\left(\pi^{o c}\right)=\frac{1}{2\left(t-\alpha_{1}\right)\left(2 t^{2}-\alpha_{1}^{2}-\alpha_{1} \alpha_{2}\right)^{2}}[ & 2\left(2 t^{2}-\alpha_{1}^{2}-\alpha_{1} \alpha_{2}\right)\left(4 t^{3}-2 t^{2} \alpha_{1}-t \alpha_{1}^{2}+\alpha_{1}^{3}-3 t \alpha_{1} \alpha_{2}+\alpha_{1}^{2} \alpha_{2}\right) \pi^{o c}- \\
& \left.-t\left(2 t-\alpha_{1}-\alpha_{2}\right)\left(t^{2}-\alpha_{1} \alpha_{2}\right)\left(6 t^{2}-t \alpha_{1}-3 \alpha_{1}^{2}+t \alpha_{2}-3 \alpha_{1} \alpha_{2}\right)\right] .
\end{aligned}
$$

${ }^{46}$ Recall that, for platforms to be willing to collude, we must have $\pi^{o c} \geq \pi^{N}=\frac{2 t-\alpha_{1}-\alpha_{2}}{2}$. 
Replacing in (11), we find that platforms are willing to collude iff:

$$
\begin{aligned}
& \frac{1}{2\left(t-\alpha_{1}\right)\left(2 t^{2}-\alpha_{1}^{2}-\alpha_{1} \alpha_{2}\right)^{2}} \times \\
& \times\left\{( 2 t - \alpha _ { 1 } - \alpha _ { 2 } ) \left[t\left(t^{2}-\alpha_{1} \alpha_{2}\right)\left[3\left(2 t^{2}-\alpha_{1}^{2}-\alpha_{1} \alpha_{2}\right)+t\left(\alpha_{2}-\alpha_{1}\right)\right]-\right.\right. \\
& \left.-\left[10 t^{5}-\left(5 \alpha_{1}-\alpha_{2}\right) t^{4}-\alpha_{1}\left(7 \alpha_{1}+13 \alpha_{2}\right) t^{3}+\alpha_{1}\left(4 \alpha_{1}^{2}+5 \alpha_{1} \alpha_{2}-\alpha_{2}^{2}\right) t^{2}+\alpha_{1}^{2}\left(\alpha_{1}+\alpha_{2}\right)\left(\alpha_{1}+4 \alpha_{2}\right) t-\alpha_{1}^{3}\left(\alpha_{1}+\alpha_{2}\right)^{2}\right] \delta\right]- \\
& \left.-2\left(2 t^{2}-\alpha_{1}^{2}-\alpha_{1} \alpha_{2}\right)\left[2 t\left(t^{2}-\alpha_{1} \alpha_{2}\right)-\left[\left(t^{2}-\alpha_{1} \alpha_{2}\right)\left(3 t-\alpha_{1}\right)+\left(t-\alpha_{1}\right)^{2}\left(t+\alpha_{1}\right)\right] \delta\right] \pi^{o c}\right\} \geq 0
\end{aligned}
$$

The coefficient of $\pi^{o c}$ is positive iff:

$$
\delta<\frac{2 t\left(t^{2}-\alpha_{1} \alpha_{2}\right)}{\left(t^{2}-\alpha_{1} \alpha_{2}\right)\left(3 t-\alpha_{1}\right)+\left(t-\alpha_{1}\right)^{2}\left(t+\alpha_{1}\right)} \equiv \bar{\delta}^{o c} .
$$

Recall, however, that we are assuming $\delta \geq \tilde{\delta}^{o c}$ and:

$$
\bar{\delta}^{o c}>\tilde{\delta}^{o c} \Leftrightarrow \frac{t\left(t-\alpha_{1}\right)\left(t^{2}-\alpha_{1} \alpha_{2}\right)\left(2 t^{2}-\alpha_{1}\left(\alpha_{1}+\alpha_{2}\right)\right)}{\left[\left(t-\alpha_{1}\right)\left(2 t^{2}-\alpha_{1}^{2}-\alpha_{1} \alpha_{2}\right)+t\left(t^{2}-\alpha_{1} \alpha_{2}\right)\right]\left[\left(t^{2}-\alpha_{1} \alpha_{2}\right)\left(3 t-\alpha_{1}\right)+\left(t-\alpha_{1}\right)^{2}\left(t+\alpha_{1}\right)\right]}>0
$$

is always satisfied.

1.2.1. If $\delta \in\left(\tilde{\delta}^{o c}, \bar{\delta}^{o c}\right)$, the signal of the coefficient of $\pi^{o c}$ in 46 is positive and the ICC is equivalent to $\pi^{o c} \leq \tilde{\pi}^{o c}(\delta)$ with:

$$
\tilde{\pi}^{o c}(\delta)=\frac{N_{\tilde{\pi}^{o c}}(\delta)}{D_{\tilde{\pi}^{o c}}(\delta)}
$$

with:

$$
\begin{aligned}
& N_{\tilde{\pi} o c}(\delta)=\left(2 t-\alpha_{1}-\alpha_{2}\right)\left\{t\left(t^{2}-\alpha_{1} \alpha_{2}\right)\left[3\left(2 t^{2}-\alpha_{1}^{2}-\alpha_{1} \alpha_{2}\right)+t\left(\alpha_{2}-\alpha_{1}\right)\right]-\right. \\
& -\left[10 t^{5}-\left(5 \alpha_{1}-\alpha_{2}\right) t^{4}-\alpha_{1}\left(7 \alpha_{1}+13 \alpha_{2}\right) t^{3}+\alpha_{1}\left(4 \alpha_{1}^{2}+5 \alpha_{1} \alpha_{2}-\alpha_{2}^{2}\right) t^{2}+\alpha_{1}^{2}\left(\alpha_{1}+\alpha_{2}\right)\left(\alpha_{1}+4 \alpha_{2}\right) t-\right. \\
& \left.\left.-\alpha_{1}^{3}\left(\alpha_{1}+\alpha_{2}\right)^{2}\right] \delta\right\} \\
& D_{\tilde{\pi} \text { oc }}(\delta)=2\left(2 t^{2}-\alpha_{1}^{2}-\alpha_{1} \alpha_{2}\right)\left[2 t\left(t^{2}-\alpha_{1} \alpha_{2}\right)-\left[\left(t^{2}-\alpha_{1} \alpha_{2}\right)\left(3 t-\alpha_{1}\right)+\left(t-\alpha_{1}\right)^{2}\left(t+\alpha_{1}\right)\right] \delta\right] .
\end{aligned}
$$

As $\lim _{\delta \rightarrow\left(\bar{\delta}^{o c}\right)^{-}} \tilde{\pi}^{o c}(\delta)=+\infty$ and:

$$
\frac{\partial \tilde{\pi}^{o c}}{\partial \delta}=\frac{t\left(t-\alpha_{1}\right)^{2}\left(2 t-\alpha_{1}-\alpha_{2}\right)\left(2 t+\alpha_{1}+\alpha_{2}\right)\left(t^{2}-\alpha_{1} \alpha_{2}\right)}{2\left[\alpha_{1}^{2}\left(\alpha_{1}+\alpha_{2}\right) \delta-2 t^{2} \alpha_{1} \delta-2 t^{3}(1-2 \delta)-t \alpha_{1}^{2} \delta+t \alpha_{1} \alpha_{2}(2-3 \delta)\right]^{2}}>0,
$$


we conclude that $\exists ! \tilde{\delta}^{o m} \in\left(\tilde{\delta}^{o c}, \bar{\delta}^{o c}\right)$ such that $\tilde{\pi}^{o c}(\delta)>\tilde{\pi}^{o m}, \forall \delta>\tilde{\delta}^{o m}$. More precisely:

$$
\tilde{\pi}^{o c}\left(\tilde{\delta}^{o m}\right)=\tilde{\pi}^{o m} \Leftrightarrow \tilde{\delta}^{o m}=\frac{N_{\tilde{\delta}^{o m}}}{D_{\tilde{\delta}}^{o m}},
$$

with:

$$
\begin{aligned}
N_{\tilde{\delta} o m}= & 2 t\left(t^{2}-\alpha_{1} \alpha_{2}\right)\left[10 t^{3}-t\left(\alpha_{1}+\alpha_{2}\right)\left(4 \alpha_{1}+\alpha_{2}\right)-\left(2 t^{2}-\alpha_{1}^{2}-\alpha_{1} \alpha_{2}\right)\left(\alpha_{1}+2 \alpha_{2}+2 k_{1}\right)\right], \\
D_{\tilde{\delta} o m}= & 32 t^{6}+\alpha_{1}^{3}\left(\alpha_{1}+\alpha_{2}\right)^{2}\left(\alpha_{1}+2 \alpha_{2}\right)-4 t^{5}\left(5 \alpha_{1}+4 \alpha_{2}\right)-t^{2} \alpha_{1}\left(\alpha_{1}+\alpha_{2}\right)\left(\alpha_{1}{ }^{2}-3 \alpha_{1} \alpha_{2}-2 \alpha_{2}{ }^{2}\right)- \\
& -2 t \alpha_{1}{ }^{2}\left(\alpha_{1}+\alpha_{2}\right)\left(2 \alpha_{1}{ }^{2}+4 \alpha_{1} \alpha_{2}+3 \alpha_{2}{ }^{2}\right)-2 t^{4}\left(8 \alpha_{1}{ }^{2}+17 \alpha_{1} \alpha_{2}+\alpha_{2}{ }^{2}\right)+2 t^{3} \alpha_{1}\left(9 \alpha_{1}{ }^{2}+17 \alpha_{1} \alpha_{2}+10 \alpha_{2}{ }^{2}\right)- \\
& -2 k_{1}\left(2 t^{2}-\alpha_{1}{ }^{2}-\alpha_{1} \alpha_{2}\right)\left[4 t^{3}-2 t^{2} \alpha_{1}+\alpha_{1}{ }^{2}\left(\alpha_{1}+\alpha_{2}\right)-t \alpha_{1}\left(\alpha_{1}+3 \alpha_{2}\right)\right] .
\end{aligned}
$$

Recalling that $\tilde{\pi}^{o m}$ is the maximum collusive profit for side 1 to be fully covered, we conclude that $\pi^{o c}(\delta)=\tilde{\pi}^{o m}, \forall \delta \in\left(\tilde{\delta}^{o c}, \bar{\delta}^{o c}\right)$.

1.2.2. If $\delta \in\left(\bar{\delta}^{o c}, 1\right)$, the coefficient of $\pi^{o c}$ in 46 is negative. Thus, the ICC is equivalent to $\pi^{o c} \geq \breve{\pi}^{o c}(\delta)$ with $\breve{\pi}^{o c}(\delta)=\frac{-N_{\tilde{\pi}}^{o c}(\delta)}{-D_{\tilde{\pi}} o c(\delta)}$. Notice further that:

$$
\frac{\partial \breve{\pi}^{o c}}{\partial \delta}=\frac{\partial \tilde{\pi}^{o c}}{\partial \delta}>0 \quad \text { and } \quad \breve{\pi}^{o c}(1)=\pi^{N}
$$

Thus, any profit above the Nash profit is surely sustainable for $\delta>\bar{\delta}^{o c}$. However, if $\pi^{o c}>\tilde{\pi}^{o m}$, side 1 would not be fully covered (which is not optimal from Lemma 7). Thus: $\pi^{o c}(\delta)=\tilde{\pi}^{o m}, \forall \delta \in\left(\bar{\delta}^{o c}, 1\right)$.

2. Assume now that $0<t<\alpha_{1}$. Start by noticing that Assumption 1 and condition $t<\alpha_{1}$ are only compatible if $\alpha_{2}<\alpha_{1}$.

If the deviating platform $A$ did not monopolize any market side, it would charge prices 40 and its profit would be equal to 43 . In addition, from 41$): n_{1}^{A}\left(p_{1}^{o d}, p_{2}^{o d}, p_{1}^{o c}, p_{2}^{o c}\right)<n_{2}^{A}\left(p_{1}^{o d}, p_{2}^{o d}, p_{1}^{o c}, p_{2}^{o c}\right)$. Thus, if platform A did not monopolize side 2, it did not monopolize side 1 as well. Replacing expressions for prices 40 in the demand function 22], we obtain:

$$
n_{2}^{A}\left(p_{1}^{o d}, p_{2}^{o d}, p_{1}^{o c}, p_{2}^{o c}\right) \leq 1 \Leftrightarrow \pi^{o c} \leq \frac{\left(2 t-\alpha_{1}-\alpha_{2}\right)\left[\alpha_{1}\left(\alpha_{1}+\alpha_{2}\right)+2 t\left(\alpha_{1}-t-\alpha_{2}\right)\right]}{2 t\left(\alpha_{1}-\alpha_{2}\right)} \equiv \check{\pi}^{o c} .
$$

If Assumption 1 and condition $t<\alpha_{1}$ hold, we have:

$$
\check{\pi}^{o c}-\pi^{N}=\frac{\left(\alpha_{1}-t\right)\left(2 t-\alpha_{1}-\alpha_{2}\right)\left(2 t+\alpha_{1}+\alpha_{2}\right)}{2 t\left(\alpha_{1}-\alpha_{2}\right)}>0 .
$$

In addition 47

$$
\check{\pi}^{o c}<\hat{\pi}^{o m} \Leftrightarrow k_{2}>\frac{t^{2}\left(11 \alpha_{1}-3 \alpha_{2}\right)-\left(\alpha_{1}-\alpha_{2}\right)\left(2 \alpha_{1}+\alpha_{2}\right) t-2 \alpha_{1}\left(\alpha_{1}+\alpha_{2}\right)^{2}}{2 t\left(\alpha_{1}-\alpha_{2}\right)} \equiv \hat{k}_{2} .
$$

\footnotetext{
${ }^{47}$ The expression for $\hat{\pi}^{o m}$ is given in Lemma 8
} 
To get a richer setting, we assume that $k_{2}>\hat{k}_{2}$. Thus: if $\pi^{o c} \in\left[\pi^{N}, \check{\pi}^{o c}\right)$, the deviating platform does not monopolize any market side; while, if $\pi^{o c} \in\left[\check{\pi}^{o c}, \hat{\pi}^{o m}\right]$, it monopolizes side 2 . If $\pi^{o c} \geq \hat{\pi}^{o c}$, the deviating platform chooses prices that solve:

$$
\left\{\begin{array} { l } 
{ n _ { 2 } ^ { A } ( p _ { 1 } , p _ { 2 } , p _ { 1 } ^ { o c } , p _ { 2 } ^ { o c } ) = 1 } \\
{ \frac { \partial \pi ^ { A } } { \partial p _ { 2 } } = 0 }
\end{array} \Leftrightarrow \left\{\begin{array}{l}
p_{1}^{o d}\left(\pi^{o c}\right)=\frac{\left(3 \alpha_{1}-2 t-\alpha_{2}\right)\left(t^{2}-\alpha_{1} \alpha_{2}\right)-2 t\left(\alpha_{1}-\alpha_{2}\right) \pi^{o c}}{\left(\alpha_{1}-t\right)\left(\alpha_{1}-\alpha_{2}\right)} \\
p_{2}^{o d}\left(\pi^{o c}\right)=\frac{\left(t^{2}-\alpha_{1} \alpha_{2}\right)\left[2 t \alpha_{2}-\alpha_{1}\left(\alpha_{1}+\alpha_{2}\right)\right]+2 t \alpha_{1}\left(\alpha_{1}-\alpha_{2}\right) \pi^{o c}}{t\left(\alpha_{1}-t\right)\left(\alpha_{1}-\alpha_{2}\right)}
\end{array}\right.\right.
$$

Replacing these expressions in (2), we conclude that there is never monopolisation of side 1 in the deviating period, since:

$$
n_{1}^{A}\left(p_{1}^{o d}, p_{2}^{o d}, p_{1}^{o c}, p_{2}^{o c}\right)-1=-\frac{\left(t+\alpha_{1}\right)\left(2 t-\alpha_{1}-\alpha_{2}\right)}{2 t\left(\alpha_{1}-\alpha_{2}\right)}<0
$$

2.1. If $\pi^{o c}<\check{\pi}^{o c}$, the analysis is quite similar to the case 1.1. More precisely, any collusive profit $\pi^{o c}(\delta) \leq \breve{\pi}^{o c}$, with $\breve{\pi}^{o c}$ given in 444, is sustainable. However, this analysis is only valid if $\pi^{o c}<\check{\pi}^{o c}$, given in (50) and:

$$
\begin{aligned}
& \breve{\pi}^{o c}<\breve{\pi}^{o c} \Leftrightarrow \\
\Leftrightarrow & \frac{\left(\alpha_{1}-t\right)\left(2 t-\alpha_{1}-\alpha_{2}\right)\left(2 t+\alpha_{1}+\alpha_{2}\right)}{2 t\left(\alpha_{1}-\alpha_{2}\right)\left(t^{2}-\alpha_{1} \alpha_{2}\right)(1-\delta)}\left\{-\left(t^{2}-\alpha_{1} \alpha_{2}\right)+\left[t^{2}-\alpha_{1} \alpha_{2}+\left(\alpha_{1}-\alpha_{2}\right)\left(\alpha_{1}-t\right)\right] \delta\right\}<0 \\
\Leftrightarrow & \delta<\frac{t^{2}-\alpha_{1} \alpha_{2}}{t^{2}-\alpha_{1} \alpha_{2}+\left(\alpha_{1}-\alpha_{2}\right)\left(\alpha_{1}-t\right)} \equiv \hat{\delta}^{o c} .
\end{aligned}
$$

2.2. If $\pi^{o c} \geq \check{\pi}^{o c}$ (or, equivalently, $\delta \geq \hat{\delta}^{o c}$ ), there is monopolisation of side 2 in the deviating period. Using (53), the deviation profit is:

$$
\begin{aligned}
\pi^{o d}\left(\pi^{o c}\right)= & \frac{\left(2 t-\alpha_{1}-\alpha_{2}\right)\left(t^{2}-\alpha_{1} \alpha_{2}\right)}{2 t\left(\alpha_{1}-t\right)\left(\alpha_{1}-\alpha_{2}\right)^{2}} \times \\
& \times\left\{\left[2 t^{2}-3 t\left(\alpha_{1}-\alpha_{2}\right)-\alpha_{1}\left(\alpha_{1}+\alpha_{2}\right)\right]+2 t\left(\alpha_{1}-\alpha_{2}\right)\left[2 t^{2}-t\left(\alpha_{1}-\alpha_{2}\right)+\alpha_{1}\left(\alpha_{1}-3 \alpha_{2}\right)\right] \pi^{o c}\right\}
\end{aligned}
$$

Replacing this expression and $\pi^{N}=\frac{2 t-\alpha_{1}-\alpha_{2}}{2}$ in the ICC 11 , we obtain:

$$
\begin{aligned}
\frac{1}{2 t\left(\alpha_{1}-t\right)\left(\alpha_{1}-\alpha_{2}\right)^{2}}\{ & \left(2 t-\alpha_{1}-\alpha_{2}\right)\left[-\left(t^{2}-\alpha_{1} \alpha_{2}\right)\left[2 t^{2}-3 t\left(\alpha_{1}-\alpha_{2}\right)-\alpha_{1}\left(\alpha_{1}+\alpha_{2}\right)\right]+\right. \\
& \left.+\left[2 t^{4}-3 t^{3}\left(\alpha_{1}-\alpha_{2}\right)-\alpha_{2} t^{2}\left(5 \alpha_{1}-\alpha_{2}\right)-t \alpha_{1}\left(\alpha_{1}-4 \alpha_{2}\right)\left(\alpha_{1}-\alpha_{2}\right)+\alpha_{1}^{2} \alpha_{2}\left(\alpha_{1}+\alpha_{2}\right)\right] \delta\right]- \\
& \left.-2 t\left(\alpha_{1}-\alpha_{2}\right)\left[2\left(t^{2}-\alpha_{1} \alpha_{2}\right)-\left[2\left(t^{2}-\alpha_{1} \alpha_{2}\right)+\left(\alpha_{1}-\alpha_{2}\right)\left(\alpha_{1}-t\right)\right] \delta\right] \pi^{o c}\right\} \geq 0
\end{aligned}
$$


The signal of the coefficient of $\pi^{o c}$ is positive iff:

$$
\delta>\frac{2\left(t^{2}-\alpha_{1} \alpha_{2}\right)}{2\left(t^{2}-\alpha_{1} \alpha_{2}\right)+\left(\alpha_{1}-\alpha_{2}\right)\left(\alpha_{1}-t\right)}=\bar{\delta} .
$$

Under Assumption 1 and condition $t<\alpha_{1}$, we have:

$$
\bar{\delta}-\hat{\delta}^{o c}=\frac{\left(\alpha_{1}-t\right)\left(\alpha_{1}-\alpha_{2}\right)\left(t^{2}-\alpha_{1} \alpha_{2}\right)}{\left[2\left(t^{2}-\alpha_{1} \alpha_{2}\right)+\left(\alpha_{1}-\alpha_{2}\right)\left(\alpha_{1}-t\right)\right]\left[t^{2}-\alpha_{1} \alpha_{2}+\left(\alpha_{1}-\alpha_{2}\right)\left(\alpha_{1}-t\right)\right]}>0 .
$$

2.2.1. If $\delta \in\left(\hat{\delta}^{o c}, \bar{\delta}\right)$, the coefficient of $\pi^{o c}$ in 46 is negative and the ICC can be written as $\pi^{o c} \leq \hat{\pi}^{o c}(\delta)$ :

$$
\hat{\pi}^{o c}(\delta)=\frac{N_{\hat{\pi}^{o c}}(\delta)}{D_{\hat{\pi}^{o c}}(\delta)}
$$

with:

$$
\begin{aligned}
N_{\hat{\pi}^{o c}}(\delta) & =\left(2 t-\alpha_{1}-\alpha_{2}\right)\left\{-\left(t^{2}-\alpha_{1} \alpha_{2}\right)\left[2 t^{2}-3 t\left(\alpha_{1}-\alpha_{2}\right)-\alpha_{1}\left(\alpha_{1}+\alpha_{2}\right)\right]+\right. \\
& \left.+\left[2 t^{4}-3 t^{3}\left(\alpha_{1}-\alpha_{2}\right)-\alpha_{2} t^{2}\left(5 \alpha_{1}-\alpha_{2}\right)-t \alpha_{1}\left(\alpha_{1}-4 \alpha_{2}\right)\left(\alpha_{1}-\alpha_{2}\right)+\alpha_{1}^{2} \alpha_{2}\left(\alpha_{1}+\alpha_{2}\right)\right] \delta\right\}, \\
D_{\hat{\pi} o c}(\delta) & =2 t\left(\alpha_{1}-\alpha_{2}\right)\left[2\left(t^{2}-\alpha_{1} \alpha_{2}\right)-\left[2\left(t^{2}-\alpha_{1} \alpha_{2}\right)+\left(\alpha_{1}-\alpha_{2}\right)\left(\alpha_{1}-t\right)\right] \delta\right]
\end{aligned}
$$

As $\lim _{\delta \rightarrow \bar{\delta}^{-}} \hat{\pi}^{o c}(\delta)=+\infty$ and:

$$
\frac{\partial \hat{\pi}^{o c}}{\partial \delta}=\frac{\left(\alpha_{1}-t\right)^{2}\left(t^{2}-\alpha_{1} \alpha_{2}\right)\left(2 t-\alpha_{1}-\alpha_{2}\right)\left(2 t+\alpha_{1}+\alpha_{2}\right)}{2 t\left[2 t^{2}(1-\delta)+t\left(\alpha_{1}-\alpha_{2}\right) \delta-\alpha_{1}\left[\alpha_{2}(2-3 \delta)+\alpha_{1} \delta\right]\right]^{2}}>0,
$$

we conclude that $\exists ! \hat{\delta}^{o m} \in\left(\hat{\delta}^{o c}, \bar{\delta}\right)$ such that $\hat{\pi}^{o c}(\delta)>\hat{\pi}^{o m}, \forall \delta>\hat{\delta}^{o m}$. More precisely:

$$
\hat{\pi}^{o c}\left(\hat{\delta}^{o m}\right)=\hat{\pi}^{o m} \Leftrightarrow \hat{\delta}^{o m}=\frac{N_{\hat{\delta} o m}}{D_{\hat{\delta}^{o m}}},
$$

with:

$$
\begin{aligned}
N_{\hat{\delta} o m}= & 2\left(t^{2}-\alpha_{1} \alpha_{2}\right)\left[2 k_{2} t\left(\alpha_{1}-\alpha_{2}\right)+\alpha_{1}\left(\alpha_{1}+\alpha_{2}\right)^{2}+t\left(\alpha_{1}-\alpha_{2}\right)\left(2 \alpha_{1}+\alpha_{2}\right)-t^{2}\left(7 \alpha_{1}-3 \alpha_{2}\right)\right], \\
D_{\hat{\delta} o m}= & 2 k_{2} t\left(\alpha_{1}-\alpha_{2}\right)\left[2 t^{2}+\alpha_{1}\left(\alpha_{1}-3 \alpha_{2}\right)-t\left(\alpha_{1}-\alpha_{2}\right)\right]-2 t^{4}\left(7 \alpha_{1}-3 \alpha_{2}\right)-2 \alpha_{1}^{2} \alpha_{2}\left(\alpha_{1}+\alpha_{2}\right)^{2}+ \\
& +t \alpha_{1}\left(\alpha_{1}-3 \alpha_{2}\right)\left(\alpha_{1}-\alpha_{2}\right)\left(2 \alpha_{1}+\alpha_{2}\right)+t^{3}\left(7 \alpha_{1}^{2}-8 \alpha_{1} \alpha_{2}+\alpha_{2}^{2}\right)-t^{2}\left(3 \alpha_{1}^{3}-27 \alpha_{1}^{2} \alpha_{2}+7 \alpha_{1} \alpha_{2}^{2}+\alpha_{2}^{3}\right) \alpha_{2} .
\end{aligned}
$$

Recall that side 2 is fully covered iff $\pi^{o c}(\delta) \leq \hat{\pi}^{o m}$. Thus, from Lemma 7 , we conclude that: $\pi^{o c}(\delta)=\hat{\pi}^{o m}$, $\forall \delta \in\left(\tilde{\delta}^{o c}, \hat{\delta}^{o c}\right)$. 
2.2.2. Following the same steps as in 1 .2.2., it follows that $\pi^{o c}(\delta)=\hat{\pi}^{o m}, \forall \delta \in\left(\hat{\delta}^{o c}, 1\right)$.

3. Finally, assume that $\alpha_{1}<-\frac{\tilde{u}_{2}^{N}}{\tilde{u}_{1}^{N}} t<t$.

As in case 2., if the deviating platform does not monopolize any market side, it charges prices 40

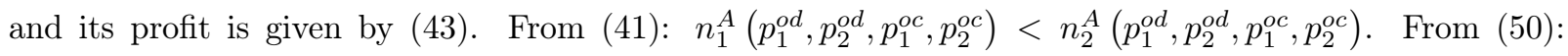
$n_{2}^{A}\left(p_{1}^{o d}, p_{2}^{o d}, p_{1}^{o c}, p_{2}^{o c}\right) \leq 1 \Leftrightarrow \pi^{o c} \leq \check{\pi}^{o c}$, with $\check{\pi}^{o c}$ given in 50. If $k_{2}>\hat{k}_{2}$, we have $\check{\pi}^{o c}<\hat{\pi}^{o m}$. In addition, as $\alpha_{2}>\alpha_{1}$, it follows from 51 that $\check{\pi}^{o c} \geq \pi^{N}$.

3.1 If $\pi^{o c}<\check{\pi}^{o c}$, there is no monopolisation of any market side in the deviating period and the analysis is identical to case 1.1. More precisely, any collusive profit such that $\pi^{o c}(\delta) \leq \breve{\pi}^{o c}$, with $\breve{\pi}^{o c}$ given in (44), is sustainable. However, this analysis is only valid if $\pi^{o c}<\breve{\pi}^{o c}$, given in (50). From (54), $\pi^{o c}(\delta)=\breve{\pi}^{o c}(\delta)$ iff $\delta<\hat{\delta}^{o c}=\frac{t^{2}-\alpha_{1} \alpha_{2}}{t^{2}-\alpha_{1} \alpha_{2}+\left(\alpha_{2}-\alpha_{1}\right)\left(t-\alpha_{1}\right)}$.

3.2. If $\pi^{o c} \geq \check{\pi}^{o c}$ (or, equivalently, $\delta \geq \hat{\delta}^{o c}$ ), there is monopolization of side 2 in the deviating period. The ICC for collusion to be sustainable is given by (56). As $t>\alpha_{1}$ and $\alpha_{2}>\alpha_{1}$, the signal of the coefficient of $\pi^{o c}$ is positive iff $\delta>\bar{\delta}$, with $\bar{\delta} \in\left(\hat{\delta}^{o c}, 1\right)$ given in 57 .

3.2.1. If $\delta \in\left(\hat{\delta}^{o c}, \bar{\delta}\right)$, the coefficient of $\pi^{o c}$ in 46 is negative and the ICC can be written as $\pi^{o c} \leq \hat{\pi}^{o c}(\delta)$ with: $\hat{\pi}^{o c}(\delta)=\frac{-N_{\hat{\hat{\pi}} o c}(\delta)}{-D_{\hat{\pi}}^{o c}(\delta)}$, where $N_{\hat{\pi}^{o c}}$ and $D_{\hat{\pi}^{o c}}$ are given in 59 and 60 , respectively. Following the same steps as in 2.2.1, we conclude that: $\pi^{o c}(\delta)=\hat{\pi}^{o m}, \forall \delta \in\left(\tilde{\delta}^{o c}, \delta^{o c}\right)$.

3.2.2. As in $\mathbf{2 . 2 . 2}$, it follows that $\pi^{o c}(\delta)=\pi^{o m}, \forall \delta \in\left(\hat{\delta}^{o c}, 1\right)$.

\section{Proof of Proposition 6.}

Assume that $\alpha_{1}=\alpha_{2} \equiv \alpha$. For Assumption 1 to be satisfied, we must have $-t<\alpha<t$. Let us determine the sign of the derivative of $\pi^{o c}$, given in $(16)$, with respect to $\alpha$.

1. If $0<\delta<\tilde{\delta}^{o c}$, with $\tilde{\delta}^{o c}=\frac{t}{3 t-2 \alpha}$ :

$$
\frac{\partial \pi^{o c}}{\partial \alpha}<0 \Leftrightarrow-\frac{t+(3 t-4 \alpha) \delta}{t(1-\delta)}<0 \Leftrightarrow(3 t-4 \alpha) \delta>-t
$$

If $t \geq \frac{4}{3} \alpha$, the last inequality is trivially satisfied. If $t<\frac{4}{3} \alpha$, we have that $\frac{\partial \pi^{o c}}{\partial \alpha}<0 \Leftrightarrow \delta<\frac{t}{4 \alpha-3 t}$. Notice, however, that we are assuming $\delta<\tilde{\delta}^{o c}$ and $\tilde{\delta}^{o c}<\frac{t}{4 \alpha-3 t}$.

1.2. If $\tilde{\delta}^{o c}<\delta \leq \tilde{\delta}^{o m}$ with $\tilde{\delta}^{o m}=\frac{t\left(2 k_{1}-5 t+3 \alpha\right)}{2 k_{1}(2 t-\alpha)-8 t^{2}+9 t \alpha-3 \alpha^{2}}$ :

$$
\frac{\partial \pi^{o c}}{\partial \alpha}<0 \Leftrightarrow-\frac{3 t^{2}-2 t(5 t-2 \alpha) \delta+\left(9 t^{2}-8 t \alpha+2 \alpha^{2}\right) \delta^{2}}{2(t+\alpha \delta-2 t \delta)^{2}}<0 .
$$




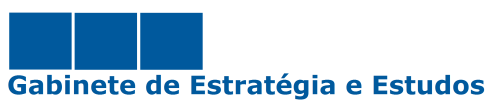

Notice that $9 t^{2}-8 t \alpha+2 \alpha^{2}>8 t(t-\alpha)+2 \alpha^{2}>0$. As $3 t^{2}-2 t(5 t-2 \alpha) \delta+\left(9 t^{2}-8 t \alpha+2 \alpha^{2}\right) \delta^{2}$ has no real roots, we conclude that $\frac{\partial \pi^{o c}}{\partial \alpha}<0$.

1.3. If $\tilde{\delta}^{o m}<\delta<1$ :

$$
\frac{\partial \pi^{o c}}{\partial \alpha}<0 \Leftrightarrow-\frac{k_{1}-t+3 \alpha}{2 t}<0 \Leftrightarrow k_{1}>t-3 \alpha .
$$

Notice, however, that for the collusive profit to be given by [16), we must have $k_{1}>\frac{7 t-3 \alpha}{2}$. As $t-3 \alpha<$ $\frac{7 t-3 \alpha}{2}$, we conclude that $\frac{\partial \pi^{o c}}{\partial \alpha}<0$. 


\section{References}

[1] Argentesi, E., \& Filistrucchi, L. (2007). Estimating market power in a two-sided market: The case of newspapers. Journal of Applied Econometrics, 22(7): 1247-1266.

[2] Armstrong, M. (2006). Competition in twoâsided markets. RAND Journal of Economics, 37(3): 668691.

[3] Boffa, F., \& Filistrucchi, L. (2014). Optimal Cartel Prices in Two-Sided Markets. NET Institute Working Paper 14-19.

[4] Choi, J. P., \& Gerlach, H. (2013). Multiâmarket collusion with demand linkages and antitrust enforcement. The Journal of Industrial Economics, 61(4): 987-1022.

[5] Dewenter, R., Haucap, J., \& Wenzel, T. (2011). Semi-collusion in media markets. International Review of Law and Economics, 31(2), 92-98.

[6] Evans, D. S., \& Schmalensee, R. (2008). Markets with two-sided platforms. Issues in Competition Law and Policy (ABA Section of Antitrust Law), 1.

[7] Evans, D. S., \& Schmalensee, R. (2013): The antitrust analysis of multi-sided platform businesses. NBER Working Paper No. 18783, February.

[8] Thomadsen, R., \& Rhee, K. E. (2007). Costly collusion in differentiated industries. Marketing Science, 26(5): $660-665$.

[9] Kaiser, U., and J. Wright. (2006). Price structure in two-sided markets: Evidence from the magazine industry. International Journal of Industrial Organization, 24(1): 1-28.

[10] Ruhmer, I. (2011). Platform collusion in two-sided markets. University of Mannheim. 


\section{GEE Papers}

1: Evolução do Comércio Externo Português de Exportação (1995-2004)

João Ferreira do Amaral

2: Nowcasting an Economic Aggregate with Disaggregate Dynamic Factors: An Application to Portuguese GDP Antonio Morgado | Luis Nunes | Susana Salvado

3: Are the Dynamics of Knowledge-Based Industries Any Different? Ricardo Mamede | Daniel Mota | Manuel Godinho

4: Competitiveness and convergence in Portugal Jorge Braga de Macedo

5: Produtividade, Competitividade e Quotas de Exportação Jorge Santos

6: Export Diversification and Technological Improvement Recent Trends in the Portuguese Economy Manuel Cabral

7: Election Results and Opportunistic Policies: An Integrated Approach

Toke Aidt | Francisco Veiga | Linda Veiga

8: Behavioural Determinants of Foreign Direct Investment Ricardo Pinheiro-Alves

9: Structural Transformation and the role of Foreign Direct Investment in Portugal: a descriptive analysis for the period 1990-2005

Miguel de Freitas | Ricardo Mamede

10: Productive experience and specialization opportunities for Portugal: an empirical assessment

Miguel de Freitas | Susana Salvado | Luis Nunes | Rui Costa Neves

11: The Portuguese Active Labour Market Policy during the period 1998-2003 - A Comprehensive Conditional Difference-In-Differences Application Alcina Nunes | Paulino Teixeira

12: Fiscal Policy in a Monetary Union: Gains from Changing Institutions

Susana Salvado

13: Coordination and Stabilization Gains of Fiscal Policy in a Monetary Union Susana Salvado

14: The Relevance of Productive Experience in the Process of Economic Growth: an Empirical Study Diana Vieira

15: Employment and Exchange rates: the Role of Openness and Technology

Fernando Alexandre | Pedro Bação | João Cerejeira Miguel Portela

16: Aggregate and sector-specific exchange rate indexes for the Portuguese economy

Fernando Alexandre | Pedro Bação| João Cerejeira | Miguel Portela
17: The Macroeconomic Determinants of Cross Border Mergers and Acquisitions and Greenfield Investments Paula Neto | Antonio Brandao | António Cerqueira

18: Does the location of manufacturing determine service sectors' location choices? Evidence from Portugal Nuno Crespo | Maria Paula Fontoura

19: A hipótese do Investment Development Path: Uma Abordagem por Dados em Painel. Os casos de Portugal e Espanha

Miguel Fonseca | António Mendonça | José Passos

20: Outward FDI Effects on the Portuguese Trade Balance, 1996-2007

Miguel Fonseca | António Mendonça | José Passos

21: Sectoral and regional impacts of the European Carbon Market in Portugal

Margarita Robaina Alves | Miguel Rodriguez | Catarina Roseta-Palma

22: Business Demography Dynamics in Portugal: A NonParametric Survival Analysis

Alcina Nunes | Elsa Sarmento

23: Business Demography Dynamics in Portugal: A Semiparametric Survival Analysis Alcina Nunes | Elsa Sarmento

24: Digging Out the PPP Hypothesis: an Integrated Empirical Coverage Miguel de Carvalho | Paulo Júlio

25: Regulação de Mercados por Licenciamento Patrícia Cerqueira | Ricardo Pinheiro Alves

26: Which Portuguese Manufacturing Firms Learn by Exporting?

Armando Silva | Óscar Afonso | Ana Paula Africano

27: Building Bridges: Heterogeneous Jurisdictions, Endogenous Spillovers, and the Benefits of Decentralization Paulo Júlio | Susana Peralta

28: Análise comparativa de sobrevivência empresarial: o caso da região Norte de Portugal Elsa Sarmento | Alcina Nunes

29: Business creation in Portugal: Comparison between the World Bank data and Quadros de Pessoal Elsa Sarmento | Alcina Nunes

30: The Ease of Doing Business Index as a tool for Investment location decisions João Zambujal Oliveira | Ricardo Pinheiro Alves

31: The Politics of Growth: Can Lobbying Raise Growth and Welfare?

Paulo Júlio

32: The choice of transport technology in the presence of exports and FDI

José Pedro Ponte | Armando Garcia Pires

33: Tax Competition in an Expanding European Union Ronald Davies | Johannes Voget 
34: The usefulness of State trade missions for the internationalization of firms: an econometric analysis Ana Paula Africano | Aurora Teixeira | André Caiado

35: The role of subsidies for exports: Evidence from Portuguese manufacturing firms Armando Silva

36: Criação de empresas em Portugal e Espanha: análise comparativa com base nos dados do Banco Mundial Elsa Sarmento | Alcina Nunes

37: Economic performance and international trade engagement: the case of Portuguese manufacturing firms

Armando Silva | Oscar Afonso | Ana Paula Africano

38: The importance of Intermediaries organizations in international R\&D cooperation: an empirical multivariate study across Europe Aurora Teixeira | Margarida Catarino

39: Financial constraints, exports and monetary integration Financial constraints and exports: An analysis of Portuguese firms during the European monetary integration

Filipe Silva | Carlos Carreira

40: FDI and institutional reform in Portugal Paulo Júlio | Ricardo Pinheiro-Alves | José Tavares

41: Evaluating the forecast quality of GDP components Paulo Júlio | Pedro Esperança | João C. Fonseca

42: Assessing the Endogeneity of OCA conditions in EMU Carlos Vieira | Isabel Vieira

43: Labor Adjustment Dynamics: An Application of System GMM

Pedro Esperança

44: Corporate taxes and the location of FDI in Europe using firm-level data Tomás Silva | Sergio Lagoa

45: Public Debt Stabilization: Redistributive Delays versus Preemptive Anticipations Paulo Júlio

46: Organizational Characteristics and Performance of Export Promotion Agencies: Portugal and Ireland compared Inês Ferreira | Aurora Teixeira

47: Evaluating the forecast quality of GDP components: An application to $\mathrm{G} 7$ Paulo Júlio | Pedro Esperança

48: The influence of Doing Business' institutional variables in Foreign Direct Investment Andreia Oliva

49: Regional and Sectoral Foreign Direct Investment in Portugal since Joining the EU: A Dynamic Portrait Irina Melo | Alexandra Lopes

50: Institutions and Firm Formation: an Empirical Analysis of Portuguese Municipalities Simão Arouca

51: Youth Unemployment in Southern Europe João Leão | Guida Nogueira
52: Financiamento da Economia Portuguesa: um Obstáculo ao Crescimento?

João Leão | Ana Martins | João Gonçalves

53: O Acordo de Parceria Transatlântica entre a UE e os EUA constitui uma ameaça ou uma oportunidade para a Economia Portuguesa? João Leão | Guida Nogueira

54: Prescription Patterns of Pharmaceuticals Ana Gonçalves

55: Economic Growth and the High Skilled: the Role of Scale Eects and of Barriers to Entry into the High Tech Pedro Gil | Oscar Afonso | Paulo Brito

56: Finanças Públicas Portuguesas Sustentáveis no Estado Novo (1933-1974)? Ricardo Ferraz

57: What Determines Firm-level Export Capacity? Evidence from Portuguese firms

Ana Gouveia I Ana Luisa Correia

58: The effect of developing countries' competition on regional labour markets in Portugal Tiago Pereira

59: Fiscal Multipliers in the 21st century Pedro Brinca | Hans Holter | Per Krusell | Laurence Malafry

60: Reallocation of Resources between Tradable and NonTradable Sectors in Portugal: Developing a new Identification Strategy for the Tradable Sector Ana Fontoura Gouveia | Filipa Canas

61: Is the ECB unconventional monetary policy effective? Inês Pereira

62: The Determinants of TFP Growth in the Portuguese Manufacturing Sector Daniel Gonçalves | Ana Martins

63: Practical contribution for the assessment and monitoring of product market competition in the Portuguese Economy - estimation of price cost margins Luis Folque

64: The impact of structural reforms of the judicial system: a survey

Ana Gouveia | Silvia Santos | Corinna Herber

65: The short-term impact of structural reforms on productivity growth: beyond direct effects Ana Gouveia | Silvia Santos | Inês Gonçalves

66: Assessing the Competitiveness of the Portuguese Footwear Sector Fábio Batista | José Matos | Miguel Matos

67: The empirics of agglomeration economies: the link with productivity Ana Gouveia | Silvia Santos | Marli Fernandes

68: Determinants of the Portuguese GDP stagnation during the 2001-2014 period: an empirical investigation Carlos Figueira

69: Short-run effects of product markets' deregulation: a more productive, more efficient and more resilient economy? Ana Gouveia | Silvia Santos | Gustavo Monteiro 
70: Portugal: a Paradox in Productivity

Ricardo Pinheiro Alves

71: Infrastructure Investment, Labor Productivity, and International Competitiveness: The Case of Portugal Alfredo Pereira | Rui Pereira

72: Boom, Slump, Sudden stops, Recovery, and Policy Options. Portugal and the Euro Olivier Blanchard | Pedro Portugal

73: Case Study: DBRS Sovereign Rating of Portugal. Analysis of Rating Methodology and Rating Decisions Annika Luisa Hofmann | Miguel Ferreira | João Lampreia

74: For Whom the Bell Tolls: Road Safety Effects of Tolls on Uncongested SCUT Highways in Portugal Alfredo Pereira | Rui Pereira | João Pereira dos Santos

75: Is All Infrastructure Investment Created Equal? The Case of Portugal

Alfredo Pereira | Rui Pereira

76: Why Virtuous Supply-Side Effects and Irrelevant Keynesian Effects are not Foregone Conclusions: What we Learn from an Industry-Level Analysis of Infrastructure Investments in Portugal Alfredo Pereira | Rui Pereira

77: The Role of Gravity Models in Estimating the Economic Impact of Brexit Graham Gudgin | Ken Coutts | Neil Gibson | Jordan Buchanan

78: Infrastructure Investment in Portugal and the Traded/NonTraded Industry Mix Alfredo Pereira | Rui Pereira

79: Goods and Factor Market Integration: A Quantitative Assessment of the EU Enlargement

Lorenzo Caliendo | Fernando Parro | Luca David Opromolla | Alessandro Sforza

80: Understanding productivity dynamics:a task taxonomy approach

Tiago Fonseca | Francisco Lima | Sonia C. Pereira

81: On the Effects of Infrastructure Investments on Industrial CO2 Emissions in Portugal Alfredo Pereira | Rui Pereira

82: Assessing Competition With the Panzar-Rosse Model: An empirical analysis of European Union banking industry Suzana Cristina Silva Andrade

83: Health Care Investments and Economic Performance in Portugal: An Industry Level Analysis Alfredo Pereira | Rui Pereira | Pedro G. Rodrigues

84: Is deregulation of product and labour markets promoting employment and productivity? A difference-indifferences approach

Hugo Correia | Ana Fontoura Gouveia

85: Foreign acquisition and internal organization Paulo Bastos | Natália P. Monteiro | Odd Rune Straume

86: Learning, Prices, and Firm Dynamics Paulo Bastos | Daniel A. Dias | Olga A. Timoshenko
87: The Diffusion of Knowledge via Managers' Mobility Giordano Mion | Luca David Opromolla|Alessandro Sforza

88: Empresas Zombie em Portugal - Os sectores não transacionáveis da Construção e dos Serviços Gabriel Osório de Barros | Filipe Bento Caires | Dora Xarepe Pereira

89: Collective bargaining through the magnifying glass: A comparison between the Netherlands and Portugal Alexander Hijzen | Pedro Martins | Jante Parlevliet

90: A Lower VAT Rate on Electricity in Portugal: Towards a Cleaner Environment, Better Economic Performance, and Less Inequality Alfredo Pereira | Rui Manuel Pereira

91: Who Seeks Re-Election: Local Fiscal Restraints and Political Selection

Susana Peralta | João Pereira dos Santos

92: Assessing the Competitiveness of the Metalworking Sector João Marinho | Pedro Carvalho

93: The efficiency of Portuguese Technology Transfer Offices and the importance of university characteristics Aurora Teixeira | André Monteiro

94: Persistence in innovation and innovative behavior in unstable environments

Joana Costa | Anabela Botelho | Aurora Teixeira

95: The effect of entrepreneurial origin on firms' performance - The case of Portuguese academic spinoffs Natália Barbosa | Ana Paula Faria

96: Absorptive Capacity and Firms' Generation of Innovation Revisiting Zahra and George's Model Dina Pereira | João Leitão

97: Innovations in digital government as business facilitators: implications for Portugal João Martins | Linda Veiga

98: Innovation and the economic downturn: Insights from Portuguese firms Hugo Pinto | Tiago Santos Pereira | Elvira Uyarra

99: European Funds and Firm Dynamics: Estimating Spillovers from Increased Access

João Pereira dos Santos | José Tavares

100: Corporate Leverage and Investment in Portugal Ana Martins |José Henrique Gonçalves|João Mário Ferreira Duque

101: The effects of official and unofficial information on tax compliance

Filomena Garcia | Luca David Opromolla | Andrea Vezzulli | Rafael Marques

102: Competition effect on innovation and productivity - The Portuguese case Anabela Santos | Michele Cincera | Paulo Neto | Maria Manuel Serrano

103: Measuring the Welfare of Intermediation in Vertical Markets

Javier D. Donna | Pedro Pereira | Tiago Pires | Andre Trindade 
104: Of course Collusion Should be Prosecuted. But Maybe... Or (The case for international antitrust agreements) Filomena Garcia | Jose Manuel Paz y Minõ | Gustavo Torrens

105: Product market competition and gender discrimination Dudley Cooke | Ana P. Fernandes | Priscila Ferreir

106: Integration of Small Technology-Based Firms in Aeronautics

Anabela Reis | Joana Mendonça | Ligia Urbina

107: The Effects of Highway Tolls on Private Business Activity Results from a Natural Experiment João Pereira dos Santos | David B. Audretsch | Dirk Dohse

108: Competition and Firm Productivity: Evidence from Portugal Pedro Carvalho

109: Do Exchange Traded Funds (ETFs) Outperform the Market? Evidence from the Portuguese Stock Index Carlos Manuel Pinheiro | Hugo Hilário Varela

110: Assessing the Competitiveness of the Portuguese Chemical Sector

Ana Rita Marques | Cátia Silva

111: A General Equilibrium Theory of Occupational Choice under Optimistic Beliefs about Entrepreneurial Ability Michele Dell'Era | Luca David Opromolla | Luis SantosPinto

112: O Mercado Segurador em Portugal: O Papel dos Gestores na Constituição de Provisões Soraia de Sousa Bornett | Carlos Manuel Pinheiro

113: Exploring the implications of di erent loan-to-value macroprudential policy designs Rita Basto | Sandra Gomes | Diana Lima

114: The Determinants of TFP Growth in the Portuguese Service Sector Ana Martins | Tiago Domingues | Catarina Branco

115: Agglomeration and Industry Spillover Effects in the Aftermath of a Credit Shock José Jorge | Joana Rocha

116: Entrepreneurial Human Capital and Firm Dynamics Francisco Queiró

117: Global Value Chains and Vertical Specialization: The case of Portuguese Textiles and Shoes exports Tiago Domingues

118: Firm heterogeneity and exports in Portugal: Identifying export potentia Frederico Oliveira Torres

119: Vantagens Comparativas Reveladas e suas determinantes: Uma Aplicação à Economia Portuguesa Guida Nogueira | António Portugal Duarte

120: A Look at the main channels of Potential Impact of Brexit on the Portuguese Economy Guida Nogueira | Paulo Inácio
121: How internationalization and competitiveness contribute to get public support to innovation? The Portuguese case

Anabela Santos | Michele Cincera | Paulo Neto | Maria Manuel Serrano

122: Grande Guerra e Guerra Colonial: Quanto Custaram aos Cofres Portugueses?

Ricardo Ferraz

123: Financing a Renewable Energy Feed-in Tariff with a Tax on Carbon Dioxide Emissions: A Dynamic Multi-Sector General Equilibrium Analysis for Portugal Rui M. Pereira | Alfredo M. Pereira

124: Brown Sugar, how come you taste so good? The impact of a soda tax on prices and consumption Judite Gonçalves | João Pereira dos Santos

125: ARFIMA Reference Forecasts for Worldwide $\mathrm{CO} 2$ Emissions and the National Dimension of the Policy Efforts to Meet IPCC Targets

José Beirute | Alfredo M. Pereira

126: Reference Forecasts for CO2 Emissions from Fossil-Fuel Combustion and Cement Production in Portugal José M. Belbute | Alfredo M. Pereira

127: Regulated Early Closures of Coal-Fired Power Plants and Tougher Energy Taxation on Electricity Production: Synergy or Rivalry?

Alfredo Marvão Pereira | Rui Manuel Pereira

128: Picking Our Environmental Battles: Removal of Harmful Subsidies or Carbon Taxation? Alfredo Marvão Pereira | Rui Marvão Pereira

129: Financing Future Feed-in Tariffs from Currently Installed RES-E Generating Capacity Alfredo Marvão Pereira | Rui Marvão Pereira

130: Foreign Direct Investment, Income Inequality and Poverty in Portugal, 1973-2014: What does cointegration analysis tell us? Aurora Teixeira | Ana Sofia Loureiro

131: On the Spillover Effects of CO2 Taxation on the Emissions of other Air Pollutants Alfredo Marvão Pereira | Rui Marvão Pereira

132: On the Macroeconomic and Distributional Effects of the Regulated Closure of Coal-Operated Power Plants Alfredo Marvão Pereira | Rui Manuel Pereira

133: The China Shock and Employment in Portuguese Firms Lee Branstetter | Brian Kovak | Jacqueline Mauro | Ana Venâncio

134: Energy Taxation Reform with an Environmental Focus Alfredo Marvão Pereira | Rui Manuel Pereira

135: ARFIMA Reference Forecasts for Worldwide CO2 Emissions and the Need for Large and Frontloaded Decarbonization Policies José M. Belbute | Alfredo M. Pereira 
136: Exporter Firms Behaviour, Evidence From Portuguese Firms Using Microdata

Luís Pedro Manso Machado

137: Collateral Value and Entrepreneurship: Evidence from a Property Tax Reform

Miguel Ferreira | João Pereira dos Santos | Ana Venâncio

138: The Financial Channels of Labor Rigidities: Evidence from Portugal

Edoardo M. Acabbi | Ettore Panetti | Alessandro Sforza

139: Can a small leak sink a great ship? A comprehensive analysis of the Portuguese household savings Tiago Domingues | Margarida Castro Rego

140: Corporate taxes and high-quality entrepreneurship: evidence from a tax reform

Ana Venâncio | Victor Barros | Clara Raposo

141: Built Like a House of Cards? - Corporate Indebtedness and Productivity Growth in the Portuguese Construction Sector1

José Santos | Nuno Tavares | Gabriel Osório de Barros
142: Effectiveness of Simplex: The Case of Portuguese Social Security

António Alberto Nifrário de Pinho Tavares

143: Digital innovation in higher education: A questionnaire to Portuguese universities and polytechnic institutes Paulo Nuno Vicente | Margarida Lucas | Vânia Carlos

144: Portugal in the Global Innovation Index: A panel data analysis

Marcelo P. Duarte | Fernando M. P. O. Carvalho

145: Intangible investments and productivity performance Michele Cincera | Julie Delanote | Pierre Mohnen Anabela Santos | Christoph Weiss

146: Digitalization in Two-sided Platform Competition Filomena Garcia | Muxin Li

147: Collusion between two-sided platforms Joana Pinho | Yassine Lefouil 


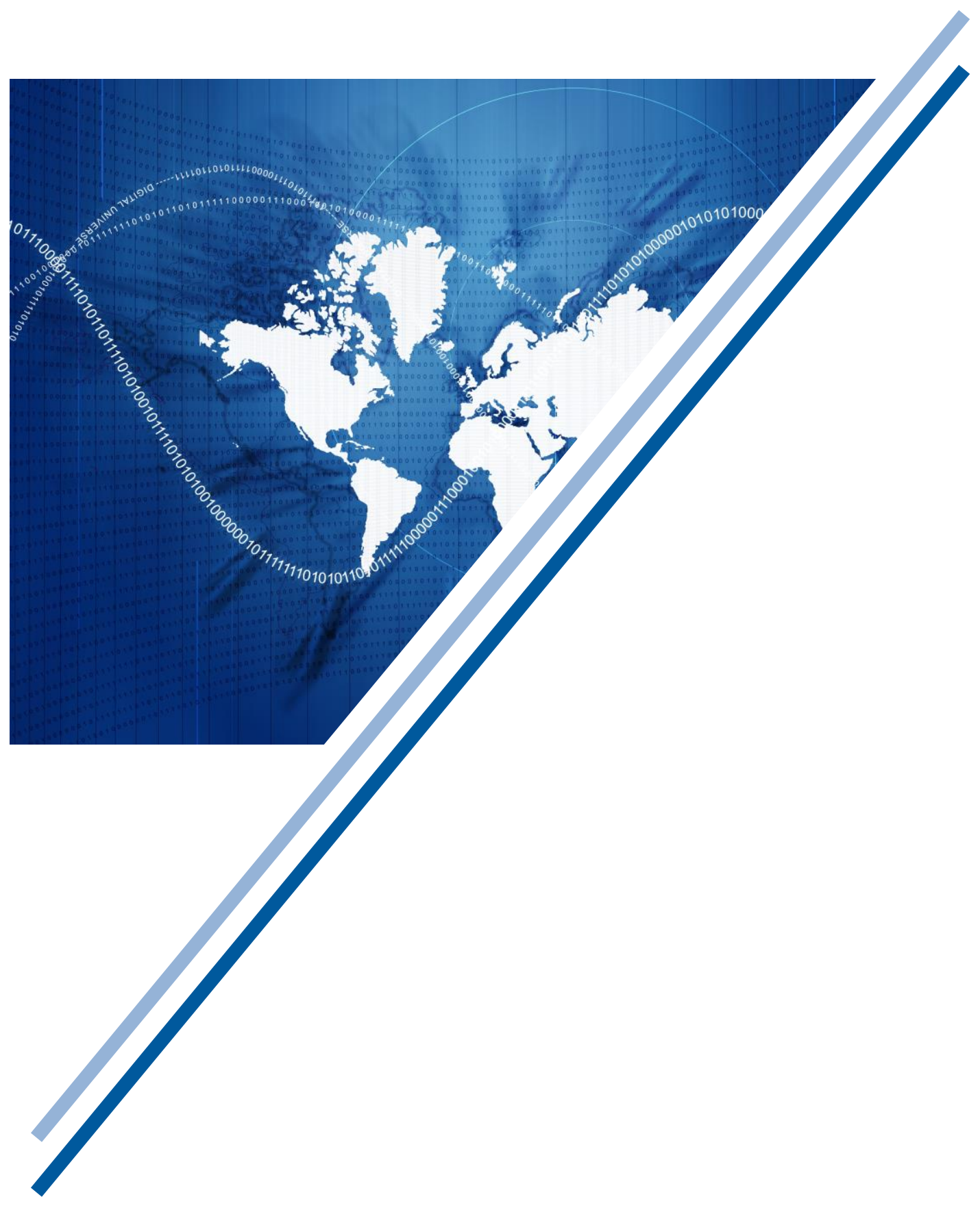

